\title{
WestVirginiaUniversity
}

THE RESEARCH REPOSITORY @ WVU

Graduate Theses, Dissertations, and Problem Reports

2003

\section{Long-term performance of pot hardware in continuous galvanizing lines}

Venkatesh Parthasarathy

West Virginia University

Follow this and additional works at: https://researchrepository.wvu.edu/etd

\section{Recommended Citation}

Parthasarathy, Venkatesh, "Long-term performance of pot hardware in continuous galvanizing lines" (2003). Graduate Theses, Dissertations, and Problem Reports. 1395.

https://researchrepository.wvu.edu/etd/1395

This Thesis is protected by copyright and/or related rights. It has been brought to you by the The Research Repository @ WVU with permission from the rights-holder(s). You are free to use this Thesis in any way that is permitted by the copyright and related rights legislation that applies to your use. For other uses you must obtain permission from the rights-holder(s) directly, unless additional rights are indicated by a Creative Commons license in the record and/ or on the work itself. This Thesis has been accepted for inclusion in WVU Graduate Theses, Dissertations, and Problem Reports collection by an authorized administrator of The Research Repository @ WVU. For more information, please contact researchrepository@mail.wvu.edu. 


\title{
Long-Term Performance of Pot Hardware in Continuous Galvanizing Lines
}

\author{
Venkatesh Parthasarathy \\ Thesis Submitted to the \\ College of Engineering and Mineral Resources \\ at West Virginia University \\ in partial fulfillment of the requirements \\ for the degree of
}

\author{
Master of Science \\ in \\ Mechanical Engineering \\ Bruce Kang, Ph.D., Chair \\ Jacky Prucz, Ph.D. \\ Xingbo Liu, Ph.D. \\ Thomas Damiani, Ph.D.
}

Department of Mechanical and Aerospace Engineering

\author{
Morgantown, West Virginia \\ 2003
}

Key Words: Wear, Journal Bearing, Molten Zinc, Dross, Galvanizing. 


\section{ABSTRACT \\ Long-Term Performance of Pot Hardware in Continuous Galvanizing Line.}

\section{Venkatesh Parthasarathy}

Preliminary comparative wearing tests were conducted on wearguard bearing system against CF3M (casting version of 316L steel), with tungsten carbide laser clad coating, at $30 \%$ and $50 \%$ production line tension. Tests were also conducted on Stellite 6 against Tribaloy $\mathrm{T} 400$ at $50 \%$ production line tension. For each test, periodic measurements of wearing rate, surface microstructure and surface hardness were carried out. An unique dross build-up setup which consists of two sleeves counter rotating against each other was designed to simulate the dross build-up in production line. The chemical composition of the dross material formed and change in sleeve microstructures were analyzed using SEM and EDX.

Microstructural analysis of the CF3M test sleeve revealed that (1) tungsten carbide bearing sleeve-wearing, was mainly due to abrasive wear, (2) ceramic inserts experienced abrasive wear and (3) the existence of intermetallic dross particles formed on the bearing sleeve surface. Microstructural analysis of the Stellite 6 test sleeve revealed that (1) wearing was due to abrasive wear and corrosive wear and (2) the sleeve reacted with zinc bath to form intermetallic compounds. 


\section{ACKNOWLEDGEMENTS}

Firstly I would like to thank my parents for their support and encouragement, without them none of this would have been possible.

I would like to thank my research advisor, Dr Bruce S Kang, for his advice and guidance to me throughout the course of this project. His indispensable contributions will never be forgotten. I am very thankful to my committee members Dr. Jacky Prucz, Dr. Xing bo Liu and Dr. Thomas Damiani for their timely advise and making me understand some of the related issues.

I am very thankful to Chuck Coleman and Lee Methney for their help in maintaining the laboratory test equipment. I would like to acknowledge the Department of Energy and WV-IOF program for providing the financial support under the grant DEFC07-01-ID-14042.

I would like to thank Anand Krishnaswamy and Kian Huat Tan for all their help and contribution during the course of the project. I would like to thank my good friend Sairam Thaigarajan for his invaluable help throughout the research work. I am thankful to all my friends and my research mates who directly or indirectly helped me in the successful completion of the work assigned to me. I would like to thank Kaarthik Sikkil and Deepthi Punyamurthula for always supporting and encouraging me, and for being great friends.

Finally, I would like to express my gratitude to God for providing the opportunity to pursue higher education. 


\section{TABLE OF CONTENTS}

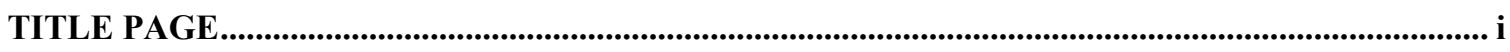

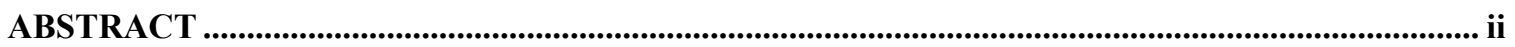

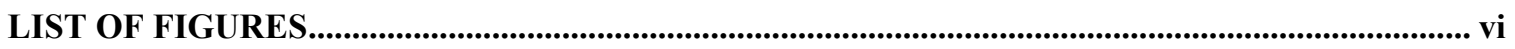

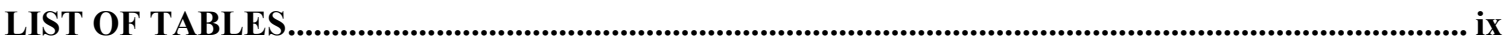

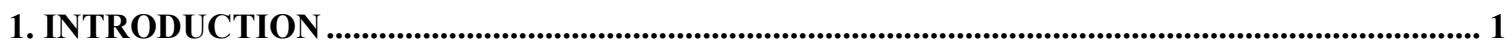

1.1 Galvalume

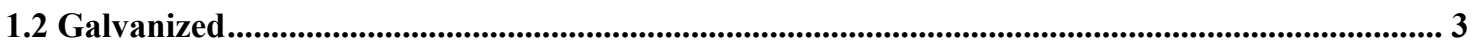

1.2.1 Premier-Minimized Spangle ......................................................................................................................... 3

1.2.2 Premier-Minimized Spangle - Extra Smooth ........................................................................................ 3

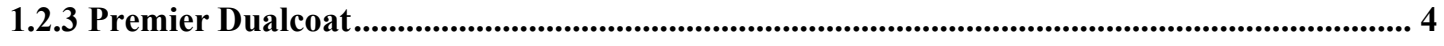

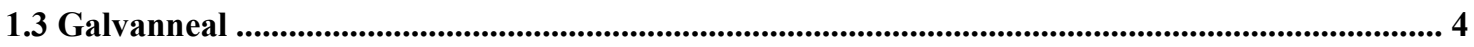

1.4 Bearing Sleeve and Bushing Materials ............................................................................................ 4

1.5 Laser Cladding Process........................................................................................................................ 5

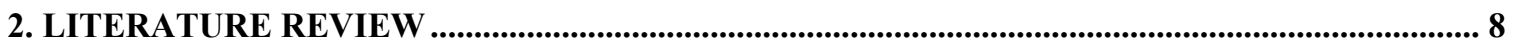

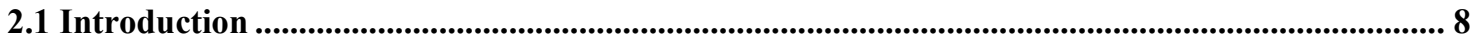

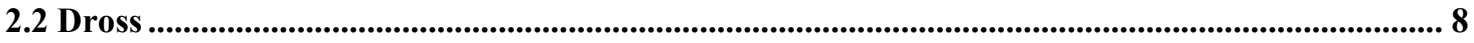

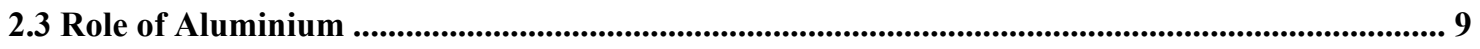

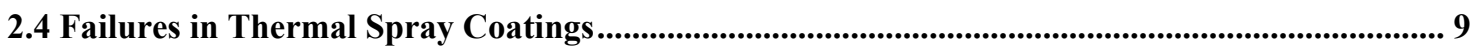

2.5 Properties of Vesuvius SiAION Ceramic ........................................................................................ 10

2.6 Advantages of the Wearguard Three Bar Bearing Assemblies ......................................................... 10

2.7 Wearing Test Results of Journal Bearing Materials .................................................................. 10

2.8 Summary

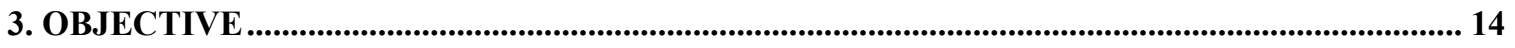

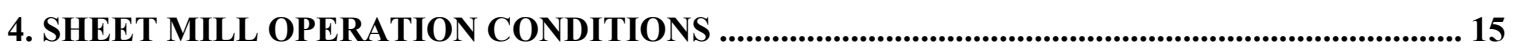

4.1 Weirton Steel Galvanizing Lines Operating Data Range (Line \# 5) ................................................ 15 
4.2 Laboratory Simulated Test Conditions …………….................................................................................. 16

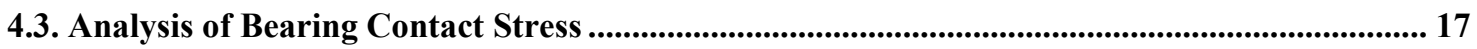

4.3.1 CF3M with Tungsten Carbide Laser Clad against SiAION Ceramic ...................................... 17

4.3.2 For Stellite 6 against Tribaloy T-400 Test:......................................................................................... 20

5. DESIGN OF A WEARING AND DROSS BUILD-UP TESTER ..................................................... 23

5.1 Wearing Test Setup for Stellite 6 against Tribaloy T-400.................................................................. 24

5.2 Design of Wearing Test ............................................................................................................................. 26

5.2.1 Wearguard System .......................................................................................................................................... 27

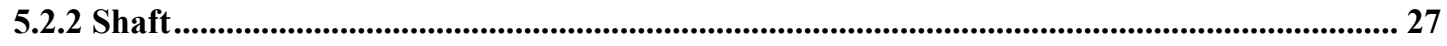

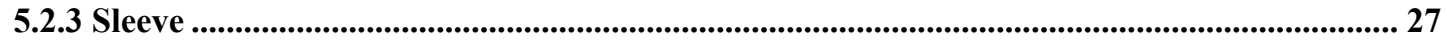

5.2.4. SiAION Ceramic Bars .......................................................................................................................... 28

5.2.5 Wearguard System .............................................................................................................................. 28

5.4 Design of Dross Build-Up Test ......................................................................................................... 30

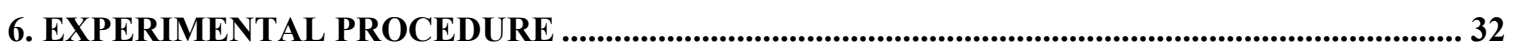

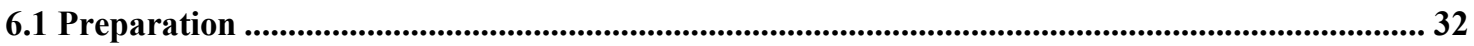

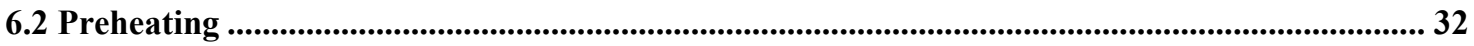

6.3 Testing Procedure .................................................................................................................................... 34

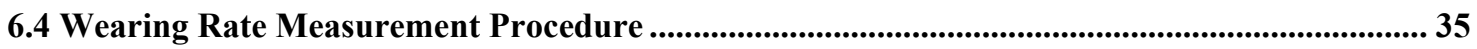

6.5 Procedure for In-Site Microstructure Viewing .................................................................................... 36

7. RESULTS \& DISCUSSIONS .................................................................................................................... 38

7.1 Test 1 CF3M with Tungsten Carbide Coating against SiAION Ceramics..................................... 38

7.2 Test 2 CF3M with Tungsten Carbide Coating against SiAION Ceramics...................................... 47

7.2.1 Correlation of Hardness with Stiffness of the Material Surface ................................................. 54

7.3 Test 3 Stellite 6 against Tribaloy T-400 ............................................................................................ 61

7.4 Dross Build-Up Test ..................................................................................................................................... 68

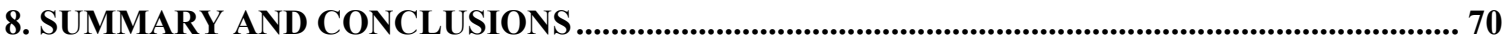

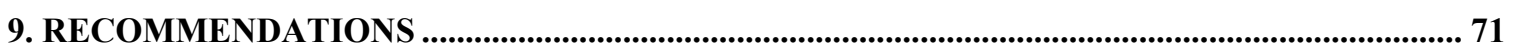

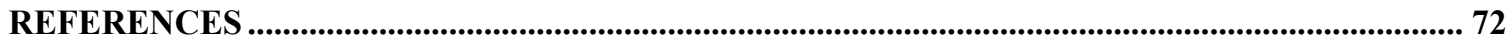




\section{LIST OF FIGURES}

Figure 1 Schematic of Continuous Galvanizing Line .................................................................................. 1

Figure 2 Tungsten Carbide Composite is Metallurgically Bonded by a Laser Process to a 316L

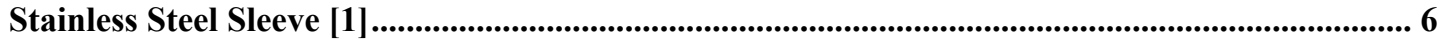

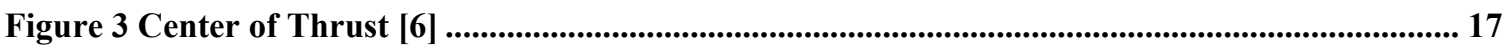

Figure 4 Area of Contact between Stellite 6 Bearing and Tribaloy T-400 Bushing................................. 20

Figure 5 Front View of Test Bath......................................................................................................... 22

Figure 6 Schematic Representation of Wearing and Dross Build-up Test .............................................. 23

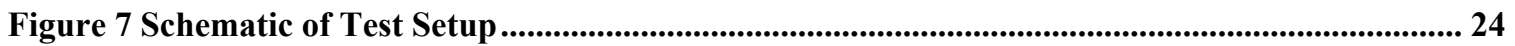

Figure 8 Schematic of Dross Build-up Test ................................................................................................. 26

Figure 9 The $500 \mathrm{lb}$ WVU Test Bath............................................................................................................. 27

Figure 10 CF3M Coated with Tungsten Carbide by Laser Cladding process ......................................... 28

Figure 11 Wearguard System and SiAION Ceramic Bar ................................................................................ 28

Figure 12 Top View of the Wearguard Test Set Up ................................................................................. 29

Figure 13 Top View of Dross Build-up Test ...............................................................................30

Figure 14 Groove Pattern on Roll Surface .......................................................................................................... 30

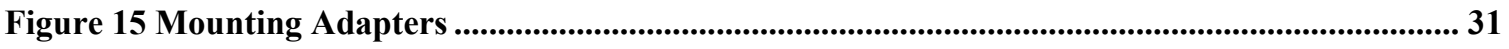

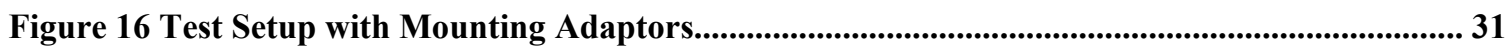

Figure 17 ( a) Adding Zinc Bars to the Bath ( b ) Removing Impurities from the Molten Zinc.......... 32

Figure 18 Preheater Wrapped Around the Test Sleeve .............................................................................. 33

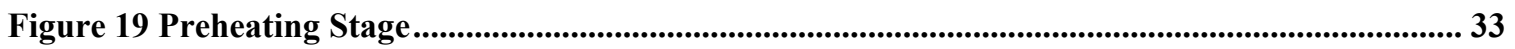

Figure 20 (a) Bearing Sleeve Immersed in Zinc Pot (b) Test Sleeve Rotating in Zinc Pot.................... 34

Figure 21 (a) Removing the Wearguard System (b) Zinc Pot Moved Out .............................................. 35

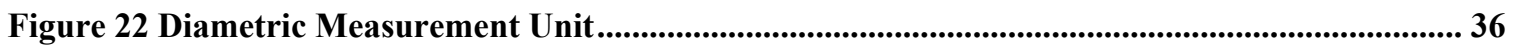

Figure 23 Wearing Result of 316 LS with WC-L against SiAION Ceramic Inserts ................................ 39

Figure 24 Wearing on Ceramic Insert after Cycle 1 ........................................................................................ 41

Figure 25 Wearing on Ceramic Insert after Cycle 2 ..................................................................................... 41 
Figure 26 Wearing on Ceramic Insert after Cycle 3 with Grooves........................................................... 42

Figure 27 Wearing on Ceramic Insert after Cycle 5 ........................................................................... 42

Figure 28 Wearing on Ceramic Insert after Cycle 6 .................................................................................... 43

Figure 29 Bearing Sleeve Microstructure after Cycle 6 .......................................................................................... 43

Figure 30 Ceramic Particles Sticking on the Bearing Sleeve ......................................................................... 44

Figure 31 SEM Picture of Ceramic Particles Sticking on the Bearing Sleeve.......................................... 45

Figure 32 SEM Picture of the Bearing Sleeve ................................................................................................... 46

Figure 33 Density of the Tungsten Carbide Particles at Wearing Cross Section...................................... 46

Figure 34 Wearing Result of 316 LS with WC-L against SiAION Ceramic Inserts ................................ 49

Figure 35 Wearing on Ceramic Insert after Cycle 1 at Production Line Tension .................................. 50

Figure 36 Wearing on Ceramic Insert after Cycle 2 ........................................................................................ 50

Figure 37 Wearing on Ceramic Insert after Cycle 3 ....................................................................................... 51

Figure 38 Wearing on Ceramic Insert after Cycle 4 .......................................................................................... 51

Figure 39 Wearing on Ceramic Insert after Cycle 5 ............................................................................. 52

Figure 40 Wearing on Ceramic Insert after Cycle 6 ........................................................................................ 52

Figure 41 Cracks on the Wearing Sleeve Surface after Test Cycle 2 ........................................................ 53

Figure 42 Hardness Variation on the Wearing Sleeve Surface ...................................................................... 55

Figure 43 Microstructure of the Wearing Sleeve Surface after Test Cycle 3........................................... 55

Figure 44 Microstructure of the Wearing Sleeve Surface after Test Cycle 4............................................. 56

Figure 45 Microstructure of the Non Wearing Sleeve Surface after Test Cycle 4.................................. 57

Figure 46 Microstructure of the Non Wearing Sleeve Surface before Polishing ...................................... 58

Figure 47 Microstructure of the Non Wearing Sleeve Surface after Polishing ........................................ 58

Figure 48 Microstructure of the Wearing Sleeve Surface with Corrosion Attack.................................... 59

Figure 49 Microstructure of the Non Wearing Sleeve Surface with Corrosion Attack.......................... 60

Figure 50 Wearing Result of Stellite 6 against Tribaloy T-400 ................................................................. 62

Figure 51 Hardness Variation of Stellite 6 Bearing Sleeve .............................................................................. 63

Figure 52 (a) Microstructure Picture of Grooves on Bearing Surface (b) Particles inside the Groove after Cycle 1 63 
Figure 53 Microstructure Picture of Narrow Grooves on Bearing Surface after Test Cycle 2

Figure 54 (a) Microstructure Picture of Grooves on Bearing Surface (b) Particles inside the Groove

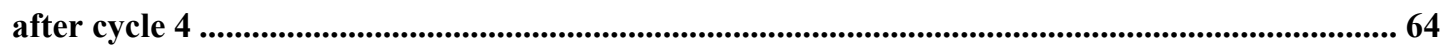

Figure 55 Cross Sectional View Showing Diffusion of Co from Matrix .......................................... 65

Figure 56 Cross Sectional View Showing Diffusion of Co from Matrix ................................................ 66

Figure 57 Cross Sectional View Showing Diffusion of Co from Matrix .......................................... 66

Figure 58 Cross Sectional View Showing Diffusion of Co from Matrix ............................................. 67

Figure 59 Cross Sectional View Showing Diffusion of Co from Matrix ........................................ 67

Figure 60 Suspected Dross Particle inside the Groove of Test Roll after Cycle 4.............................. 69

Figure 61 Existence of Intermetallic formed between Fe-Cr inside Test Roll Groove ....................... 69 


\section{LIST OF TABLES}

Table 1 Hardness Comparison of Materials [8] ............................................................................................. 12

Table 2 Operating Data Range for Continuous Galvanizing Line ............................................................... 15

Table 3 Bottom Roller Characteristics .............................................................................................. 15

Table 4 Operating Data at Laboratory Conditions .......................................................................................... 16

Table 5 Production Line Dimensions (Based on Weirton Steel Corp. Line \#5) ...................................... 18

Table 6 Calculation of Production Line Roll Pressure........................................................................................ 18

Table 7 Calculation of Production Line Bearing Pressure …………............................................................... 18

Table 8 Calculation of Applied Load for Lab Scale Test .................................................................................. 19

Table 9 Dimensions of the Bearing Sleeve \& Bushing.......................................................................... 21

Table 10 Calculation of Applied Load for Lab Scale Test (Stellite 6)........................................................ 21

Table 11 Relation between Dead Weight Load (P) \& Load Acting on Contact Surface (P2).............. 22

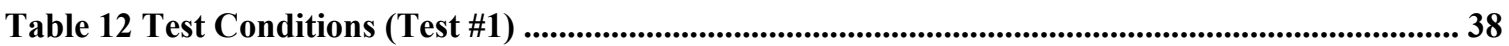

Table 13 Wearing Results of 316 LS with WC-L against SiAION Ceramic Inserts ............................... 40

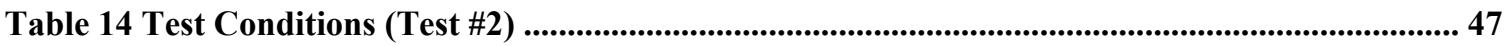

Table 15 Wearing Results of 316 LS with WC-L against SiAION Ceramic Inserts ............................... 49

Table 16 Test Conditions (Test \#3) ..................................................................................................................... 61

Table 17 Wearing Result of Stellite 6 against Tribaloy T-400 ...................................................................... 62 


\section{INTRODUCTION}

The continuous hot-dip galvanizing process for steel sheet was developed over fifty years. Molten zinc coating is applied onto the surface of the steel sheet during continuous hot dip process. Continuous ribbon of steel sheet is passed through a bath of molten zinc at selected speed. Steel sheet reacts with the molten zinc to form coating on the steel surface inside the molten bath. Gas knives are used to remove the excess coating sticking on the sheet surface. Figure 1 shows the schematic of continuous galvanizing line.

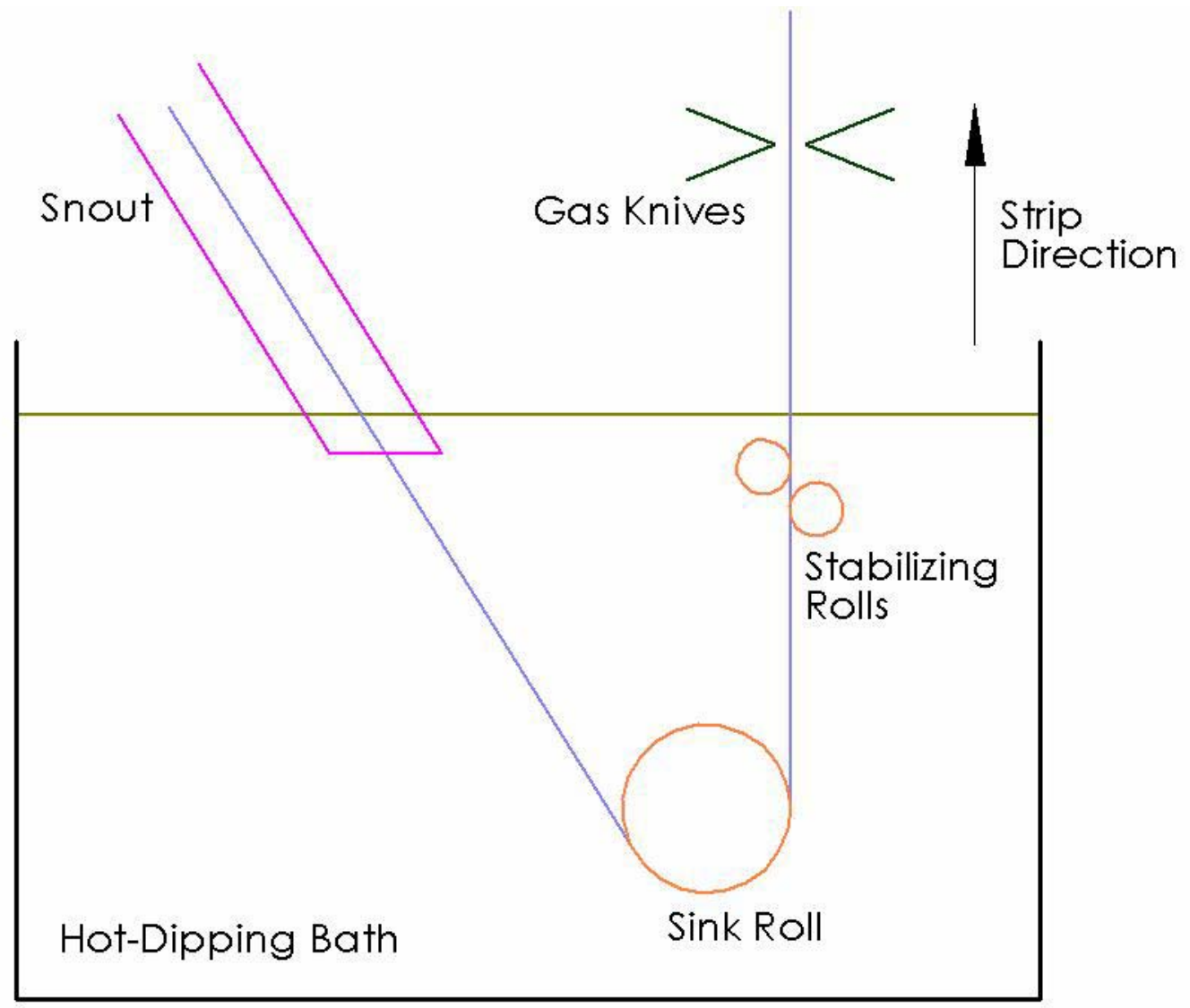

Figure 1 Schematic of Continuous Galvanizing Line 
Intimate metallurgical bond is formed between the sheet and molten zinc bath by the process of diffusion. The bond is an intermetallic compound, called "alloy layer", which is hard and brittle. Correct thickness of the alloy layer on the sheet surface allows easy machining without the loss of adhesion between the steel and zinc coating. Cracks may develop on the coating surface during machining, if the alloy layer is too thick. Galvanized steel sheet are characterized by the correct thickness, composition of the alloy layer and proper bonding zone. The desired characteristic of coating layer can be accomplished by controlling the following parameters:

1. Addition of a controlled amount of aluminum to the zinc bath,

2. Control of the zinc bath temperature, and

3. Control the steel sheet temperature at the point of entry into the zinc bath.

There are three types of galvanizing lines typically used in production line in galvanizing industries, galvalume, galvanized, and galvanneal

\subsection{Galvalume}

The zinc bath in a typical galvalume coating consists of approximately $55 \%$ aluminum and $45 \%$ zinc. Galvalume coating by continuous hot-dip process offers at least twice the corrosion resistance comparing to galvanized coating. The galvalume coating exhibits the following characteristics: superior corrosion resistance, heat reflectivity, bare edge protection and forming qualities. The smooth silvery metallic spangle appearance makes it readily applicable for unpainted applications. It is also available in prepainted form and can be readily post-painted for other applications. 


\subsection{Galvanized}

Galvanized steel is produced on continuous hot dip galvanizing lines by passing prepared coils through a bath of molten zinc. Galvanized coating layer consists mainly zinc, with a small amount of aluminum ranging from $0.10 \%$ to $0.30 \%$. Aluminum is added to the coating to improve the adhesion between coating layer and steel sheet during forming operations. A galvanized coating is soft and easily scratched during handling. Corrosion performance of galvanized coating is directly related to the thickness of the coating layer. There are various styles available in galvanized coating such as Premier Minimized Spangle, Premier - Minimized, and Premier Dualcoat.

\subsubsection{Premier-Minimized Spangle}

The coating consists of a layer of zinc on top of a thin layer of a mixture of intermetallic compounds containing iron, aluminum and zinc. The products produced are "spangle" free. The surface has a bright appearance and is normally intended for plain unpainted construction applications or unexposed appliance/ automotive applications.

\subsubsection{Premier-Minimized Spangle - Extra Smooth}

This product is skin passed or temper rolled after coating to impart a uniform matt surface appearance. This coating can be readily painted hence is used for applications requiring an improved surface appearance such as painted construction applications and semi-exposed automotive parts. 


\subsubsection{Premier Dualcoat}

Dualcoat coatings are produced with different coating weight on each surface of the sheet. There are limitations to the range of differential coating that can be obtained.

\subsection{Galvanneal}

Galvanneal coatings produced by the continuous hot-dipping process are zinc-iron alloy coating consisting about $90 \%$ zinc and $10 \%$ iron. The main difference in the production process of galvanneal coating as compared to galvanized coating is that steel sheet are heated by passing through furnace directly above the coating bath. A galvanneal coating exhibits the following properties: no spangles, simply a grey matte appearance, improved spot weldability, ease of painting, and improved coating adhesion.

\subsection{Bearing Sleeve and Bushing Materials}

Typically, materials used for the bearing sleeve are Stellite 6, CF3M (cast version 316 stainless steel) with tungsten carbide laser cladding, Tribaloy T-800, Tribaloy T-400, and Metaullic 2012 and 2020. These bearing sleeves work with maximum efficiency when they are run against appropriate bushing materials. Typical bearing sleeve and bushing assembly used in production lines are Stellite 6 sleeve against half moon Stellite 6 bushing, CF3M with tungsten carbide laser cladding against SiAlON ceramic, Tribaloy T-800 sleeve against half moon Tribaloy T-800 bushing or Metaullic 2012 sleeve against Metallic 2012 self aligning bushing. Similarly for the roll bearing materials, CF3M with thermal spray tungsten carbide coating is typically used in the production line. New materials have been developed for roll bearing such as Oak Ridge National Lab alloy 4-2 (ORNL alloy 4-2). 


\subsection{Laser Cladding Process}

According to Praxair S.T Technology Inc. Patent \# 6,037,287 [1], laser cladding and hard-surfacing provided unique methods for applying metallurgically bonded coatings to virtually any size and configuration of work piece. The $\mathrm{CO}_{2}$ laser generator directs a collimated $\mathrm{CO}_{2}$ laser beam to a selected work cell through an enclosed laser duct using optically polished, water cooled mirrors. Appropriate optics attached to the tooling end-effector directs the laser beam to a spot of high power density. The focused beam when translated over the work piece surface rapidly melts and solidifies the cladding or hardsurfacing alloys. Precise control of laser energy permits accurate deposition of coating thickness ranging from 0.01 to 0.08 inches ( $250-2000$ microns) in single pass. Figure 2 shows a typical laser cladding process. The laser clad coatings are impervious overlays metallurgically bonded to the substrate alloy. The dilution caused by intermixing of the coating alloy and the substrate alloy is routinely controlled at less than $5 \%$. Due to low heat input of the laser cladding process, coated components exhibit minimal distortion. Also metallurgical changes in the substrate alloy are negligible. Various component geometry, desired size, shape and different coating thickness can be obtained by the laser cladding and hard surfacing processes. To ensure a uniform coating thickness for broad surface area, parallel beads of clad deposit are applied with sufficient overlap. Laser cladding and hardsurfacing processes are applicable to all combinations of iron-base, nickel-base and cobalt-base alloys, both as clad overlays and substrate alloys. Through the laser cladding process, hard, wearresistant carbides can be incorporated in zinc-resistant alloys in the protective overlay. 


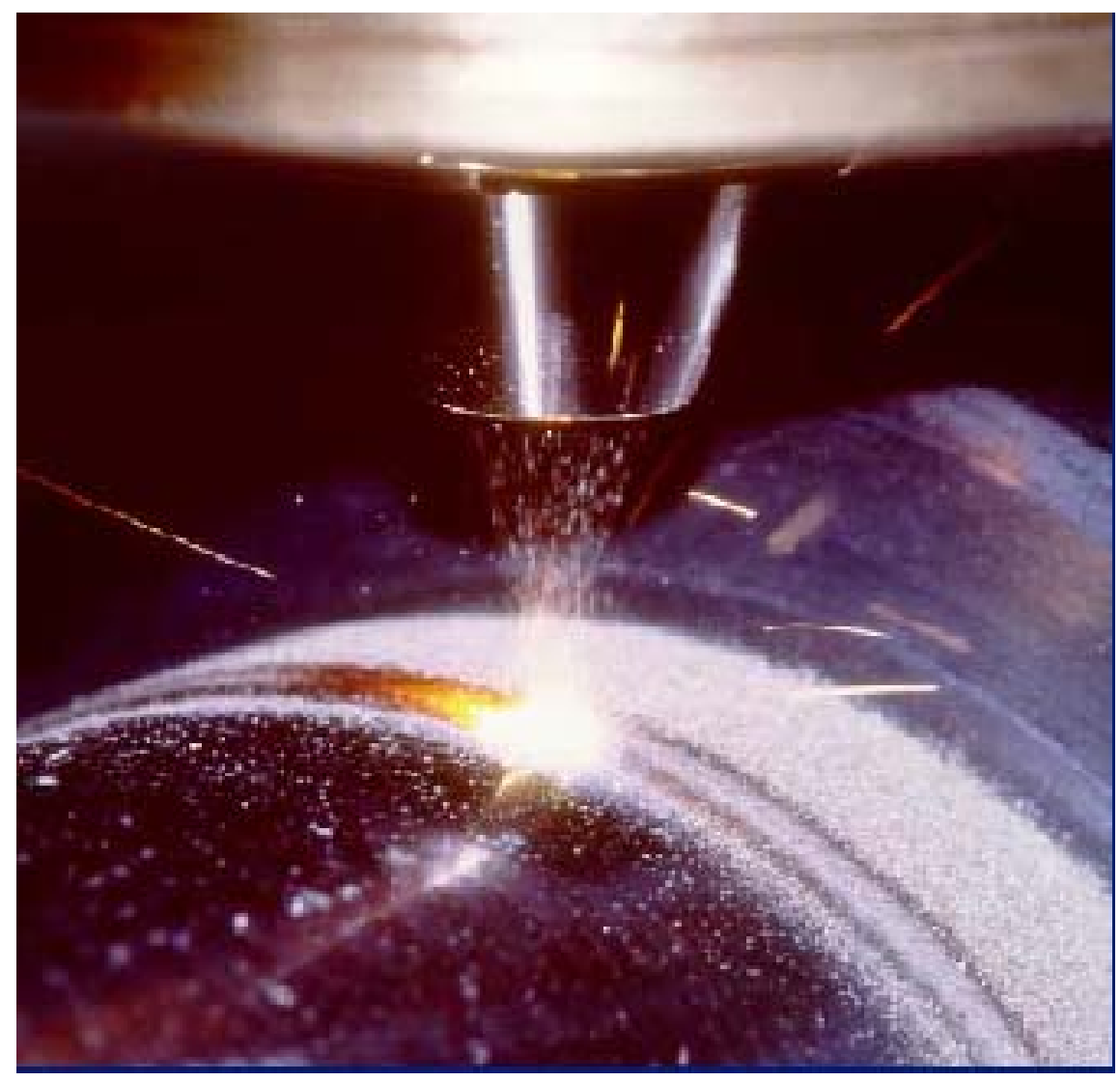

Figure 2 Tungsten Carbide Composite is Metallurgically Bonded by a Laser Process to a 316L Stainless Steel Sleeve [1]

Preferably, the tungsten-carbide (WC) and or tungsten--cobalt--carbide (W--C-Co) component ranges from about 20 to about $80 \mathrm{wt} \%$, most preferably about 40 to about 60 wt \%. Preferably the Co content in $\mathrm{W}-\mathrm{C}-\mathrm{Co}$ carbide powder is about 1 to $15 \%$. Preferably, the chemistry of the alloy is about 1 to $25 \% \mathrm{Cr}, 2$ to $12 \% \mathrm{Ni}, 0$ to $7 \%$ $\mathrm{Cu}, 0$ to $5 \% \mathrm{Mo}, 0$ to $1.5 \% \mathrm{Mn}, 0$ to $0.7 \% \mathrm{Nb}$ and Ta, 0 to $1.2 \% \mathrm{Ti}, 0$ to $2.0 \% \mathrm{Al}, 0.1$ to $1.2 \% \mathrm{Si}$, and 0.02 to $0.15 \% \mathrm{C}$, and balance Iron $(\mathrm{Fe})$, exclusive of minor amounts of trap elements (such as Phosphorus (P) and Sulfur (S)).

For a better quality control, the chemistry of the alloy should be 14 to $18 \% \mathrm{Cr}, 3$ to $7 \% \mathrm{Ni}, 3$ to $6 \% \mathrm{Cu}, 0.5$ to $1.0 \% \mathrm{Mn}, 0.15$ to $0.3 \% \mathrm{Nb}$ and $\mathrm{Ta}, 0.4$ to $0.8 \% \mathrm{Si}$, and 0.04 
to $0.10 \% \mathrm{C}$, and balance Iron $(\mathrm{Fe})$, exclusive of minor amounts of trap elements. Usually, fusion of powder by laser is accomplished by feeding the powder directly into the weld pool formed by the laser beam on the substrate, controlling the powder feed and laser power to minimize dilution without sacrificing fusion bonding. The substrate can be any alloy used in the galvanizing, galvalume, and aluminizing lines. 


\section{LITERATURE REVIEW}

\subsection{Introduction}

The galvanizing industries are trying to improve the coating quality due to the increased use of galvanized sheet as exposed automobile body panels. Excessive strip vibration in the coating process and poor surface quality is caused by the degradation of the submerged pot hardware (rolls, journal and bearings). Many studies have been conducted on the pot hardware materials to study factors governing the failure of theses materials in molten zinc. Efforts are made to find new materials with good wear resistance and are non-wettable in molten zinc.

\subsection{Dross}

Dross inclusions in the coating resulting from agitation of dross layer can produce surface protrusions. There are two types of dross particles formed in CGL: top dross and bottom dross. Bottom dross is a zinc-iron alloy that settles to the bottom of zinc bath. Bottom dross is formed through the following reaction

$$
2 \mathrm{Fe}+5 \mathrm{Al}<-->\mathrm{Fe}_{2} \mathrm{Al}_{5}
$$

Bottom dross is generally identified as $\delta\left(\mathrm{FeZn}_{10}\right)$ or $\Gamma\left(\mathrm{FeZn}_{10}\right)$ or the combination of both. The top dross is identified as $\eta\left(\mathrm{Fe}_{2} \mathrm{Al}_{5}\right)$. The reaction takes place at coating interface to form the inhibition layer, preventing the direct contact between steel substrate and the molten zinc. Reaction also takes place in the bath, resulting in the formation of top dross particles as an undesirable byproduct. [2] 


\subsection{Role of Aluminium}

A continuous ribbon of steel sheet is immersed into the molten zinc bath during the continuous galvanizing process. The surface atom in solid state of the steel sheet and atoms of the zinc in molten state react with each other and form an intermetallic alloy. This intermetallic alloy layer is hard and brittle, hence has high tendency to develop cracks on the alloy layer.

The zinc-iron alloy compounds that are formed at fast rate are not stable, at the instance when aluminium is added to the coating bath. When the steel sheet enters the bath, an iron-aluminium intermetallic compound is formed instantly, as aluminium has greater affinity for iron than zinc. This thin ternary intermetallic layer retards the zinciron reaction and is composed of approximately $45 \% \mathrm{Al}, 35 \% \mathrm{Fe}$ and $20-35 \% \mathrm{Zn}$ $\left(\mathrm{Fe} 2 \mathrm{~A} 15_{-\mathrm{X}} \mathrm{Zn} \mathrm{n}_{\mathrm{X}}\right)$. The diffusion characteristic of zinc through aluminum-iron compound determines the diffusion rate. Final thickness of the alloy layer is small, as the reaction rate between zinc and iron is reduced drastically. This enables coated sheet to be bent or shaped to any form, without cracking or loss adhesion of the coated layer from the steel sheet.[3]

\subsection{Failures in Thermal Spray Coatings}

Failure modes of thermal spray coatings are classified into ten different categories: [4]

1. Loss of coating by mechanical impact (mishandling, cracking),

2. Partial wear of coating by abrasion, adhesion, erosion and cavitations,

3. Loss of coating due to concentrated load,

4. Loss of coating due to excessive heating (development of high shear in the coating),

5. Loss of coating by corrosion or electrochemical reactions (dissolution of coating),

6. Loss of coating by crevice corrosion (corrosion of base metal at interface), 
7. Attack on coating by molten metals (erosive corrosion),

8. Localized electrical discharge/ arc damage (cracking, crevice corrosion, spalling),

9. Adhesion / pickup (surface reaction but no visible damage to the coating),

10. Substrate related (excessively hard/soft or improper base material).

\subsection{Properties of Vesuvius SiAlON Ceramic}

This ceramic is impervious to corrosion by molten zinc or aluminium. Ceramic exhibits excellent wear resistance, low coefficient of friction and excellent thermal shock capability. [5]

\subsection{Advantages of the Wearguard Three Bar Bearing Assemblies}

1. Dross from the journal is cleaned by the leading bars before the journal rotates to the center bar.

2. Dross from the journal/bearing interface is removed by the space between the ceramic bars.

3. Smaller bearing area than conventional bearings.

4. Lower bearing friction due to reduced bearing area.

5. Bearing friction is constant for the entire life of the bearing wear. [6]

\subsection{Wearing Test Results of Journal Bearing Materials}

Zhang, Tang and Goodwin [7] conducted wearing test of Stellite 6 bearing against Stellite 6 bushing. The experiment was performed at temperature $465 \pm 5 \mathrm{C}$ and in load range of $2.2 \mathrm{KN}$ to $8 \mathrm{KN}$. Deep and wide wear grooves were formed on the bearing sleeve and bushing surface. Cross sectional view of the wear surface showed that intermetallic compounds ( $\mathrm{Zn}-\mathrm{Co}-\mathrm{Fe}-\mathrm{Cr}-\mathrm{W})$ grew on top of an aluminium rich layer. 
Wearing of the Stellite 6 journal bearing was mainly due to fatigue, abrasive and adhesive wear.

Zhang and Battiston [8] investigated the friction and wear behavior of some cobalt and iron based superalloys in molten zinc bath using a submerged bearing test rig. Commonly used Cobalt based alloys reacted with molten zinc to form hard intermetallics compounds which were responsible for the wear of the journal bearing. The iron based superalloys had negligible reaction with the zinc bath and cracks were developed near the contacting surfaces. The wearing of the journal bearing was mainly due to abrasive and adhesive wear. Table 1 shows the hardness comparison of different materials in galvanizing lines.

Zhang, Tang and File [9] conducted a detailed study on the wear mechanism of the Stellite 6 journal bearing. The study showed that the growth and buildup of the CoAl based wear debris was mainly responsible for the wear of the bearing. The CoAl based wear debris was formed when the deattached wear particles from the test material react with the molten zinc-aluminium alloy.

Zhang and Tang [10] studied the reaction of various materials with a galvanizing bath. All the Co based and Fe based superalloys and cermet coating reacted with the molten zinc bath. Iron aluminide was formed on the Co based superalloys. These iron aluminide are based on the $\mathrm{Fe}_{2} \mathrm{Al}_{5}$ phase, which enhanced the growth of top dross on the sleeve surface and attachment of the top dross to the bearing sleeve surface. The reaction of matrix layer of the cermet coating with molten zinc, decreases the bonding strength between the binding phases and WC particles, hence making the bearing material more suspectable to wear damage. 


\begin{tabular}{|c|c|}
\hline MATERIALS & HARDNESS (HV) \\
\hline Eta $(\mathrm{Zn})$ & 45 \\
\hline Zeta $\left(\mathrm{FeZn}_{13}\right)$ & 181 \\
\hline Delta $\left(\mathrm{FeZn}_{7}\right)$ & 265 \\
\hline Gama $\left(\mathrm{Fe}_{3} \mathrm{Zn}_{21}\right)$ & 421 \\
\hline Al-Fe-Zn-Co-W & 763 \\
\hline WC/Co Coating & 1360 \\
\hline Stellite \# 6 & 515 \\
\hline MSA 2020 & 611 \\
\hline Tribaloy T - 800 & 580 \\
\hline
\end{tabular}

Table 1 Hardness Comparison of Materials [8]

Zhang, Battiston and Goodwin [11] conducted a wear test of WC laser cladding coating against SiAlON ceramic using a submerged bearing test rig. Wear cracks were seen on the WC coated sleeve surface and the WC spherical particles cracked and became debris. These particles got trapped between the contacting surface and caused grooves during sliding. Cross-sectional view of the test sleeve surface showed a highly deformed layer. The wearing of the journal bearing was mainly due to fatigue wear and ceramic experienced abrasive wear. 


\subsection{Summary}

These wearing tests and studies of dross in CGL form the basis for longterm testing at WVU test site. The wearing tests at WVU were conducted at $30 \%$ and $50 \%$ production line tension and at production line speed of the Weirton Production line \# 5. The aim of these long-term wearing and dross build-up tests at WVU is to study the surface degradation of the various bearing materials at selected testing conditions. 


\section{OBJECTIVE}

The objective of this research is to study the long-term performance of selected bearing materials used in galvanizing line and to study the mechanism and process conditions related to roller dross build-up. A $500 \mathrm{lb}$ zinc test bath equipment donated by Duraloy Technologies, Inc. was modified to conduct the bearing wearing test and roll dross build up test. A specially designed diametric unit was used to measure the wearing rate of the bearing sleeve. Hardness of bearing sleeve and on-site microstructure evaluation of bearing sleeve and roll sleeve surface were conducted at the end of each test cycle. The change in hardness value of the sleeve is correlated to change in surface microstructure of the sleeve. The wearing rate and hardness value of different bearing materials under similar testing conditions were compared. The result can lead to the life estimate of the bearing sleeve materials in continuous hot dip galvanizing line. A unique dross build-up setup which consists of two sleeves counter rotating against each other was designed to simulate the dross build-up in production line. Line contact was produced between the two sleeves by applying the calculated spring force which was adjusted to be same as the roll pressure in the production line. At the end of each cycle the test was stopped and characteristics of dross build-up on the roll surface studied. At the end of each test, a detailed microstructure evaluation was done on the tested roll and bearing sleeve materials using Scanning Electron Microscope. Correlation between the wearing rate and changes of the bearing surface microstructures were analyzed. Characteristics of dross build-up on the roll surface were also discussed. 


\section{SHEET MILL OPERATION CONDITIONS}

\subsection{Weirton Steel Galvanizing Lines Operating Data Range (Line \# 5)}

Table 2 and 3 shows the operating data range and bottom roll characteristics of Weirton Steel galvanizing lines (Line \# 5).

\begin{tabular}{|c|c|}
\hline Zinc Pot Chemistry & $0.08-0.22 \%$ of Aluminium \\
\hline Temperature & $880 \mathrm{~F}-900 \mathrm{~F}$ \\
\hline Sheet Width & $24-49 \mathrm{inch}$ \\
\hline Sheet Thickness & $0.012-0.045 \mathrm{inch}$ \\
\hline Sheet Tension & $3200 \mathrm{lbf}-4800 \mathrm{lbf}$ \\
\hline Sheet Velocity & $110 \mathrm{ft} / \mathrm{min}-550 \mathrm{ft} / \mathrm{min}$ \\
\hline
\end{tabular}

Table 2 Operating Data Range for Continuous Galvanizing Line

\begin{tabular}{|c|c|}
\hline Bearing Life & $14-30$ Days \\
\hline Outside Diameter & 20 inch \\
\hline Shaft Diameter & 3.875 inch \\
\hline Bearing Length & 4 inch \\
\hline Bearing Pressure & $257 \mathrm{psi}-1445 \mathrm{psi}$ \\
\hline Roll Pressure & $13 \mathrm{psi}-75 \mathrm{psi}$ \\
\hline
\end{tabular}

Table 3 Bottom Roller Characteristics 


\subsection{Laboratory Simulated Test Conditions}

Table 4 represents the operating data range for the Laboratory test conditions calculated to be equivalent to the Weirton Steel galvanizing line \# 5 .

\begin{tabular}{|c|c|}
\hline Outside Diameter & 3.875 inch \\
\hline Bath temperature & $850 \mathrm{~F}-870 \mathrm{~F}$ \\
\hline Line Speed & $108 \mathrm{rpm}-550 \mathrm{rpm}$ \\
\hline Bearing Pressure & $257 \mathrm{psi}-1445 \mathrm{psi}$ \\
\hline Roll Pressure & $13 \mathrm{psi}-75 \mathrm{psi}$ \\
\hline
\end{tabular}

Table 4 Operating Data at Laboratory Conditions 


\subsection{Analysis of Bearing Contact Stress}

\subsubsection{CF3M with Tungsten Carbide Laser Clad against SiAION Ceramic}

The center of thrust is the line of action of the force of the strip on the roll. The center of thrust is determined by the wrap of the strip on the roll and the center of thrust is located at the center of the wrap [6]. The figure shows the schematic drawing of center of thrust between roll and the steel strip.

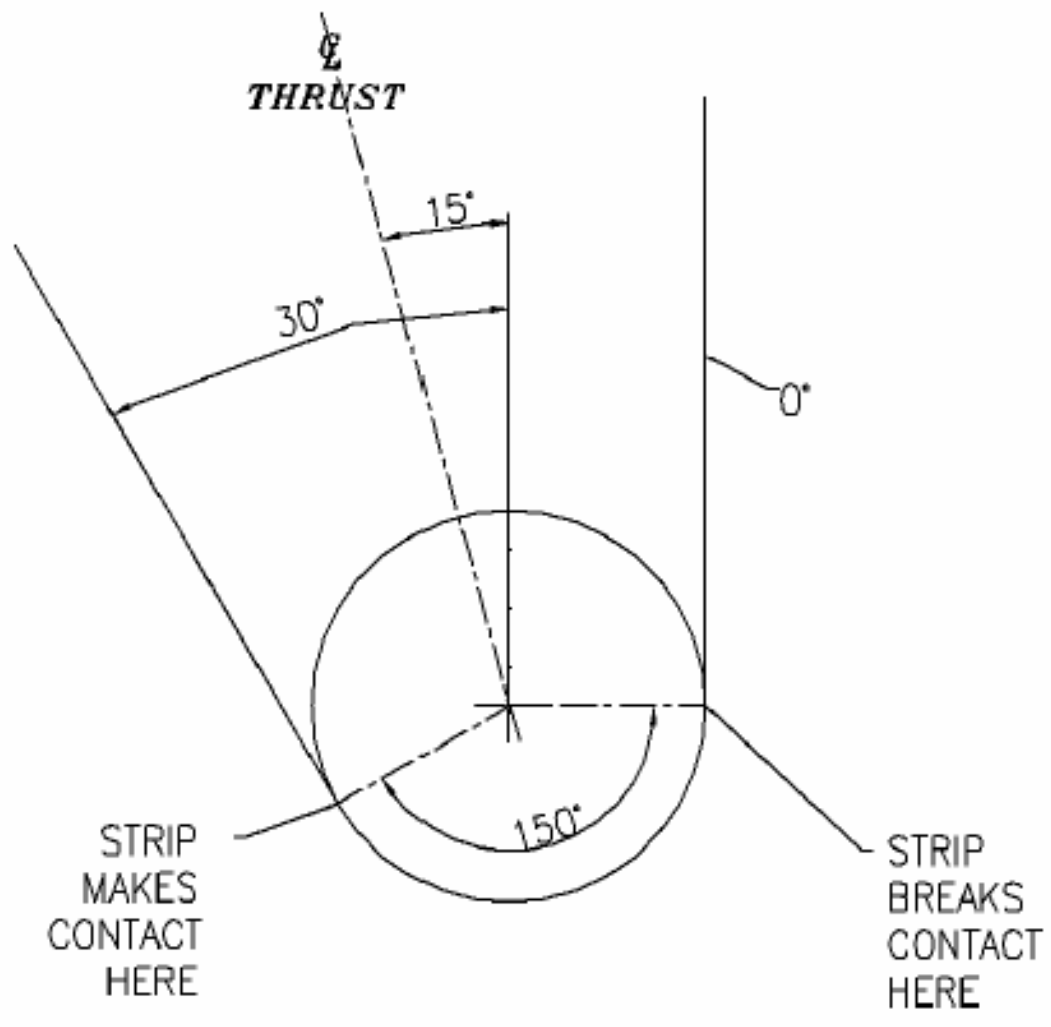

Figure 3 Center of Thrust [6] 


\begin{tabular}{|c|c|c|c|}
\hline Production Line Tension - T & Bottom Roll Dia - $d$ & Sheet Width - $\mathrm{t}$ & Angle of Contact - a \\
\hline (lbs) & (inch) & (inch) & (deg) \\
\hline 3200 & 20 & 24 & 150 \\
\hline
\end{tabular}

Table 5 Production Line Dimensions (Based on Weirton Steel Corp. Line \#5)

\begin{tabular}{|c|c|c|}
\hline Resultant Force $-\mathrm{F}$ & $\begin{array}{c}\text { Area of Contact - } \\
\mathrm{A}\end{array}$ & Roll Pressure \\
\hline $2{ }^{*} \mathrm{~T}^{*} \cos (15)$ & $\mathrm{a} / 360^{*} \Pi^{*} \mathrm{~d}^{*} \mathrm{t}$ & $\mathrm{F} / \mathrm{A}$ \\
\hline$(\mathrm{lbs})$ & $($ inch`2) & $(\mathrm{psi})$ \\
\hline 6182 & 620 & 10 \\
\hline
\end{tabular}

Table 6 Calculation of Production Line Roll Pressure

\begin{tabular}{|c|c|c|c|}
\hline Force on Each Bearing - FB & $\begin{array}{c}\text { Area of Ceramic - } \\
\text { AC }\end{array}$ & Area of Contact - A1 & Bearing Pressure - P \\
\hline F/2 & $4 * 1$ & AC * $3^{* 1}$ & FB / A1 \\
\hline$($ lbs $)$ & $\left(\right.$ inch $\left.^{\wedge} 2\right)$ & $\left(\right.$ inch $\left.^{\wedge} 2\right)$ & $(\mathrm{psi})$ \\
\hline 3091 & 4 & 12 & 257 \\
\hline
\end{tabular}

Table 7 Calculation of Production Line Bearing Pressure 


\begin{tabular}{|c|c|c|c|}
\hline Bearing Pressure $-\mathrm{P}$ & $\begin{array}{c}\text { Area of Ceramic }- \\
\text { ac }\end{array}$ & Area of Contact - a1 & Applied Load - Pt \\
\hline FB / A1 & $2 * 1$ & $\mathrm{ac}^{*} 3$ & $\mathrm{P}^{*} \mathrm{a} 1$ \\
\hline$(\mathrm{psi})$ & $\left(\right.$ inch^$\left.^{\wedge}\right)$ & $\left(\right.$ inch $\left.^{\wedge} 2\right)$ & $($ Ibs $)$ \\
\hline 257 & 2 & 6 & 1542 \\
\hline
\end{tabular}

Table 8 Calculation of Applied Load for Lab Scale Test

Table 5 shows the dimension of the components used in Weirton Steel Line \#5. Production line roll pressure is calculated by dividing resultant force by area of contact between the roll and steel strip. Calculations are shown in Table 6. Table 7 shows the calculation for production bearing pressure. Bearing pressure is calculated by dividing the force acting on the bearing by total area of contact of three ceramics. It should be noted that in this calculation, we use the full area of the ceramic insert $(2 \times 1)$ for estimating the bearing pressure. However in reality the sleeve will only make line contact with the ceramic inserts. As such the bearing pressure calculation is an approximation and not an accurate description at the initial line contact bearing wearing situation. Table 8 shows the calculations for applied load for WVU lab scale test. Bearing pressure was assumed to be same as the production line pressure. Applied load was calculated by multiplying bearing pressure and total area of contact of ceramics. 


\subsubsection{For Stellite 6 against Tribaloy T-400 Test:}

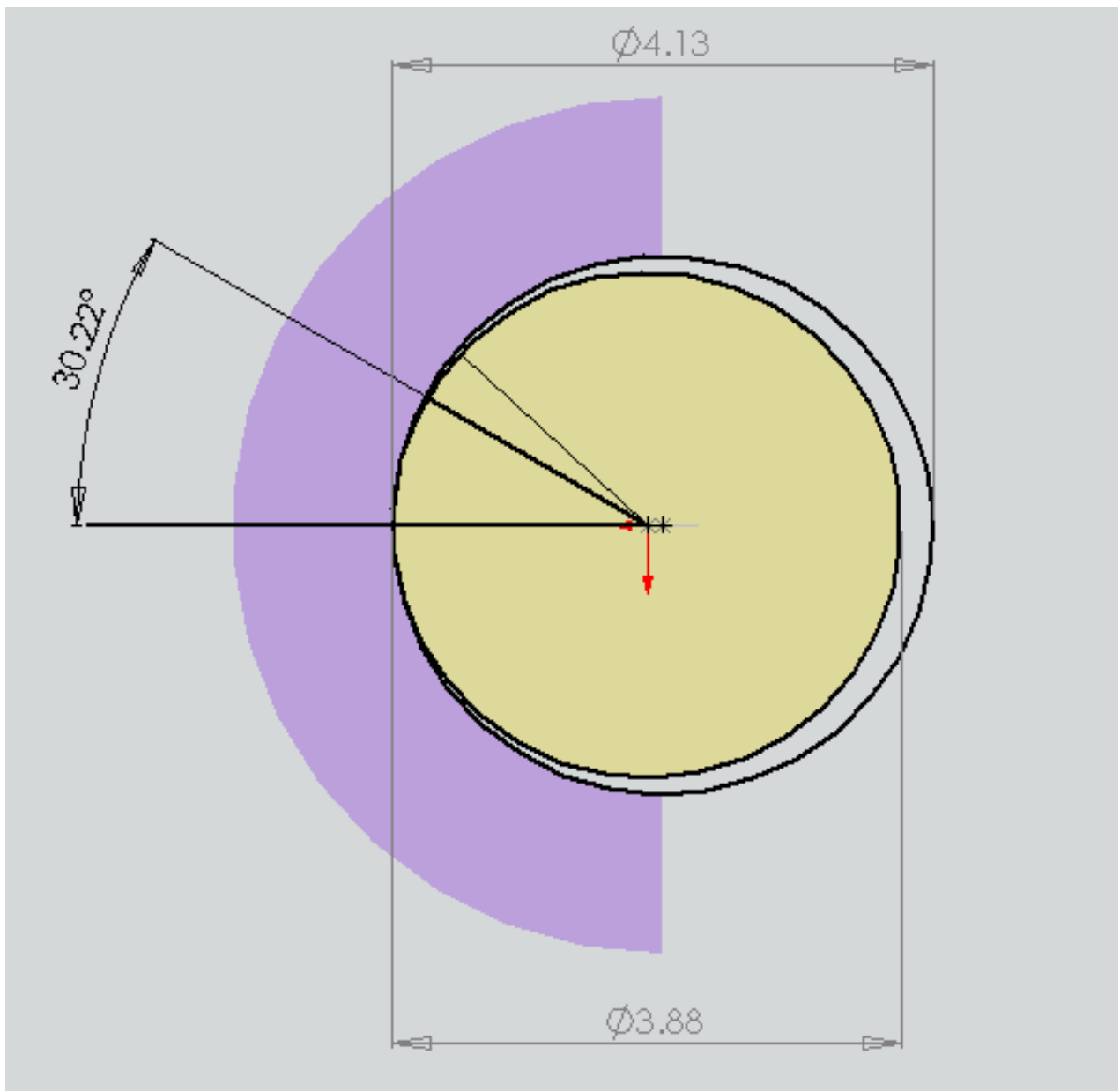

Figure 4 Area of Contact between Stellite 6 Bearing and Tribaloy T-400 Bushing

Figure 4 shows the area of contact between the Stellite 6 bearing sleeve against Tribaloy T-400 half moon bushing obtained from Solid Works ${ }^{\mathrm{TM}}$. 


\begin{tabular}{|c|c|c|}
\hline $\begin{array}{c}\text { Outside Diameter of Bearing } \\
\text { Sleeve }\end{array}$ & Inside Diameter of Bushing & $\begin{array}{c}\text { Height of Bearing \& } \\
\text { Bushing }\end{array}$ \\
\hline D & $\mathrm{d}$ & $\mathrm{H}$ \\
\hline (inch) & ( inch $)$ & ( inch $)$ \\
\hline 3.875 & 4.125 & 2 \\
\hline
\end{tabular}

Table 9 Dimensions of the Bearing Sleeve \& Bushing

\begin{tabular}{|c|c|c|}
\hline Bearing Pressure & Area Of Contact & Applied Load \\
\hline P & A & $\mathrm{L}=\mathrm{P} / \mathrm{A}$ \\
\hline$(\mathrm{psi})$ & $\left(\right.$ inch $\left.^{\wedge} 2\right)$ & $($ lbs $)$ \\
\hline 257 & 4.08 & 1048 \\
\hline
\end{tabular}

Table 10 Calculation of Applied Load for Lab Scale Test (Stellite 6)

Table 9 shows the dimensions of bearing sleeve and bushing used in wearing test. Area of contact of bushing and bearing is obtained from Solid Works ${ }^{\mathrm{TM}}$. Applied load for the laboratory test condition is calculated as shown in Table 10. Figure 5 shows the front view of test bath with the loads. The relation between load acting between contact surface and dead weight is calculated by taking moment about the point $\mathrm{O}$ as shown in Table 11. 


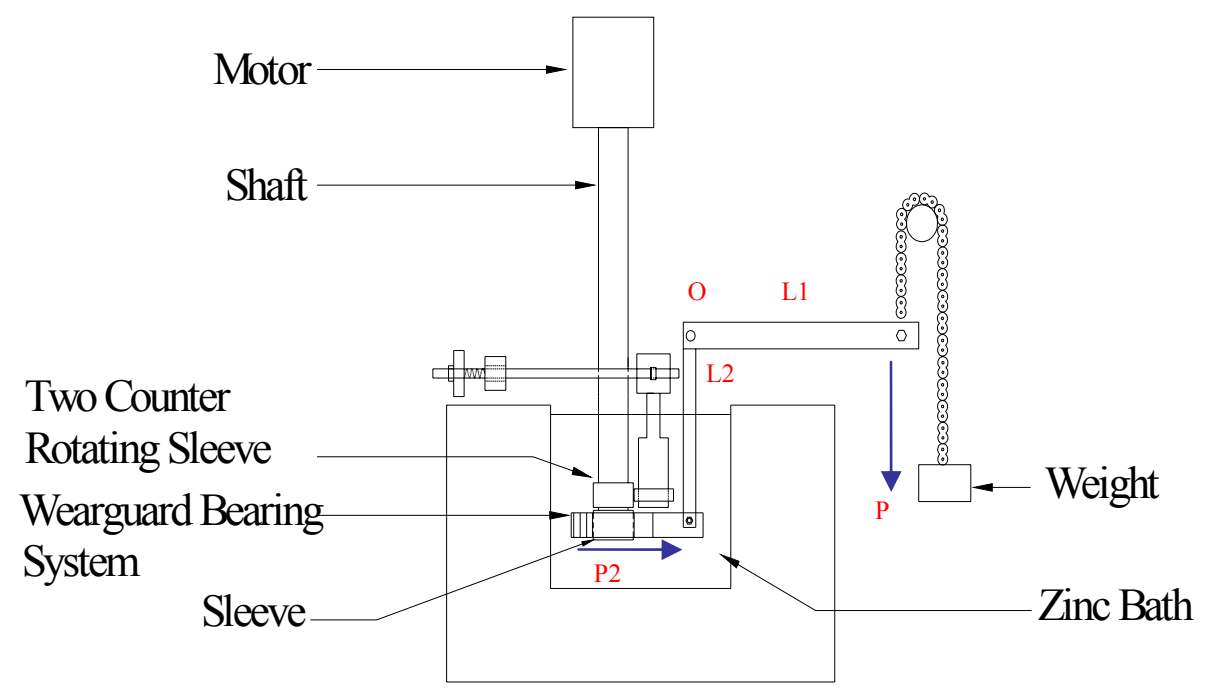

Figure 5 Front View of Test Bath

\begin{tabular}{|c|c|c|c|c|}
\hline $\begin{array}{l}\text { Dead Weight } \\
\text { Load }\end{array}$ & $\begin{array}{c}\text { Length of } \\
\text { Horizontal Arm }\end{array}$ & $\begin{array}{l}\text { Length of } \\
\text { Vertical Arm }\end{array}$ & $\begin{array}{l}\text { Load Acting on } \\
\text { Contact Surface }\end{array}$ & $\begin{array}{c}\text { Taking Moment About } \\
\text { Point } O\end{array}$ \\
\hline $\mathrm{P}$ & L1 & L2 & $\mathrm{P} 2$ & $P 2 * L 2=P * L 1$ \\
\hline (lbs) & (inch) & (inch) & (lbs) & $P 2=(P * L 1) / L 2$ \\
\hline$P$ & 34 & 11 & P2 & $P 2=3 * P$ \\
\hline
\end{tabular}

Table 11 Relation between Dead Weight Load (P) \& Load Acting on Contact

Surface (P2) 


\section{DESIGN OF A WEARING AND DROSS BUILD-UP TESTER}

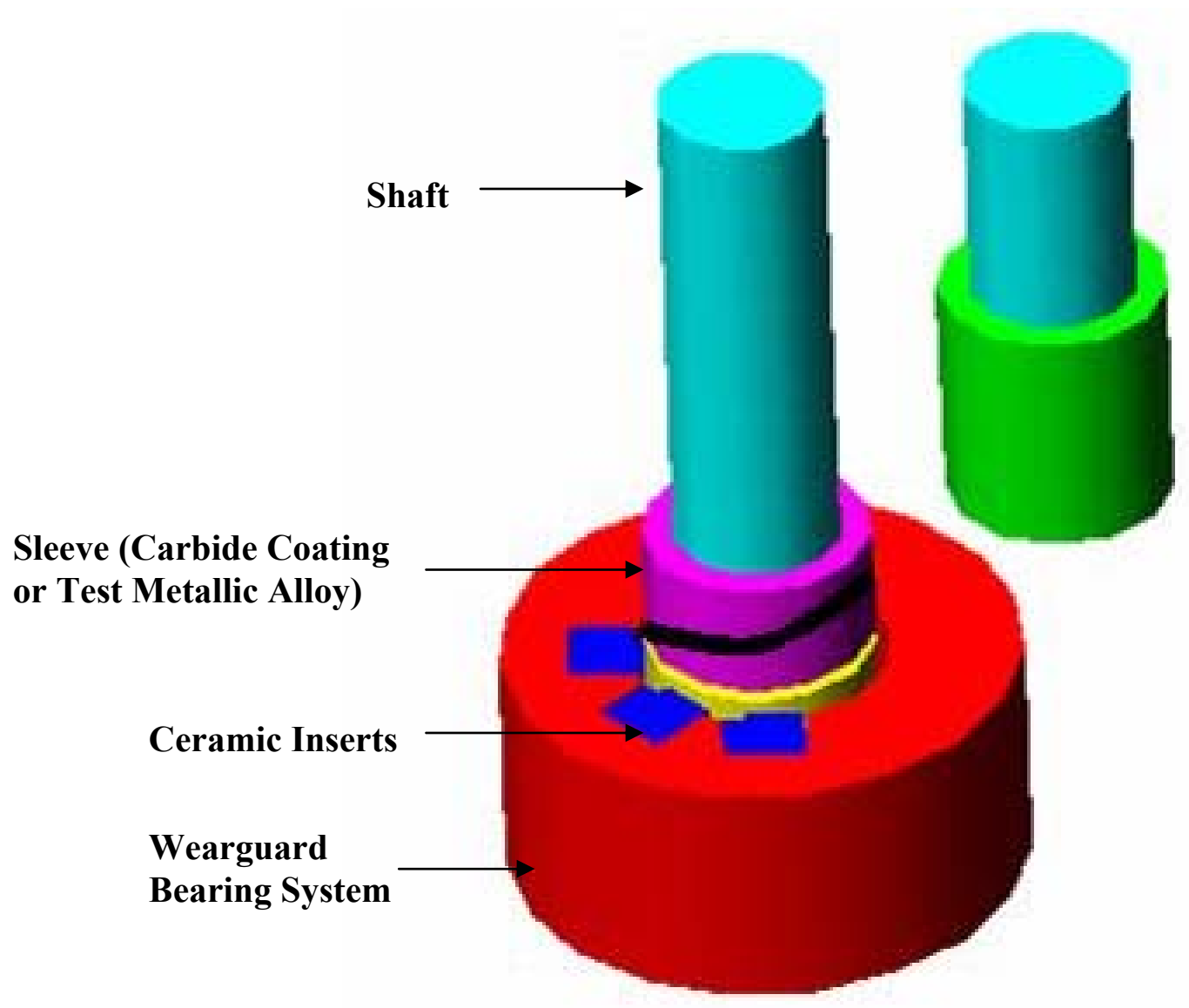

Figure 6 Schematic Representation of Wearing and Dross Build-up Test

Figure 6 represents the basic working principle of wearing bearing test and dross build up test. The dross build up test is simulated by running two counter sleeve rotating against each other. The $316 \mathrm{~L}$ sleeve with tungsten carbide spray coating represents the roll surface and the low carbon steel sleeve represents the sheet metal. For bearing wearing test the $316 \mathrm{~L}$ with tungsten carbide laser cladding is against the three SiAlON ceramic insert which are mounted on the wearguard bearing system. 


\subsection{Wearing Test Setup for Stellite 6 against Tribaloy T-400}

Figure 7 shows the schematic of Stellite 6 against Tribaloy T-400 wearing test set up. The wearing test for the Stellite 6 was run with the typical set up as shown below.

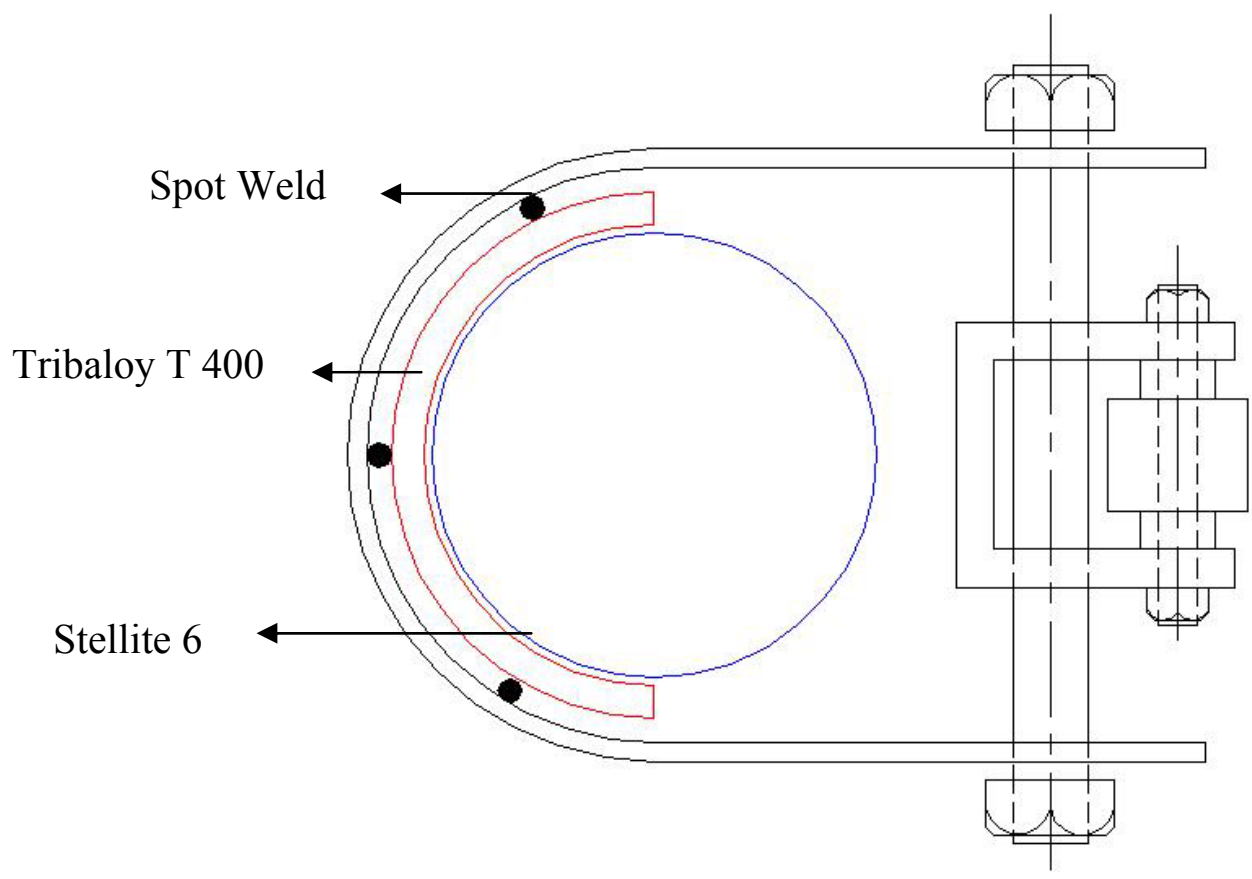

Figure 7 Schematic of Test Setup

Stellite 6 is a Cobalt-based alloy. The microstructure of Stellite 6 consists of eutectoid $\Gamma$ - $\mathrm{Co}$ and $\mathrm{Cr}_{7} \mathrm{C}_{3}$ carbide in a $\Gamma-\mathrm{Co}-\mathrm{Cr}$ matrix [12]. The machined Stellite 6 bearing sleeve with outside diameter of 3.875 " and a length of 2 " was welded to the shaft connected to the motor. The Stellite 6 sleeve is running against a half moon Tribaloy T-400 bearing with inside diameter of 4.125 " and outside diameter of 6" which was welded to the bearing holder and connected to the loading through adapter assembly as shown. When the calculated load is applied, the half moon comes in contact with bearing sleeve, with the contact pressure between them approximately equal to $50 \%$ of the production line pressure. 
Figure 5 represents the front view of the $500 \mathrm{lb}$ zinc Test bath. The motor is used to rotate the shaft with the tungsten carbide sleeve to the speed equivalent to the production line speed. For the dross build-up test, a $316 \mathrm{~L}$ sleeve with tungsten carbide spray coating is rotated against the low carbon steel sleeve which are in line contact with each other. Spring force is used to keep the two sleeves in line contact so as to keep the roll pressure the same as in the production line. When calculated spring load is applied the low carbon sleeve moves towards the tungsten carbide sleeve, thereby producing the line contact between them. For the wearing test the three SiAlON ceramics are placed inside the Wearguard bearing system. Simulated load equivalent to percentage of production line tension is applied by adding suitable amount of weight to the loading arm. When the load is applied the loading arm (L1) moves up, thereby pulling (via arm L2) the wearguard bearing system towards the center. The three SiAlON ceramic inserts placed in the wear guard system comes in line contact with the sleeve. Diametric measurement is taken on the sleeve after each test cycle. The change in diameter of the sleeve with respect to time represents the wearing of the sleeve. 


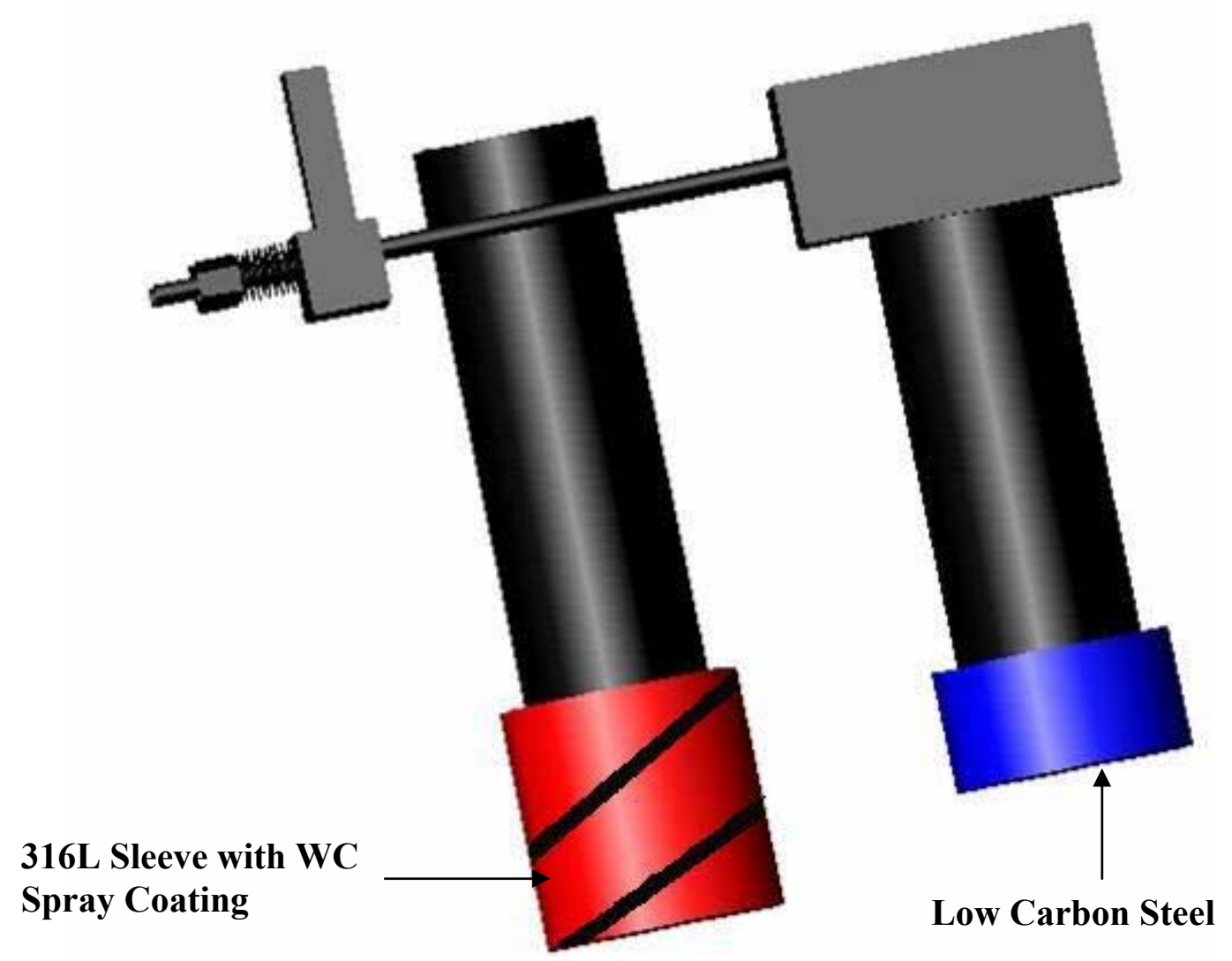

Figure 8 Schematic of Dross Build-up Test

Figure 8 represents the experimental set-up of the dross build-up. The spray coated ASB tungsten carbide $316 \mathrm{~L}$ steel representing the roll surface is mounted on the shaft connected to the motor. The counter rotating low carbon steel shaft is brought in contact with ASB sleeve by spring force. This set up simulates the roll and steel sheet in the production line.

\subsection{Design of Wearing Test}

The wearing test is conducted to study the long-term performance of the bearing materials used in the continuous galvanization lines. 


\subsubsection{Wearguard System}

The CF3M sleeve with tungsten carbide spray coating is to run against three SiAlON bars housed inside the wearguard system.

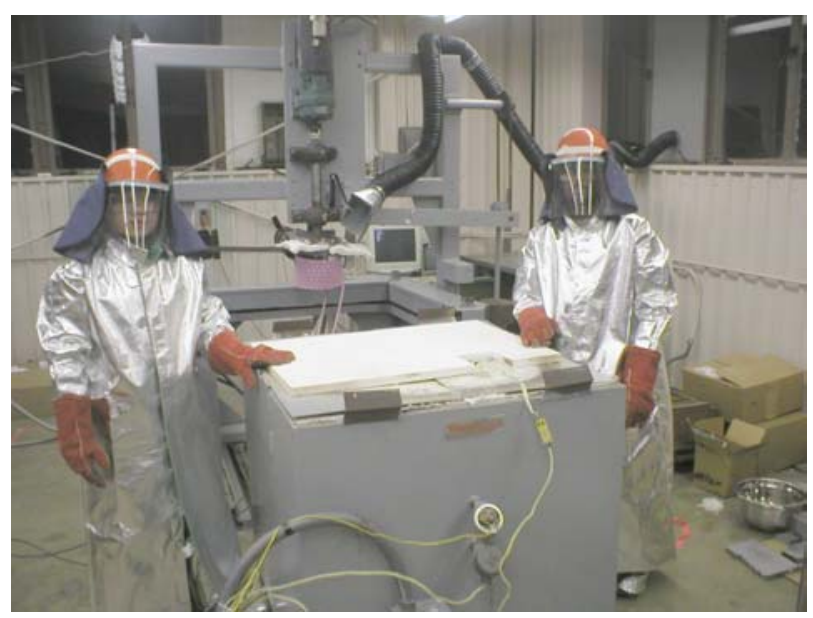

Figure 9 The 500 lb WVU Test Bath

\subsubsection{Shaft}

A low carbon steel rod was machined to 2.85 " outside diameter and to a length of 29 inches. The slot was made on the top end of the shaft to couple it to the motor.

\subsubsection{Sleeve}

The sleeve was cut into 2" in length using a wire cut EDM. The outside and inside diameter of sleeve was 3.875 " and 2.85 " respectively. The sleeve was then welded to the shaft for the wearing test. 

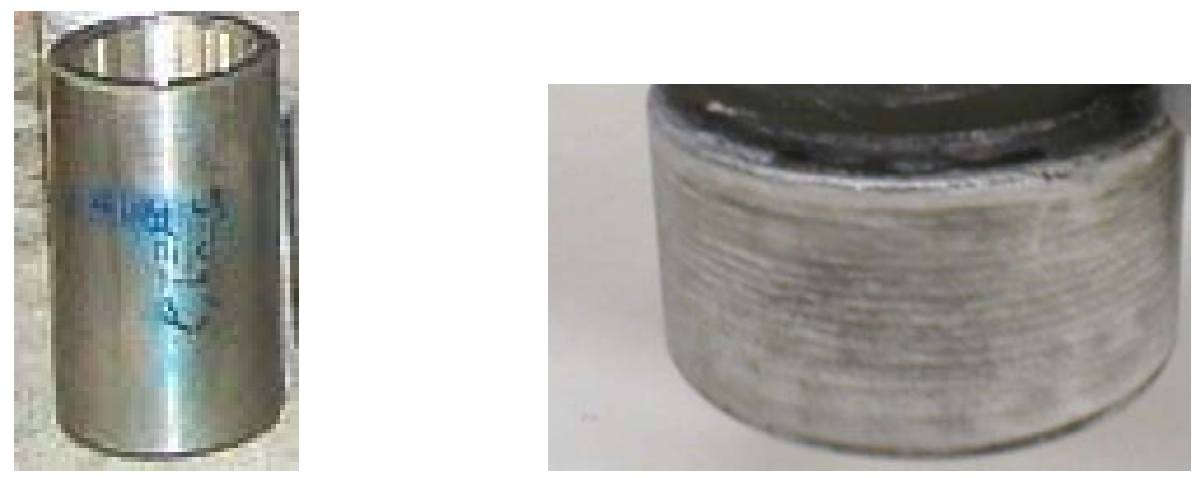

Figure 10 CF3M Coated with Tungsten Carbide by Laser Cladding process

\subsubsection{SiAlON Ceramic Bars}

Three ceramic bar of dimensions 2" x 1" x 1.25" was placed inside the wearguard system with 2 " 1 " surface facing the test bearing.
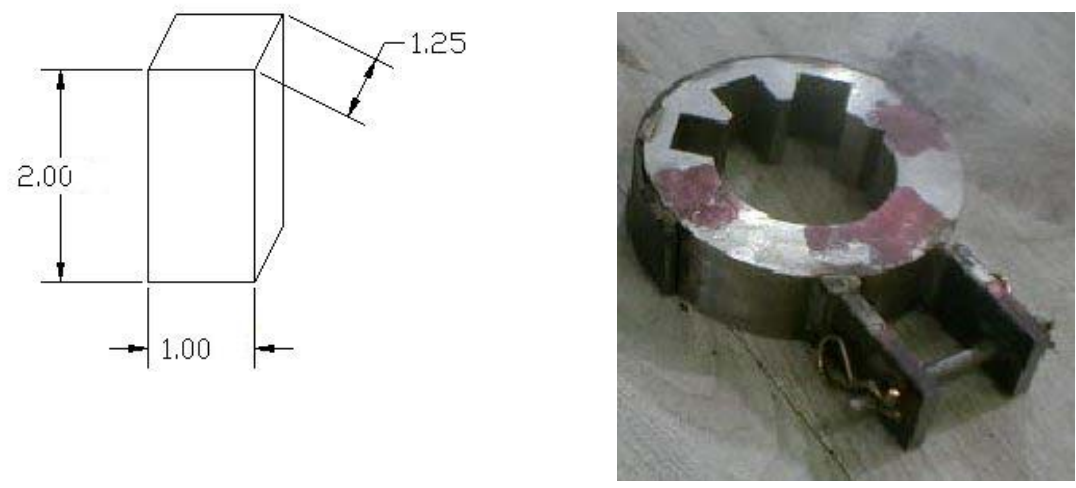

Figure 11 Wearguard System and SiAION Ceramic Bar

\subsubsection{Wearguard System}

Figure 12 shows the schematic of wearguard bearing test setup. The three SiAlON bars are placed inside the three slots in the wearguard bearing system. The SiAlON ceramic bars and wearguard bearing system was cut to 2 " in length instead of the 4" setup used in the production line. Stainless steel wedges were used to hold the ceramic bar in the bearing slot during the test. Two steel bars were welded at the end of the 
bearing with $1 / 2$ " hole machined at the end bar and a $1 / 2$ " steel rod was used to connect the bearing to the loading arm. The rod was locked at the ends by pull pins. The pull pin was preferred to nut to enable the easy removal of the wearguard system after each test cycle. When the calculated load is applied on the loading arm the wearguard system is pulled towards the sleeve, thereby bringing the ceramic bar in contact with the sleeve. The contact pressure is set to be either $30 \%$ or $50 \%$ of the production line tension.

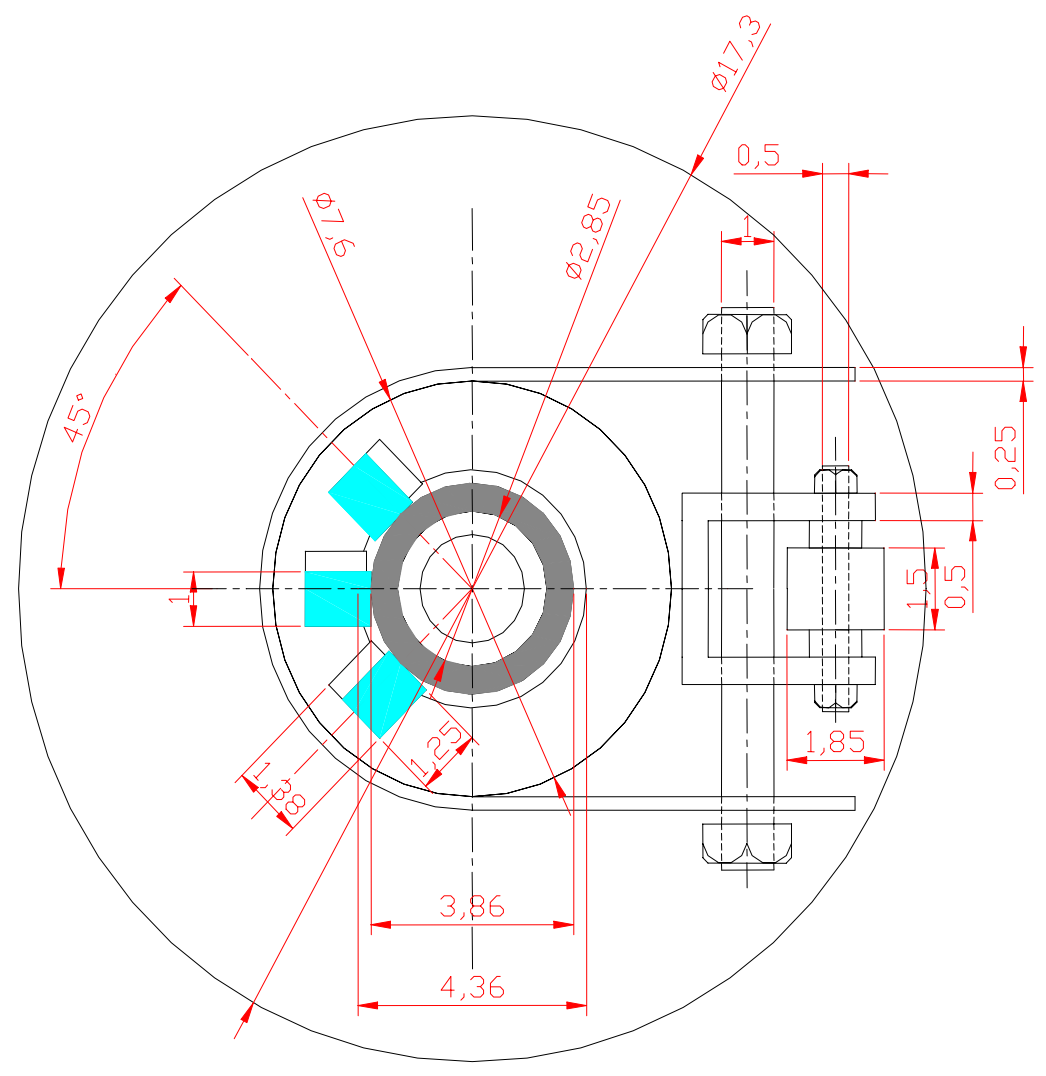

Figure 12 Top View of the Wearguard Test Set Up 


\subsection{Design of Dross Build-Up Test}

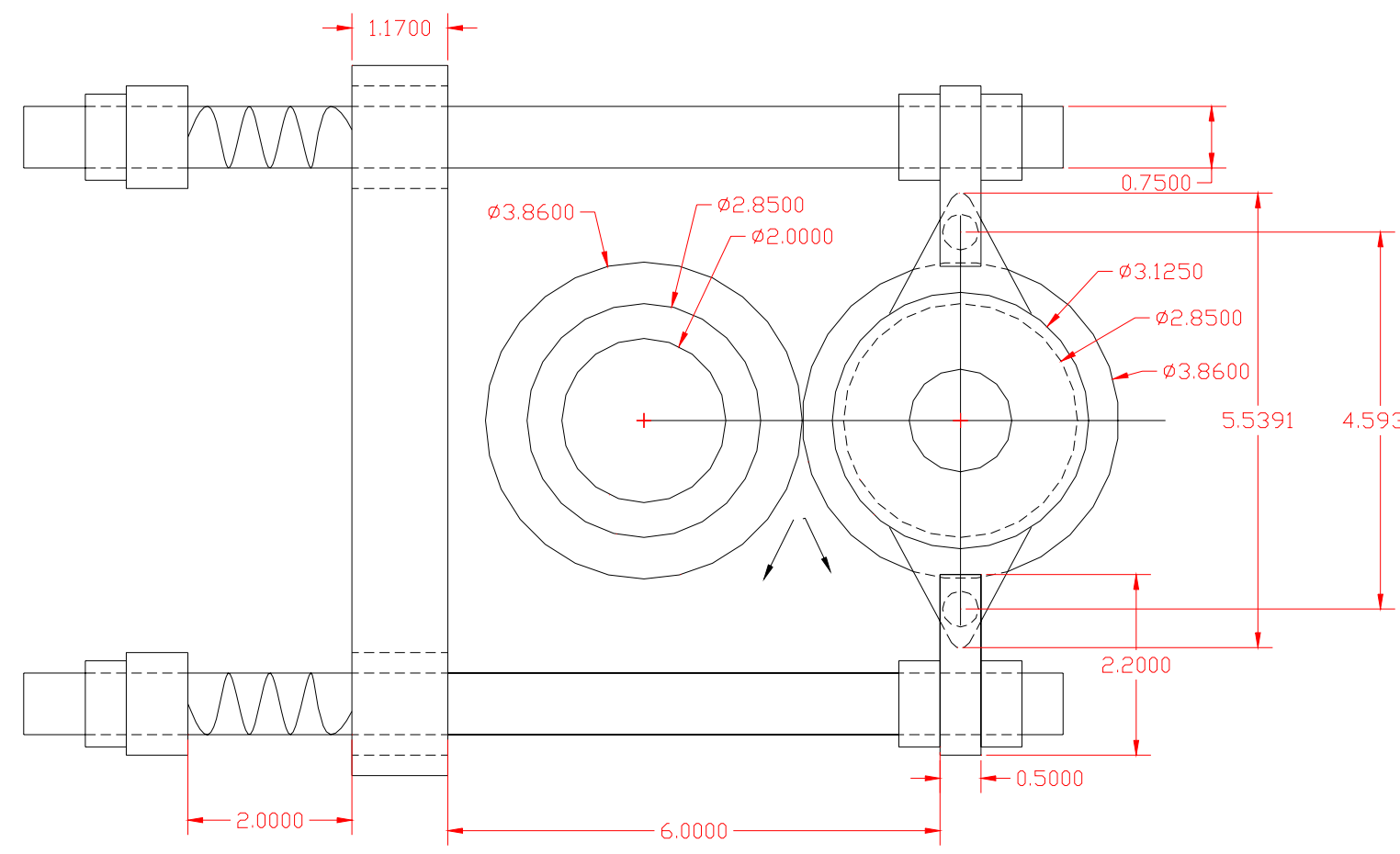

Figure 13 Top View of Dross Build-up Test

Figure 13 represents the top view of the dross build-up test setup. A typical roll surface groove as shown in Figure 14 was machined.

Figure 14 Groove Pattern on Roll Surface 
The low carbon steel shaft simulating the steel sheet in the production line, was fixed to the high temperature self aligning bearing which is held by two steel rods connected to the mounting adapters. The self aligning bearing was fixed to the test bath frame using the mounting adaptors shown in Figure 15. Figure 16 shows the test set up of the high temperature bearing with mounting adapters.
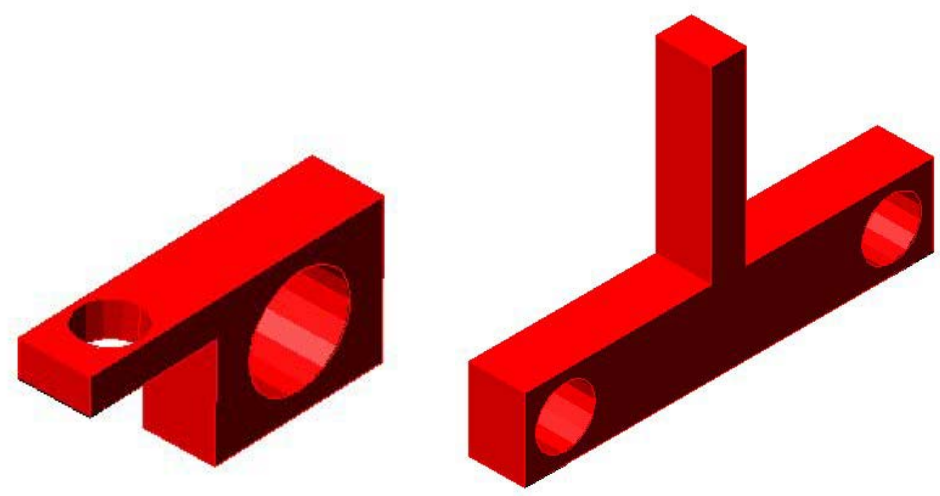

Figure 15 Mounting Adapters

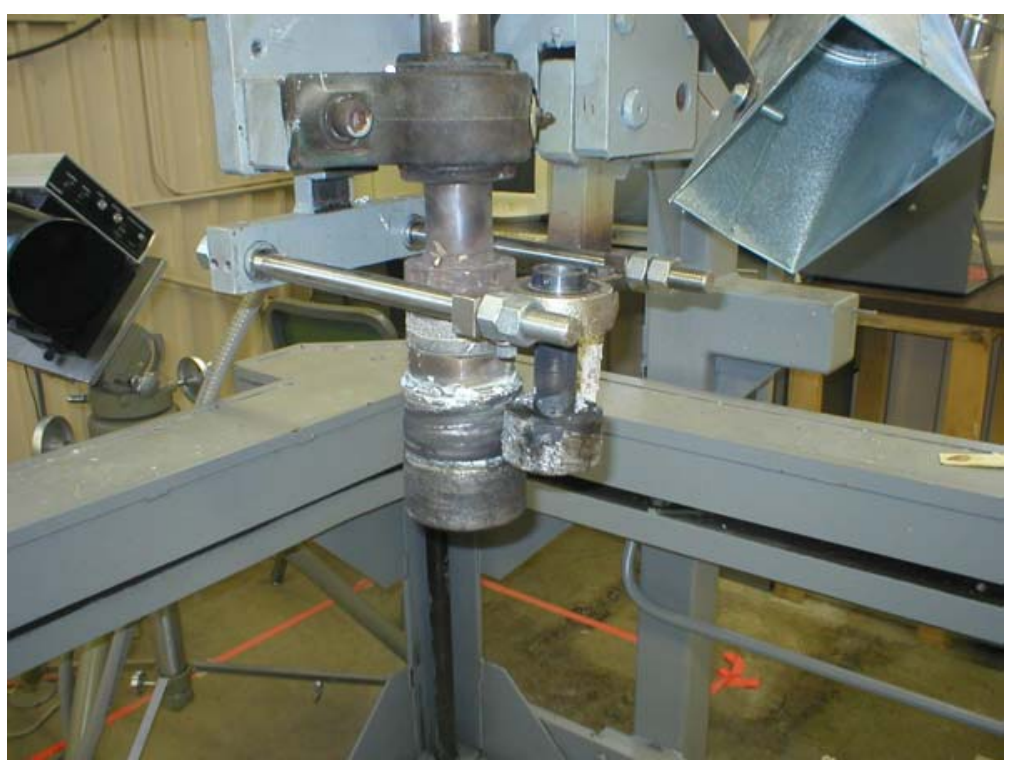

Figure 16 Test Setup with Mounting Adaptors 


\section{EXPERIMENTAL PROCEDURE}

\subsection{Preparation}

Cut zinc bars were melted in the furnace before the start of the preheating stage as shown in Figure 17a. A ceramic insulator was used to cover the zinc pot. Figure $17 \mathrm{~b}$ shows the cleaning of impurities floating on top of the bath. The temperature of molten zinc bath was maintained at $860 \mathrm{~F}$. The pull pin connecting the wearguard system to the loading arm was painted with boron nitride paint. This paint prevents the molten zinc from sticking to the pin surface during testing, which enabled the easy removal of the wearguard system for wearing measurement. The initial diameter, hardness and microstructure of the bearing sleeve were measured before starting the test.

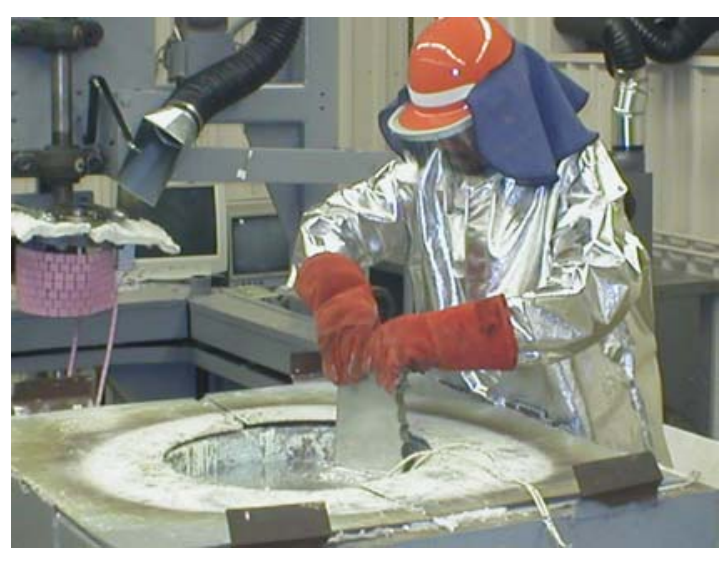

( a )

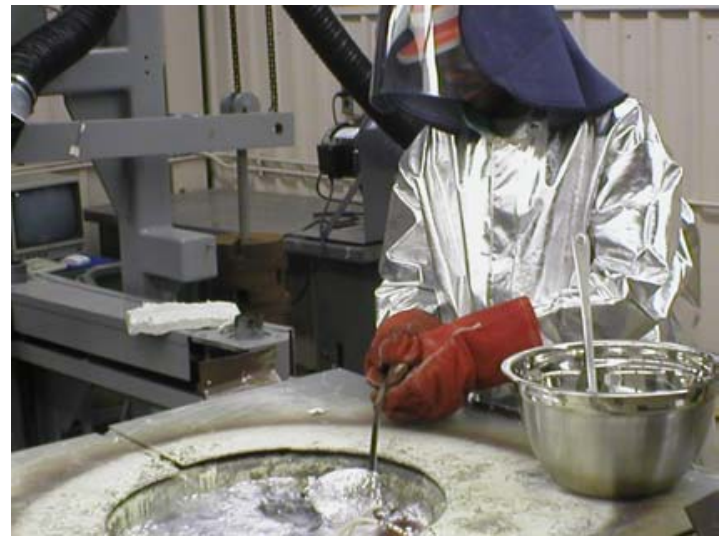

( b )

Figure 17 ( a) Adding Zinc Bars to the Bath ( b ) Removing Impurities from the Molten Zinc

\subsection{Preheating}

The flexible preheater was carefully wrapped around the sleeve making sure that the heater does not touch the metal surface as shown in Figure 18. A k-type thermocouple was kept close to the testing bearing sleeve to provide the temperature 
feedback to the temperature controller during the preheating stage. Then the flexible heater was covered with the insulation to reduce the loss of heat during preheating as shown in Figure 19. The bearing sleeve is usually preheated upto a temperature of $850 \mathrm{~F}$. The insulation and the preheater were unwrapped and moved away. The k-type thermocouple was also removed before immersing the bearing sleeve into the zinc pot.

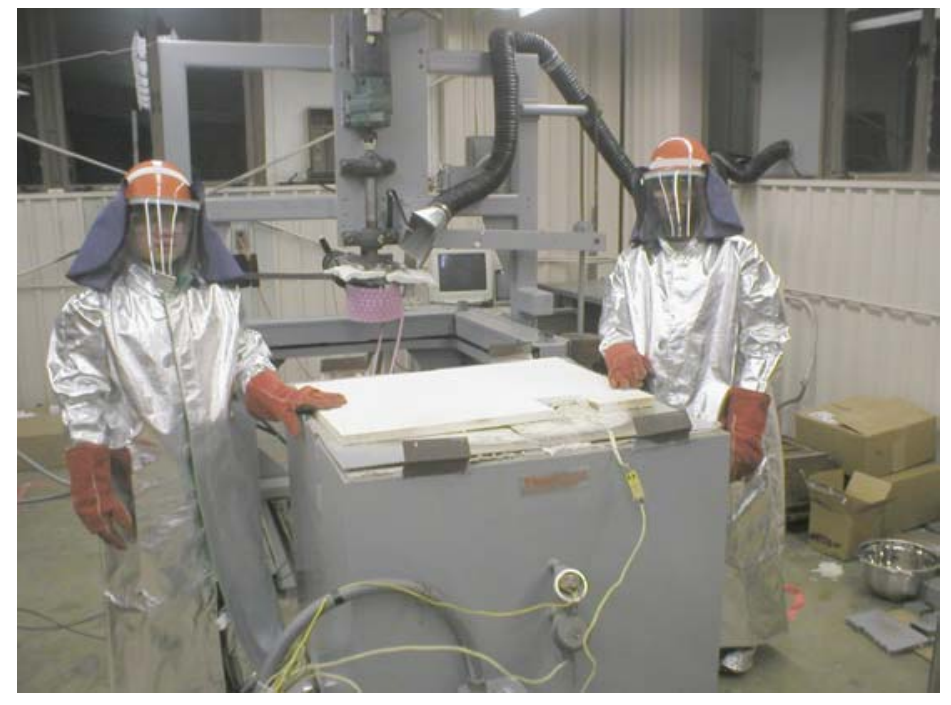

Figure 18 Preheater Wrapped Around the Test Sleeve

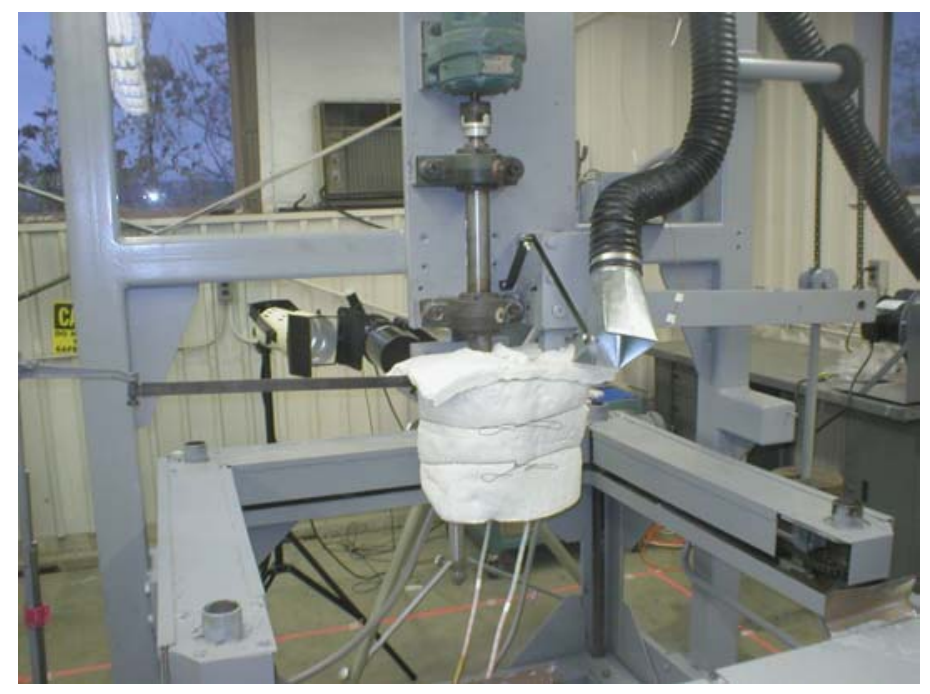

Figure 19 Preheating Stage 


\subsection{Testing Procedure}

After preheating, the zinc pot was moved below the bearing sleeve. The calculated load was applied to the loading arm to bring the bushing in contact with the bearing sleeve surface. Figure 20a shows that the zinc pot was raised to immerse the test sleeve in to the molten zinc. The sleeve was made to rotate inside the zinc pot at the speed same as that of the production line as shown in Figure 20b.

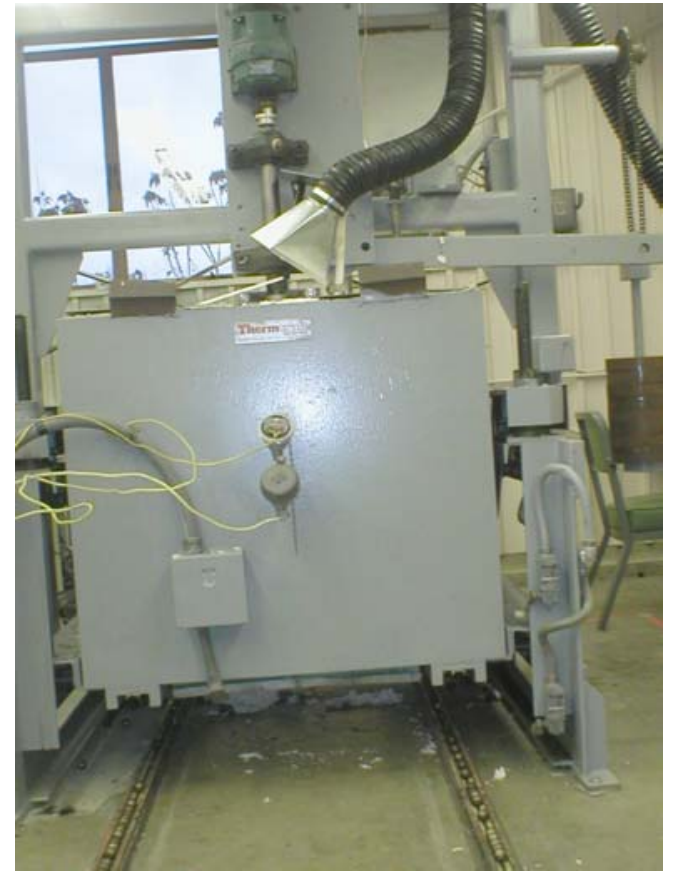

( a )

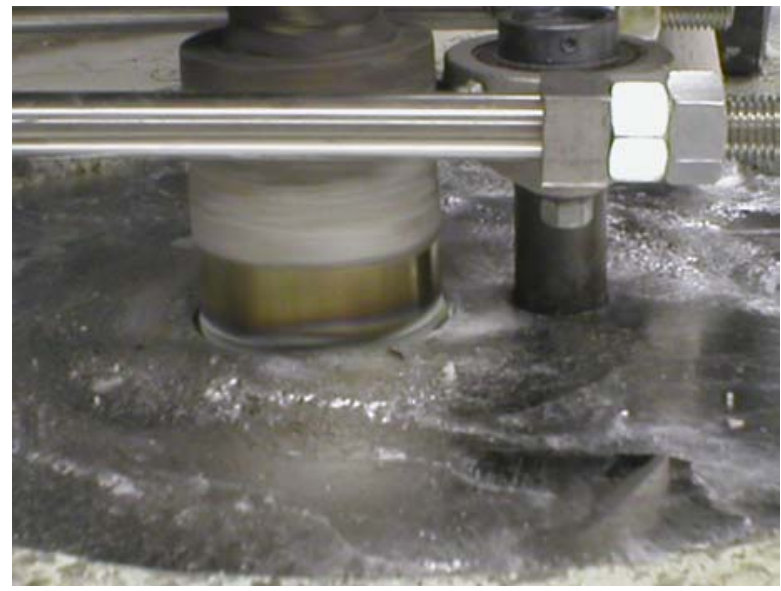

( b )

Figure 20 (a) Bearing Sleeve Immersed in Zinc Pot (b) Test Sleeve Rotating in Zinc Pot

The test was stopped at periodic intervals. The zinc pot was lowered down and wearguard system was cleaned with wooden shims to remove the molten zinc sticking on the surface. A steel plate was placed on top of the zinc pot, then the load was removed from the loading arm and pull pin was pulled out. Figure 21a 
shows the wearguard system dropped to the steel plate, the steel plate along with the wearguard system was moved out. The zinc pot was moved out as shown in Figure 21b.

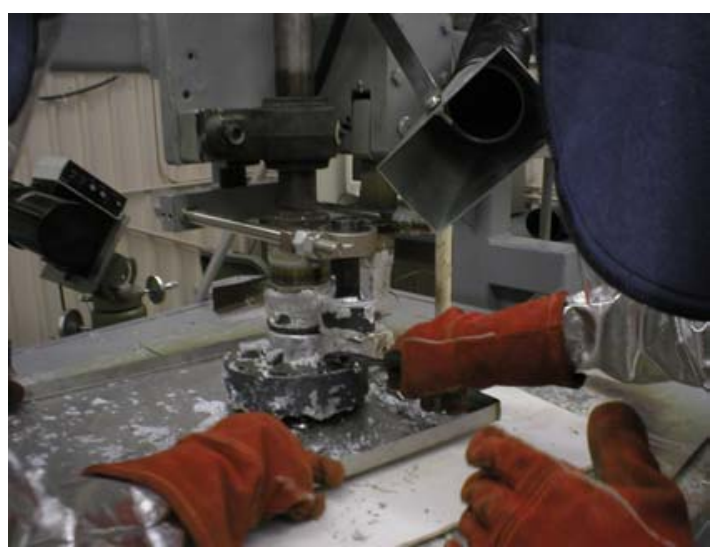

( a )

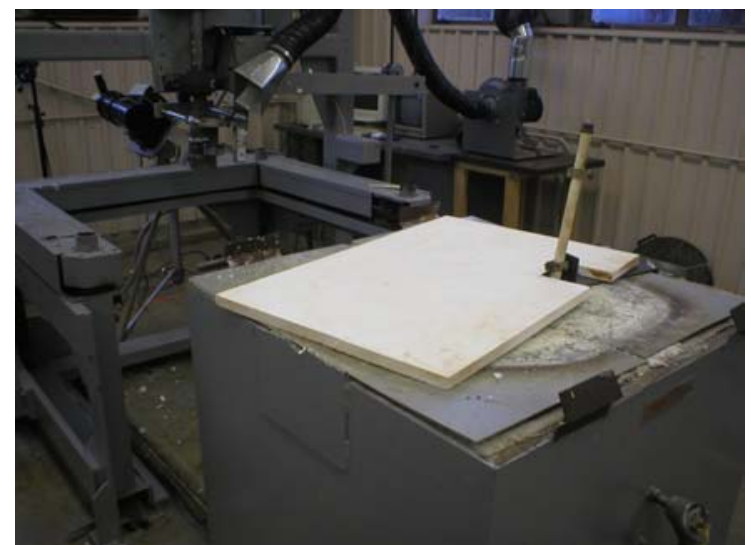

( b )

Figure 21 (a) Removing the Wearguard System (b) Zinc Pot Moved Out

\subsection{Wearing Rate Measurement Procedure}

After stopping the test, the bearing sleeve was allowed to cool down to the room temperature. Then the selected spots of the bearing sleeve were cleaned using dilute hydrochloric acid to remove the zinc sticking on the surface. The sleeve diameter was measured using a high precision diametric unit. This unit was specially designed for this task with a measurement resolution of $1 \mu \mathrm{m}$. Before taking measurement of the bearing sleeve, measurement was made on a reference block. The indicators read zero value when they touch the reference block. The arm was swung out until it hits the stops. The indicators were aligned with the mark made on top of the bearing sleeve. The two indicators were moved close to the diametric point using the precision XYZ stage. The diametric point was identified when the indicator reaches a maximum value and then decreased. The above procedure was repeated three times to the exact diametric point. 
The difference of initial diameter and the new diameter gives the wearing rate after each test cycle.

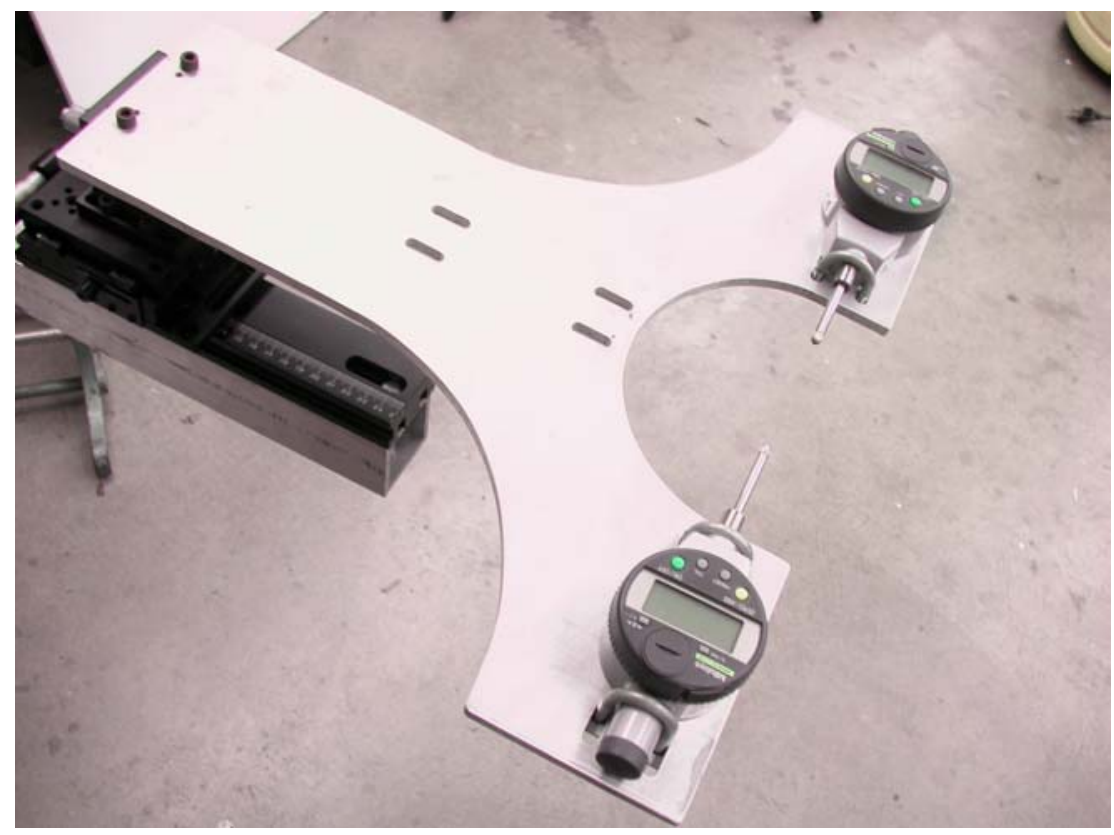

Figure 22 Diametric Measurement Unit

\subsection{Procedure for In-Site Microstructure Viewing}

The infinity microscope was first fixed to the motorized stage which rests on the $\mathrm{Y}$ and $\mathrm{Z}$ stages. The 10X objective was then mounted to the Infinity system. The digital camera was attached to the microscope through an adapter. The motorized probe was connected to the controller. Finally the optical fiber lighting was connected to the infinity microscope. An internal lighting for the infinity system was used to give the best possible results in terms of clarity of details. The internal lighting causes a uniform lighting of the viewed area and also helps to eliminate unwanted shadows. Now the camera was connected to the monitor to get the focused image. 
After adjusting the $\mathrm{Y}$ and $\mathrm{Z}$ stages to the proper location (the area of interest), the $\mathrm{X}$ stage was moved using the controller in relatively large steps. Once a good focus is achieved, a smaller step in the controller was used to get to the best focused image. Care was taken to ensure that the microscope is perpendicular to the surface of the specimen. A remote control was used to capture the picture, and to avoid shaking. Then the objective lens was changed to 20X for more detailed views. Microscopic details can also be captured using the $50 \mathrm{X}$ objective.

Once the entire test was completed, the bearing sleeve was removed from the shaft and was cut using the electrical discharge machine (EDM) for a detailed microstructure study using SEM. 


\section{RESULTS \& DISCUSSIONS}

\subsection{Test 1 CF3M with Tungsten Carbide Coating against SiAION Ceramics}

\begin{tabular}{|l|l|}
\hline BEARING WEARING TEST & $\begin{array}{l}\text { Wearguard bearing system with } 316 \mathrm{LS} \\
\text { with WC- L \& SiAlON ceramic inserts } \\
\text { DROSS BUILD-UP TEST }\end{array}$ \\
\hline BEARING LOAD & $316 \mathrm{LS}$ with WC- S/C \& low carbon steel \\
\hline BEARING PRESSURE & $4801 \mathrm{~b}(32 \%$ Production Line Tension) \\
\hline LINE SPEED & $82 \mathrm{psi}(32 \%$ Production Bearing Pressure) \\
\hline BATH TEMPERATURE & $108 \mathrm{rpm}(\mathrm{Same}$ as Production Line Speed \\
\hline & $110 \mathrm{ft} / \mathrm{min})$ \\
\hline
\end{tabular}

\section{Table 12 Test Conditions (Test \#1)}

Table 12 shows the test conditions for CF3M with tungsten carbide laser clad coating against SiAlON ceramics. When two solid materials are made to contact under pressure, only certain regions of their surfaces will come in actual contact, while other regions remain apart with no contact. Adhesive wear occurs by moving materials from one contact surface to the other, due to the adhesion of contact material during sliding. When hard phases plow the softer surfaces, abrasive wear occurs. The plowing of hard phases on the soft surface creates a series of surface grooves during sliding. The hard WC particles imbedded in soft iron - based exhibits composite nature. The WC particles are brittle hence might crack due to the contact pressure. Soft iron based matrix retards crack propagation and can endure repeated loading conditions without cracking. The cracked WC particles may get imbedded in the coating or entrapped between contacting surface 
as debris, are harder than the SiAlON ceramic material. They readily wear SiAlON ceramic during sliding, resulting in grooves on the ceramic wearing area.

Figure 23 shows wearing of the tested sleeve versus time. The bearing sleeve had a high wearing rate in the early stages up to test cycle 3 . There was smaller wearing on the bearing sleeve between test cycle 3 and test cycle 4 as seen from the graph. The sleeve is expected to have a constant wearing rate after test cycle 4.

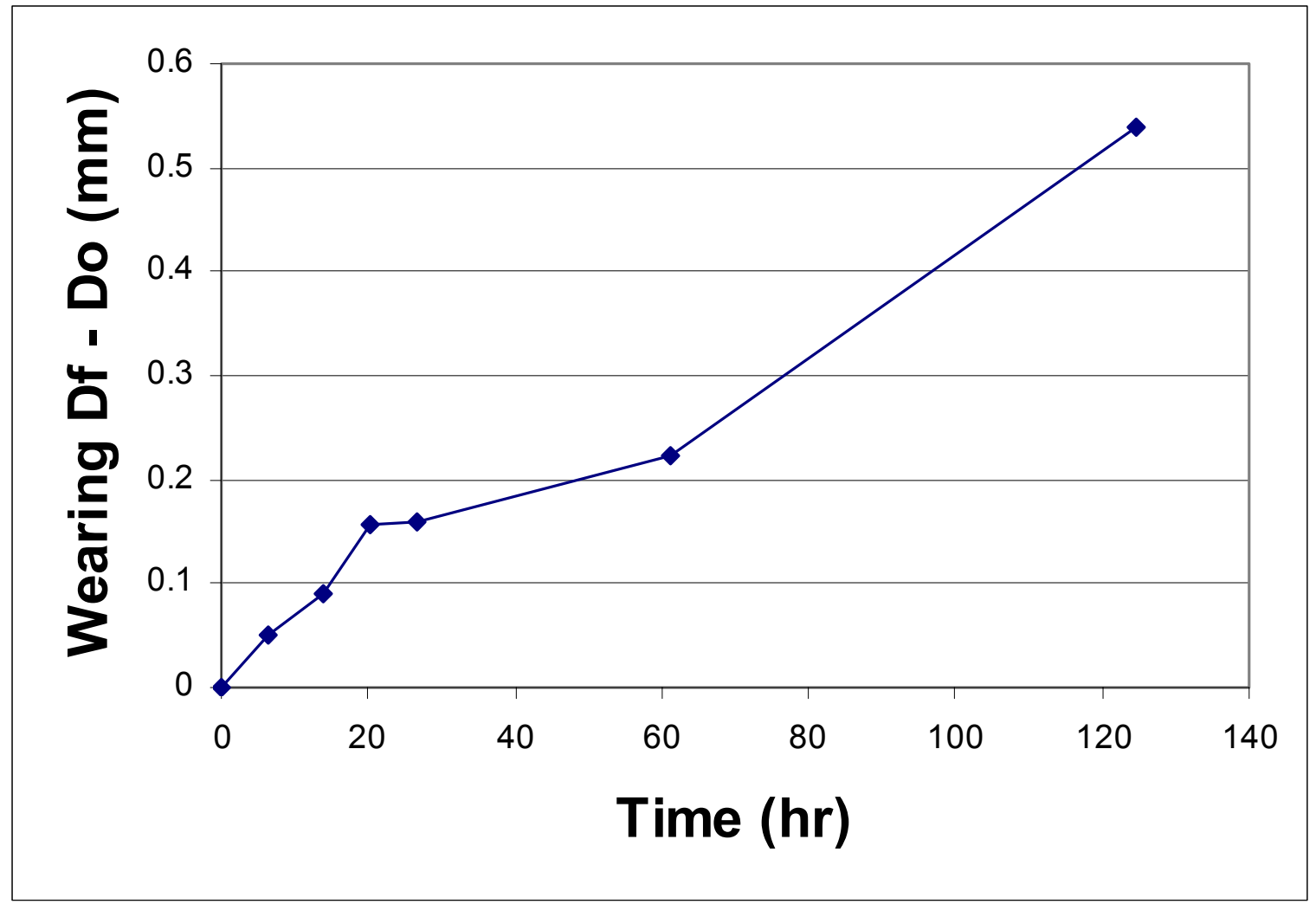

Figure 23 Wearing Result of 316 LS with WC-L against SiAION Ceramic Inserts 


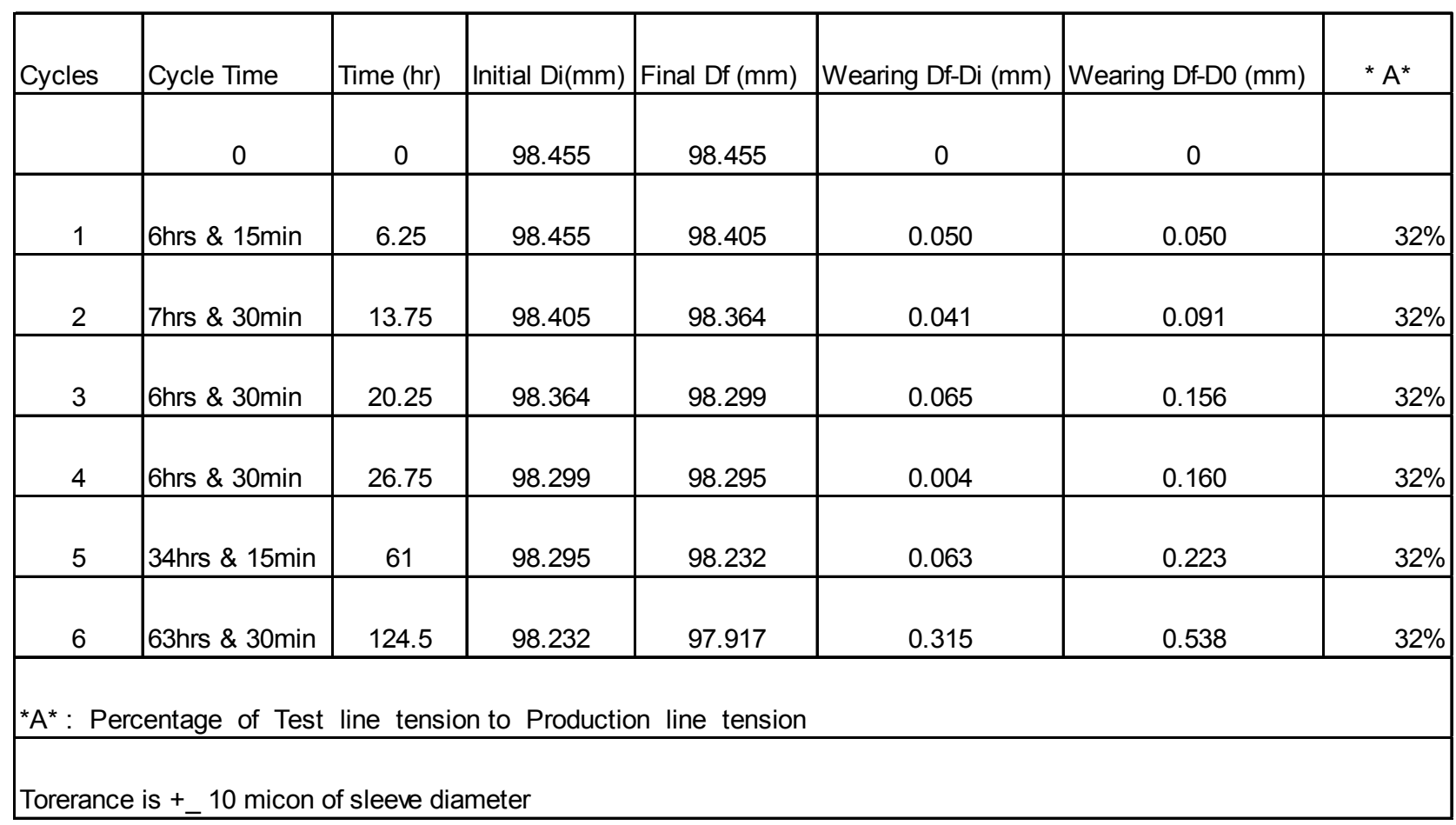

Table 13 Wearing Results of 316 LS with WC-L against SiAION Ceramic Inserts

Table 13 shows the wearing rate of CF3M with WC laser clad coating against SiAlON ceramic material. The three bar bushing design resulted in uneven wear of the bar components. The three ceramic bars experienced maximum wear at the top. Figure 26 shows that the groves were formed on the ceramic after the third test cycle. A mould was made to replicate the wearing surface of the ceramic inserts after each test cycle and further research is carried out to measure the wearing rate of the SiAlON ceramic using optical shadow moiré method by another graduate student. Figures 24 to 28 shows the wearing of ceramic inserts after each test cycle. Figure 29 shows the typical microstructure of the bearing sleeve after test cycle 6 . 


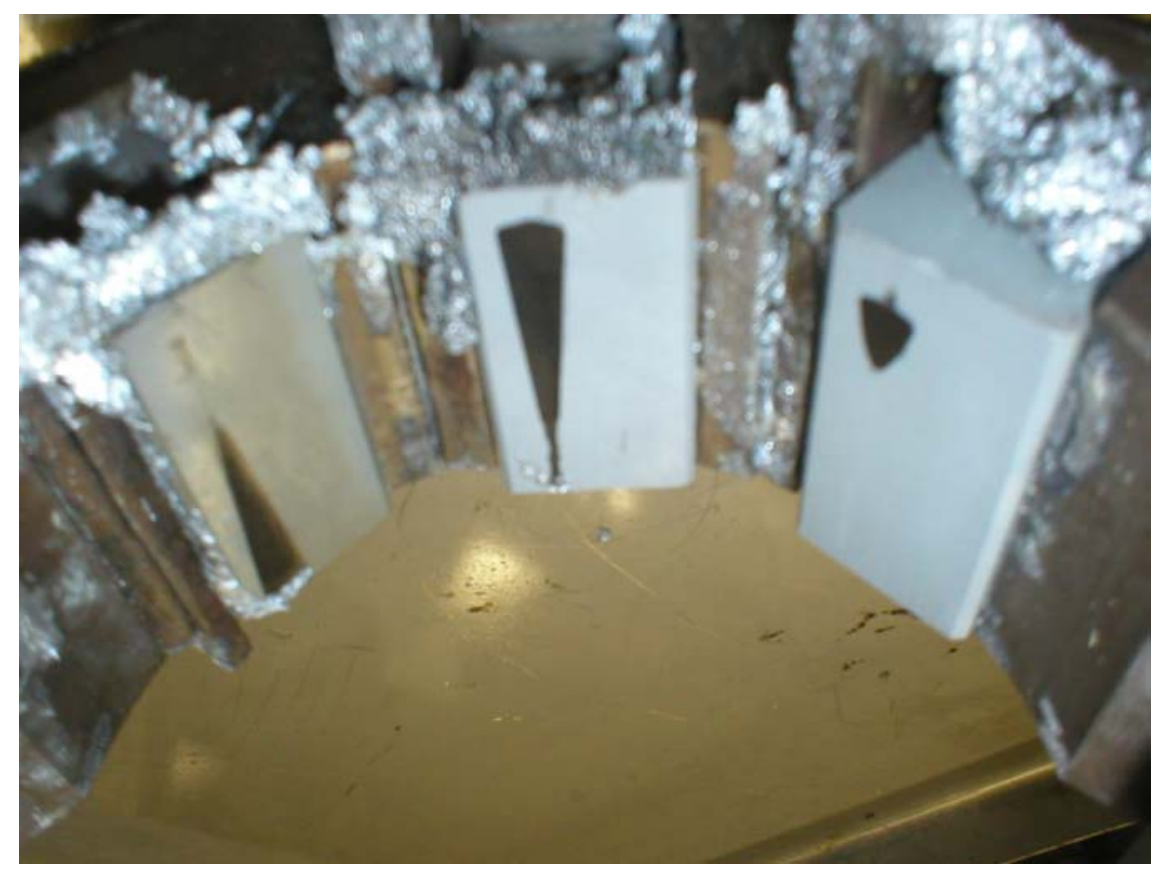

Figure 24 Wearing on Ceramic Insert after Cycle 1 (6 hr \& 15 min)

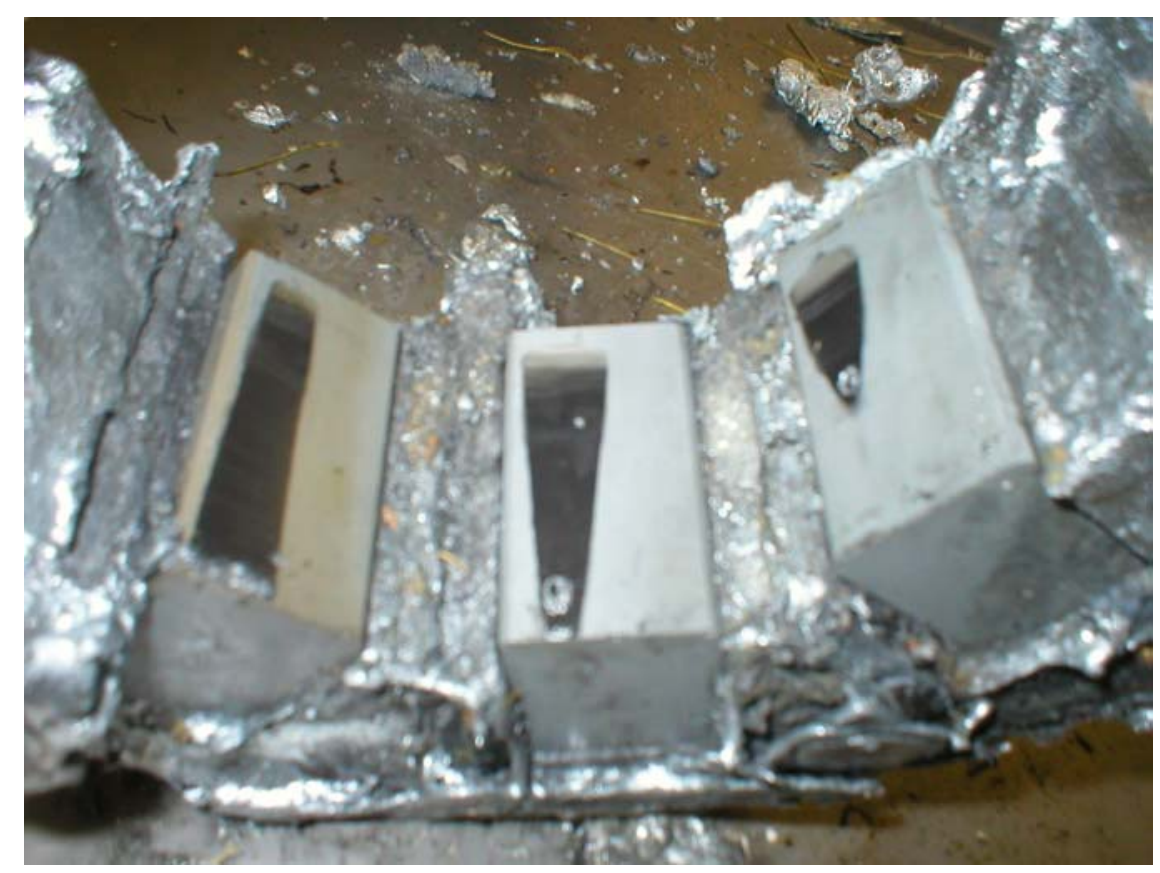

Figure 25 Wearing on Ceramic Insert after Cycle 2 (13 hr \& 45 min) 


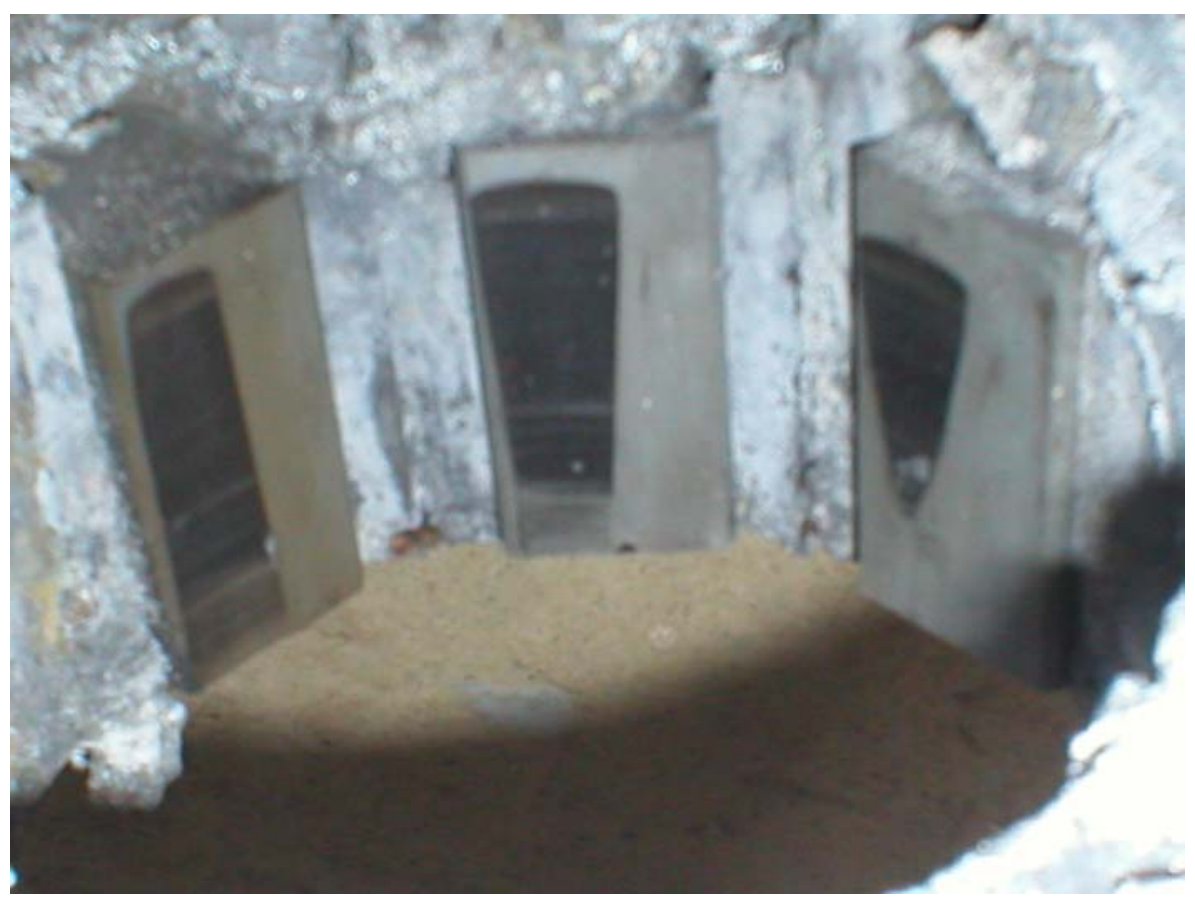

Figure 26 Wearing on Ceramic Insert after Cycle 3 with Grooves (20 hr \& 15 min)

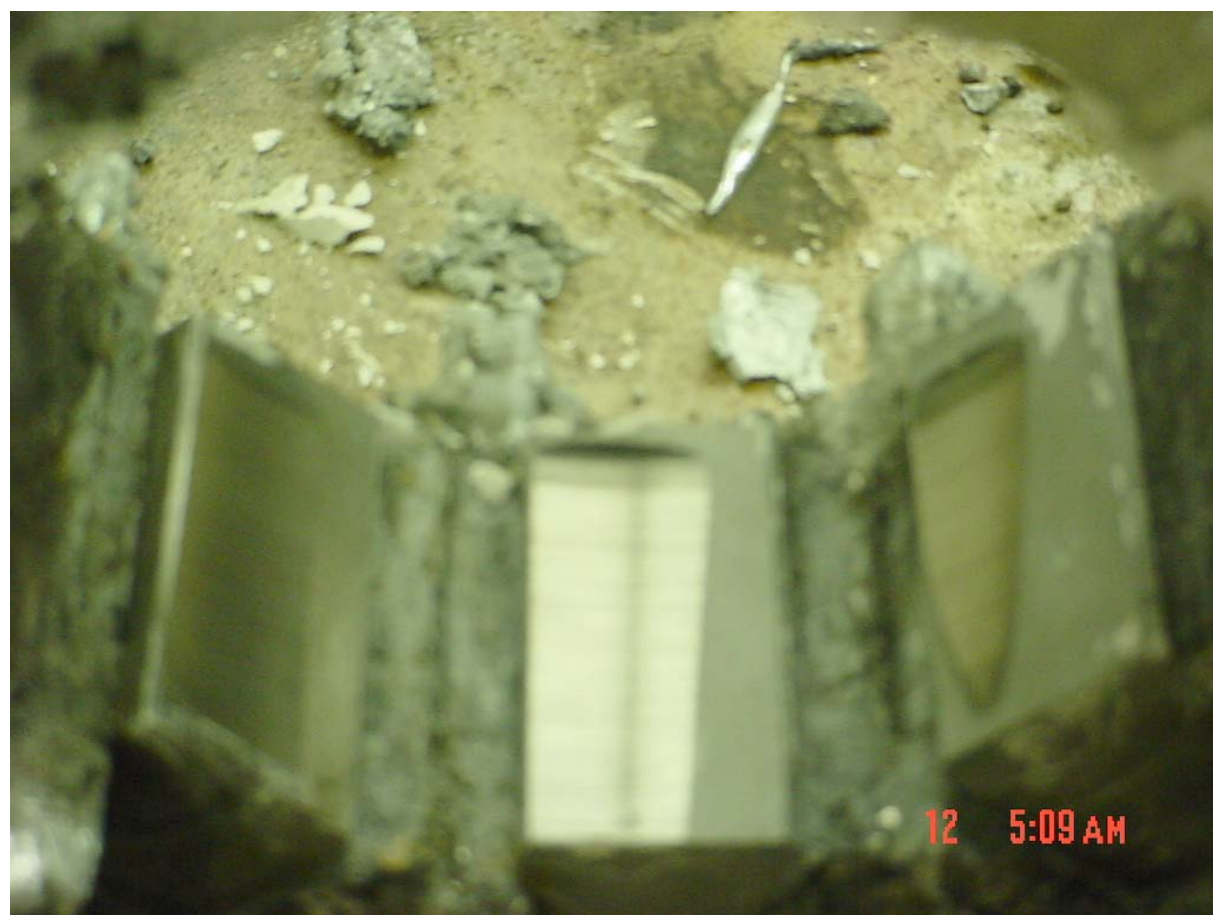

Figure 27 Wearing on Ceramic Insert after Cycle 5 (61 hr) 


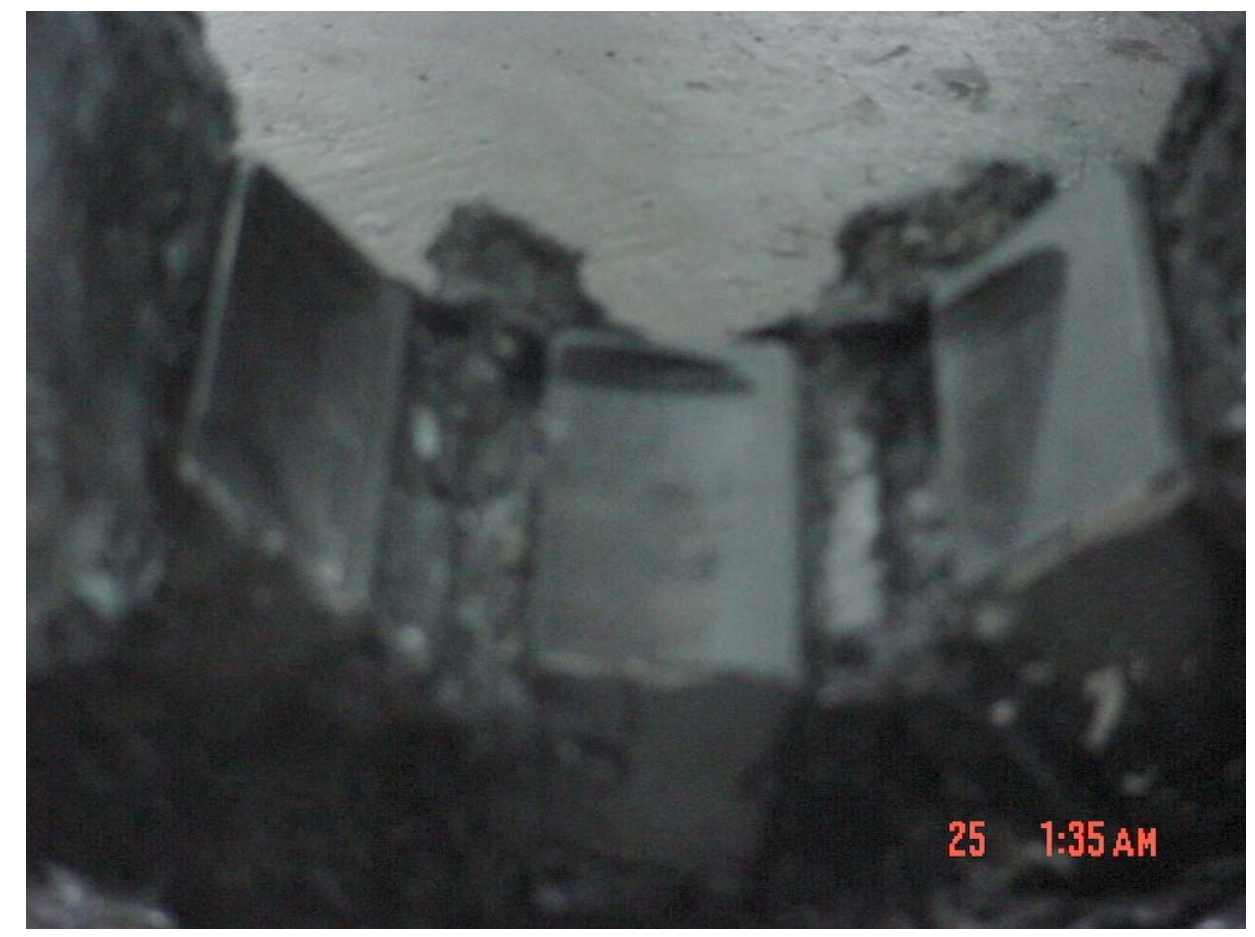

Figure 28 Wearing on Ceramic Insert after Cycle 6 (124 hr \& 30 min)

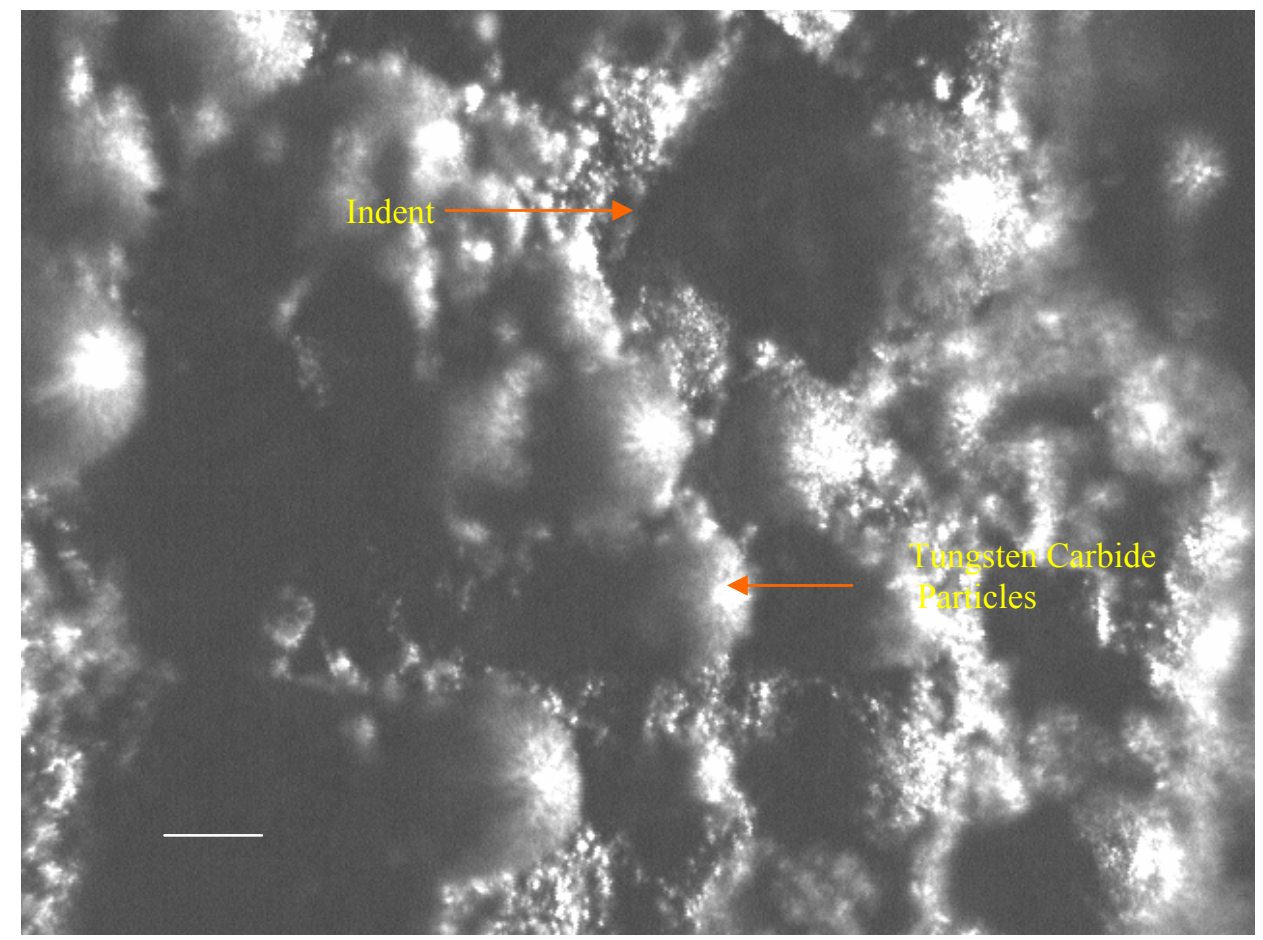

Figure 29 Bearing Sleeve Microstructure after Cycle 6 (124 hr \& 30 min) 
At the early stages of wearing, the ceramic particles from the bar struck to the soft matrix of the bearing sleeve and got imbedded in the surface of the bearing sleeve. This ceramic particle sticking on the bearing sleeve might have acted as protective layer and possibly even reduce wearing of the bearing sleeve as indicated in test cycle 3 and 4 . Thickness of ceramic coating layer was measured to be from $15 \mu \mathrm{m}$ $30 \mu \mathrm{m}$. Figures 30 and 31 confirmed the presence of ceramic particles on the bearing sleeve surface.

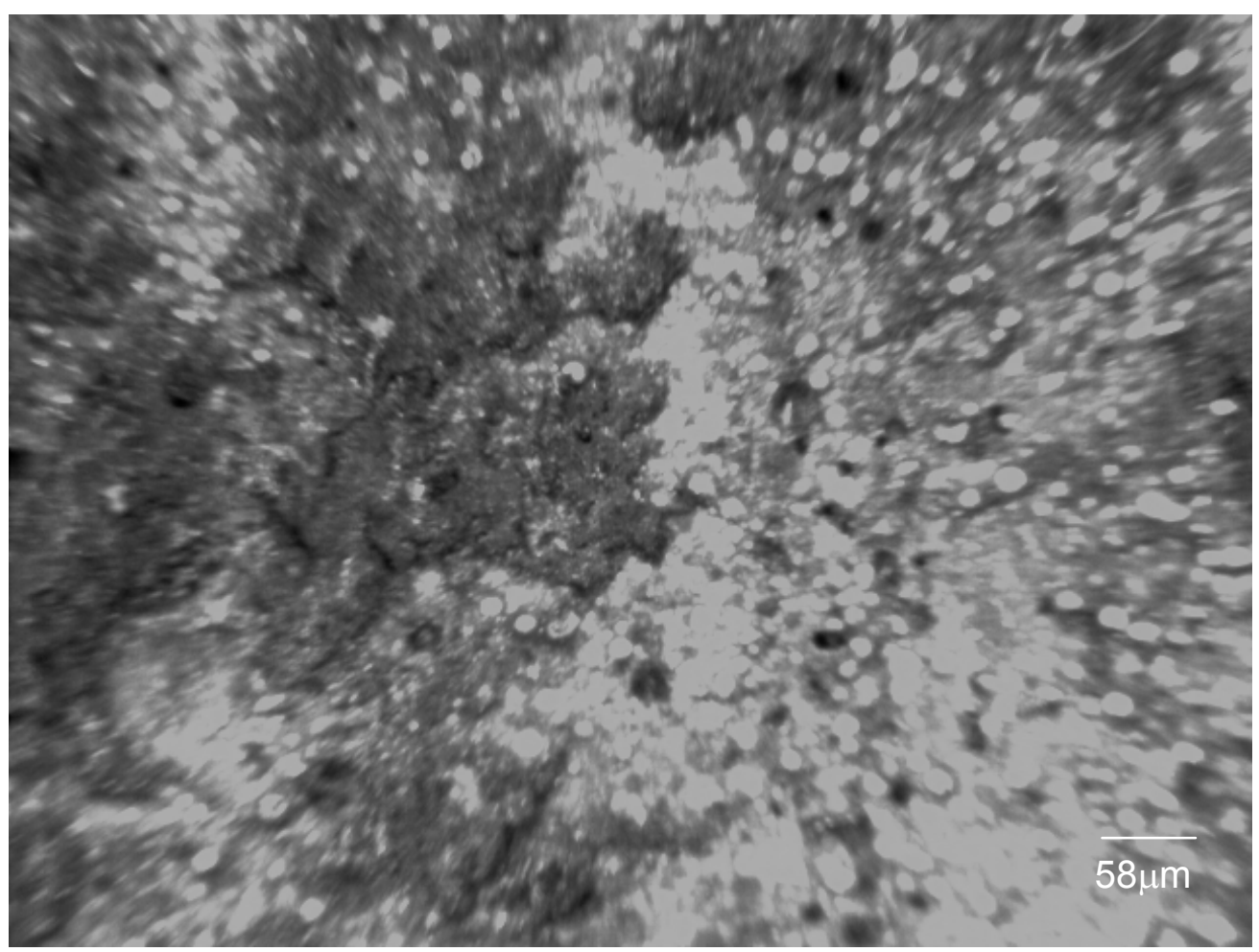

Figure 30 Ceramic Particles Sticking on the Bearing Sleeve 

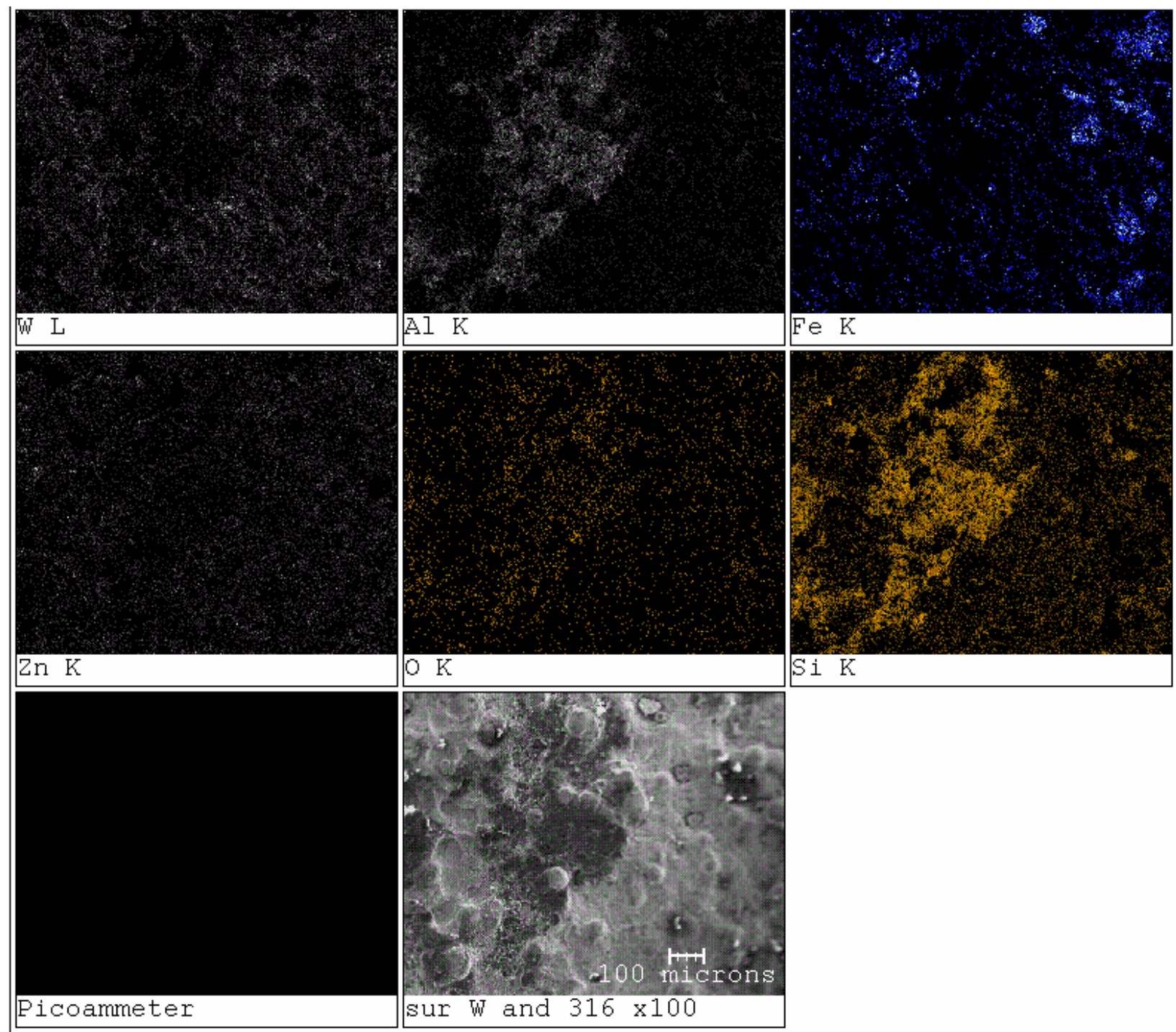

Si K

Figure 31 SEM Picture of Ceramic Particles Sticking on the Bearing Sleeve

After the test cycles, the bearing sleeve was removed from the shaft. Specimens were cut from the bearing sleeve using the wire EDM. These specimens were then polished and prepared for microstructure analyses. As shown in Figure 32, SEM results indicated the possibility of intermetallics between iron -aluminum and zinc-aluminum formed on the bearing sleeve surface. Figure 33 shows the density of the WC particles at the wearing cross section of the bearing sleeve. 


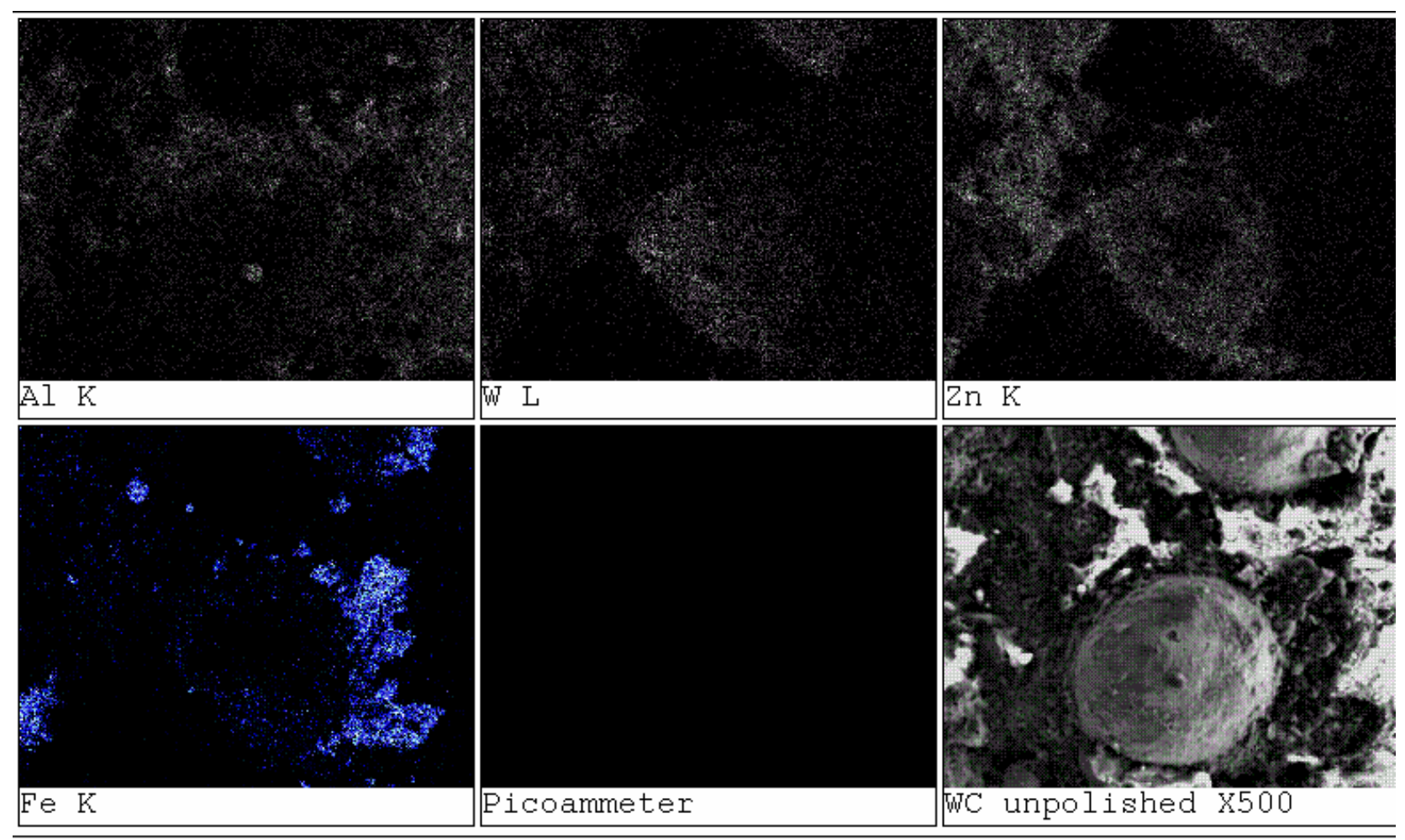

Figure 32 SEM Picture of the Bearing Sleeve

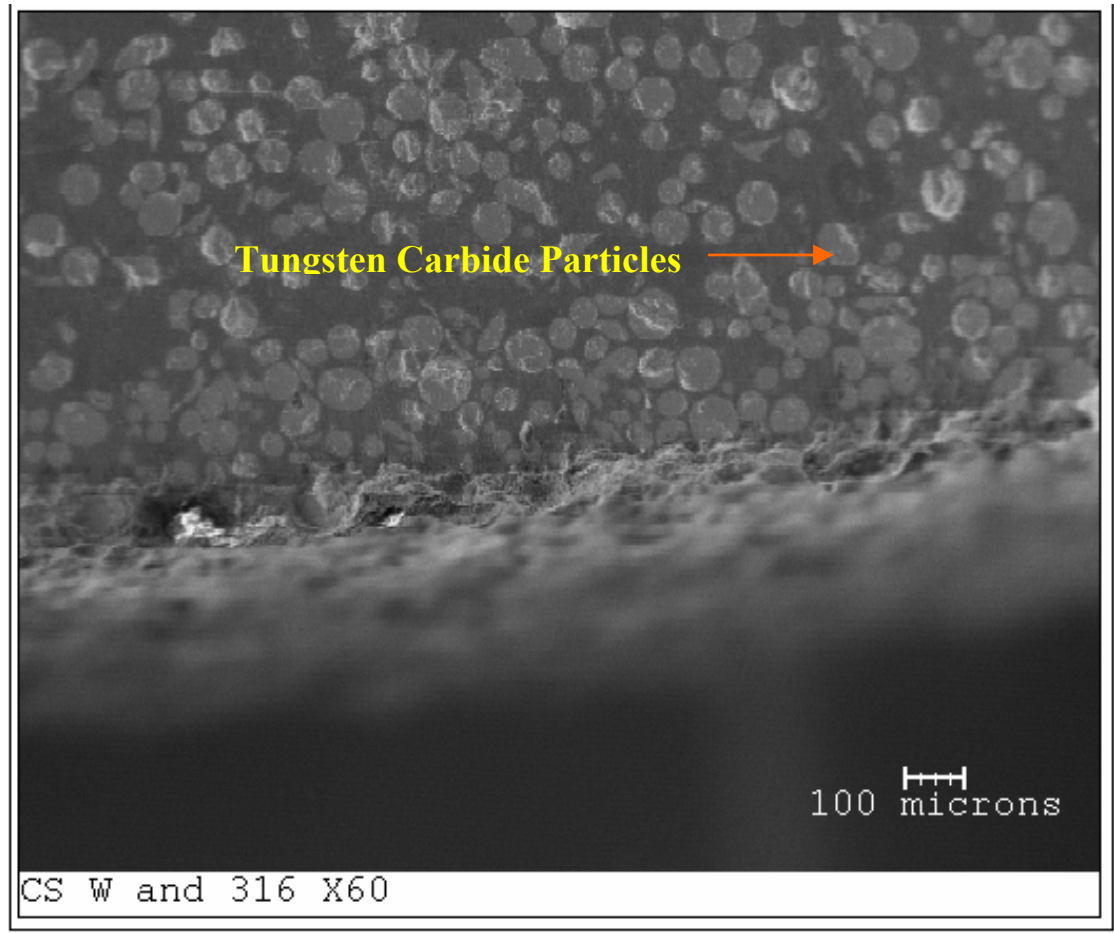

Figure 33 Density of the Tungsten Carbide Particles at Wearing Cross Section 


\subsection{Test 2 CF3M with Tungsten Carbide Coating against SiAION Ceramics}

\begin{tabular}{|c|c|}
\hline BEARING WEARING TEST & $\begin{array}{l}\text { Wearguard bearing system with } 316 \text { LS } \\
\text { with WC- L \& SiAlON ceramic inserts }\end{array}$ \\
\hline DROSS BUILD-UP TEST & 316 LS with WC- S/C \& low carbon steel \\
\hline BEARING LOAD & $\begin{array}{l}\text { 1500lb (Production Line Tension), } 10501 \mathrm{~b} \\
\text { (70\% Production Line Tension), } 7501 \mathrm{~b} \\
\text { (50\% Production Line Tension) }\end{array}$ \\
\hline BEARING PRESSURE & $\begin{array}{l}257 \mathrm{psi} \text { at } 500 \mathrm{lb} \text { (Production Bearing } \\
\text { Pressure), } 180 \text { psi at } 350 \mathrm{lb}(70 \% \text { Production } \\
\text { Bearing Pressure) \& } 128 \mathrm{psi} \text { at } 250 \mathrm{lb}(50 \% \\
\text { Production Bearing Pressure) }\end{array}$ \\
\hline LINE SPEED & $\begin{array}{l}108 \mathrm{rpm}(\text { Same as Production Line Speed } \\
110 \mathrm{ft} / \mathrm{min})\end{array}$ \\
\hline BATH TEMPERATURE & $850-870 \mathrm{~F}$ \\
\hline ROLL PRESSURE & 13 psi (Same as Production Roll Pressure) \\
\hline
\end{tabular}

Table 14 Test Conditions (Test \#2)

Table 14 shows the test conditions for CF3M with tungsten carbide laser clad coating against SiAlON ceramic. The wearing test was started at production line tension, and then the line tension was further reduced to $70 \%$ of the production line, as the motor did not have enough power to run at this load. Excessive vibration was observed during this period, causing micro cracks on the bearing surfaces. This resulted in high wearing rate of the bearing sleeve, at the end of cycle 1 and cycle 2 . The test was reduced to $50 \%$ production line tension for the rest of the test cycles. 
The cracks formed on the bearing sleeve allowed the penetration of molten metal into the matrix. Reaction of matrix with molten metal resulted in weak bonding between the WC particles and substrate. The tungsten carbide particles were easily worn out from the substrate during sliding. These grooves on the ceramic might be possibly due to tungsten carbide trapped between the contact surfaces. The high wearing rate of the bearing sleeve can be related to the above phenomenon.

The ceramic inserts showed excessive wear as compared to Test \#1. Cracks were seen on the ceramic inserts, which might have possibly occurred due to excessive vibration between test cycle 2 and 3. More prominent and deep grooves were formed on the ceramic insert surface as compared Test \# 1 . Table 15 shows the wearing rate of CF3M with WC laser clad coating against SiAlON ceramic material. Figure 35 shows that the bearing sleeve wore out at faster rate as compared to Test \# 1.Wear rate of the bearing sleeve was found to be $84 \mu / \mathrm{hr}$ for Test \# 2. Figure 35 to 40 shows the wearing of the ceramic inserts after each test cycle. 


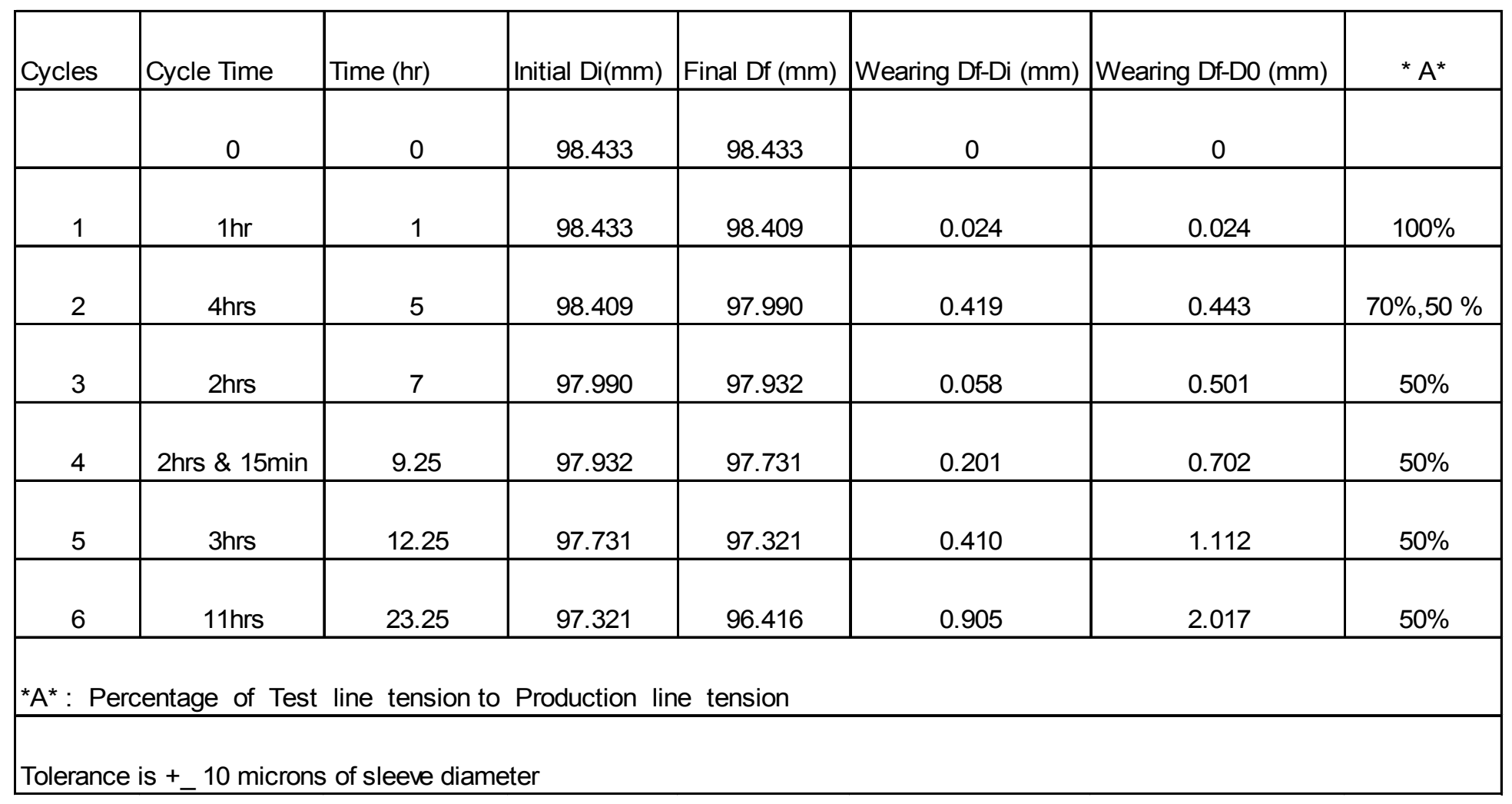

Table 15 Wearing Results of 316 LS with WC-L against SiAION Ceramic Inserts

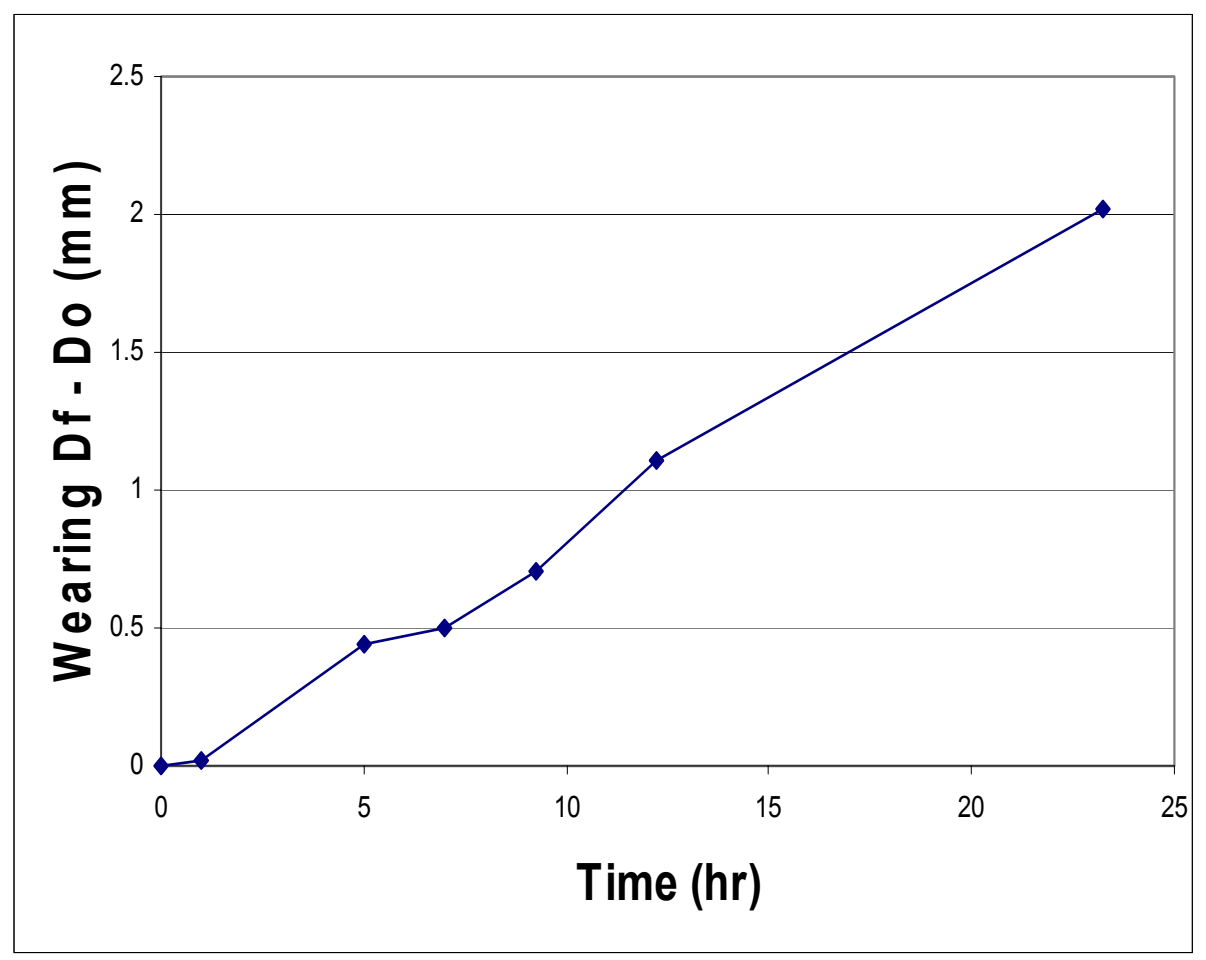

Figure 34 Wearing Result of 316 LS with WC-L against SiAION Ceramic Inserts 


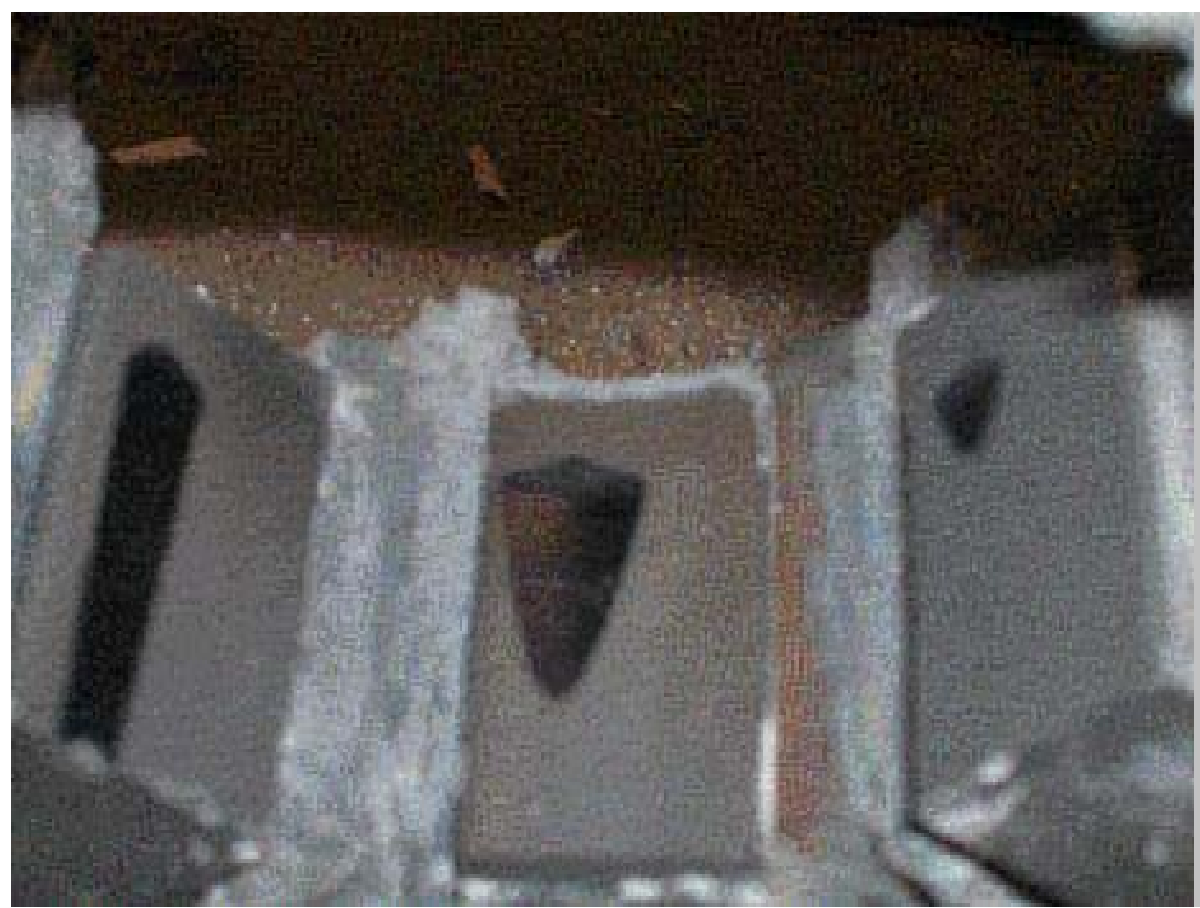

Figure 35 Wearing on Ceramic Insert after Cycle 1 at Production Line Tension(1hr)

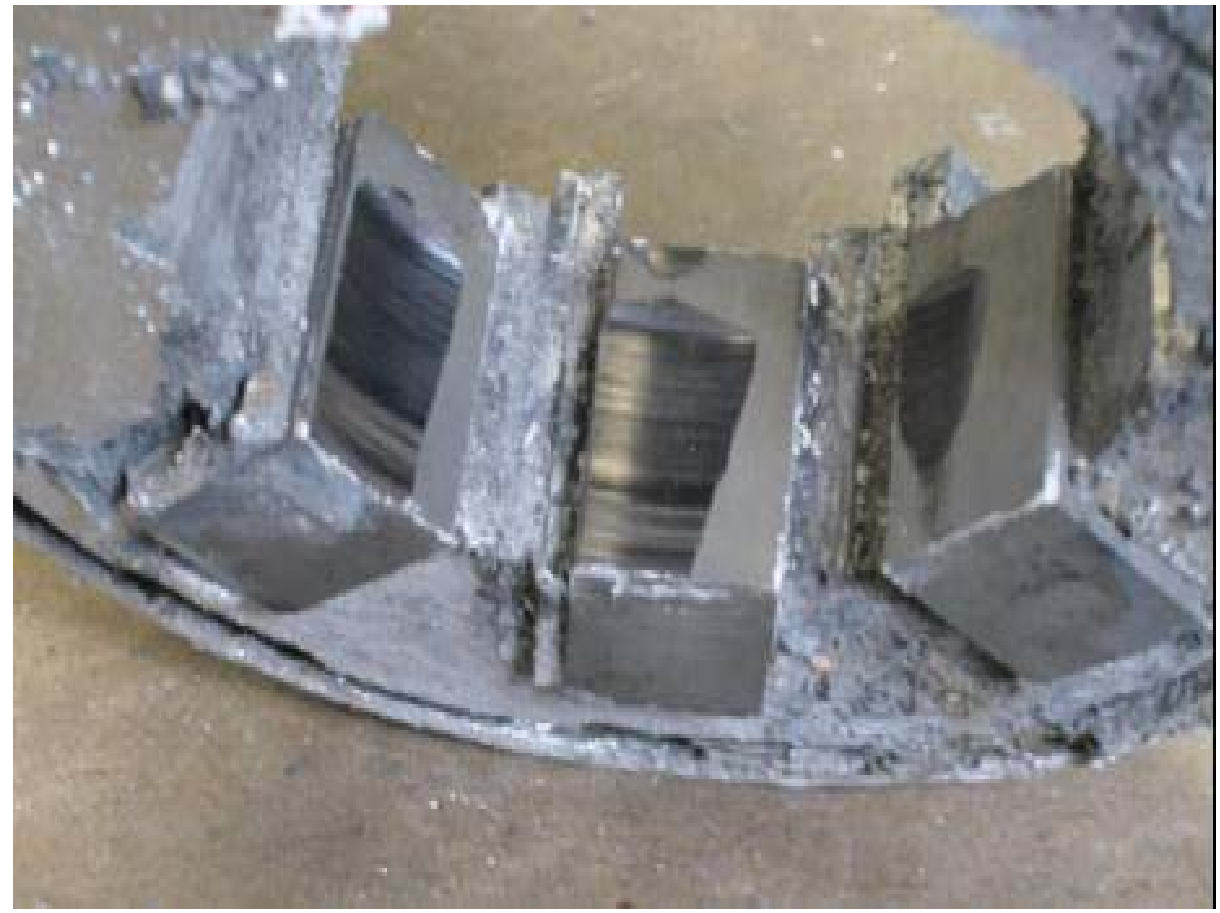

Figure 36 Wearing on Ceramic Insert after Cycle 2 (2hrs at 70\% Production Line Tension and 2 hrs at 50\% Production Line Tension) 


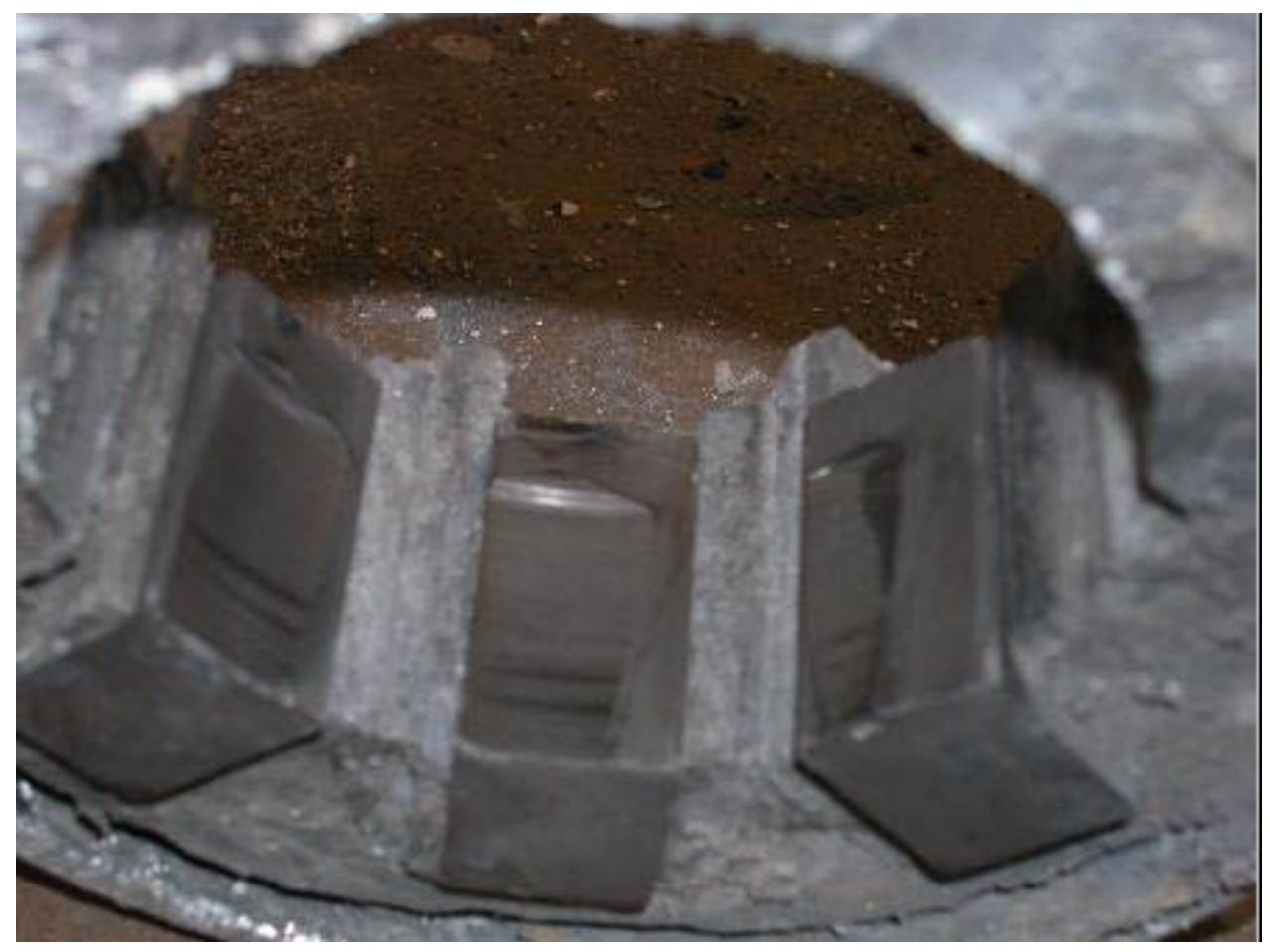

Figure 37 Wearing on Ceramic Insert after Cycle 3 (2 hrs at 50\% Production Line Tension)

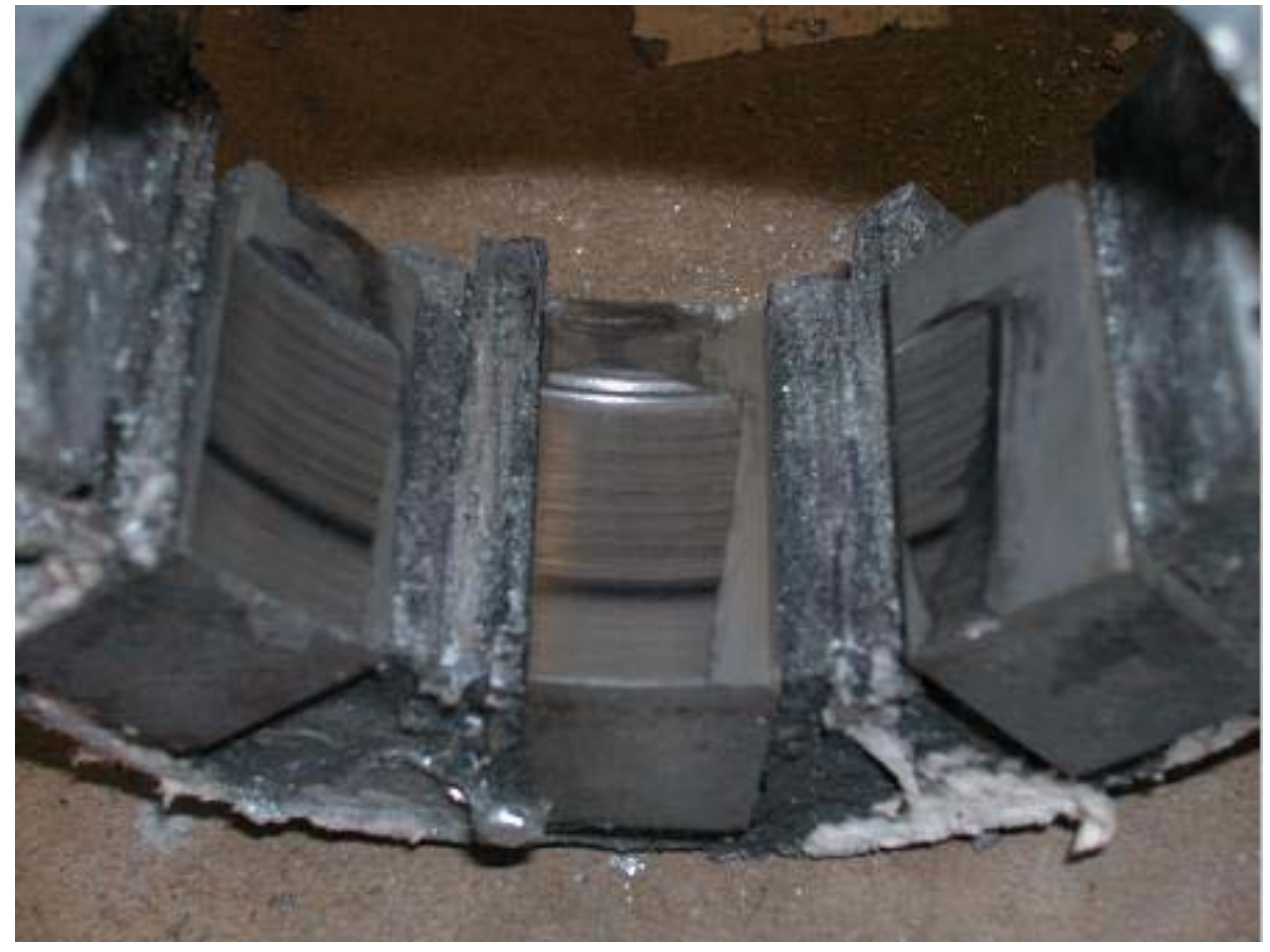

Figure 38 Wearing on Ceramic Insert after Cycle 4 (2 hrs \& 15 min at 50\% Production Line Tension) 


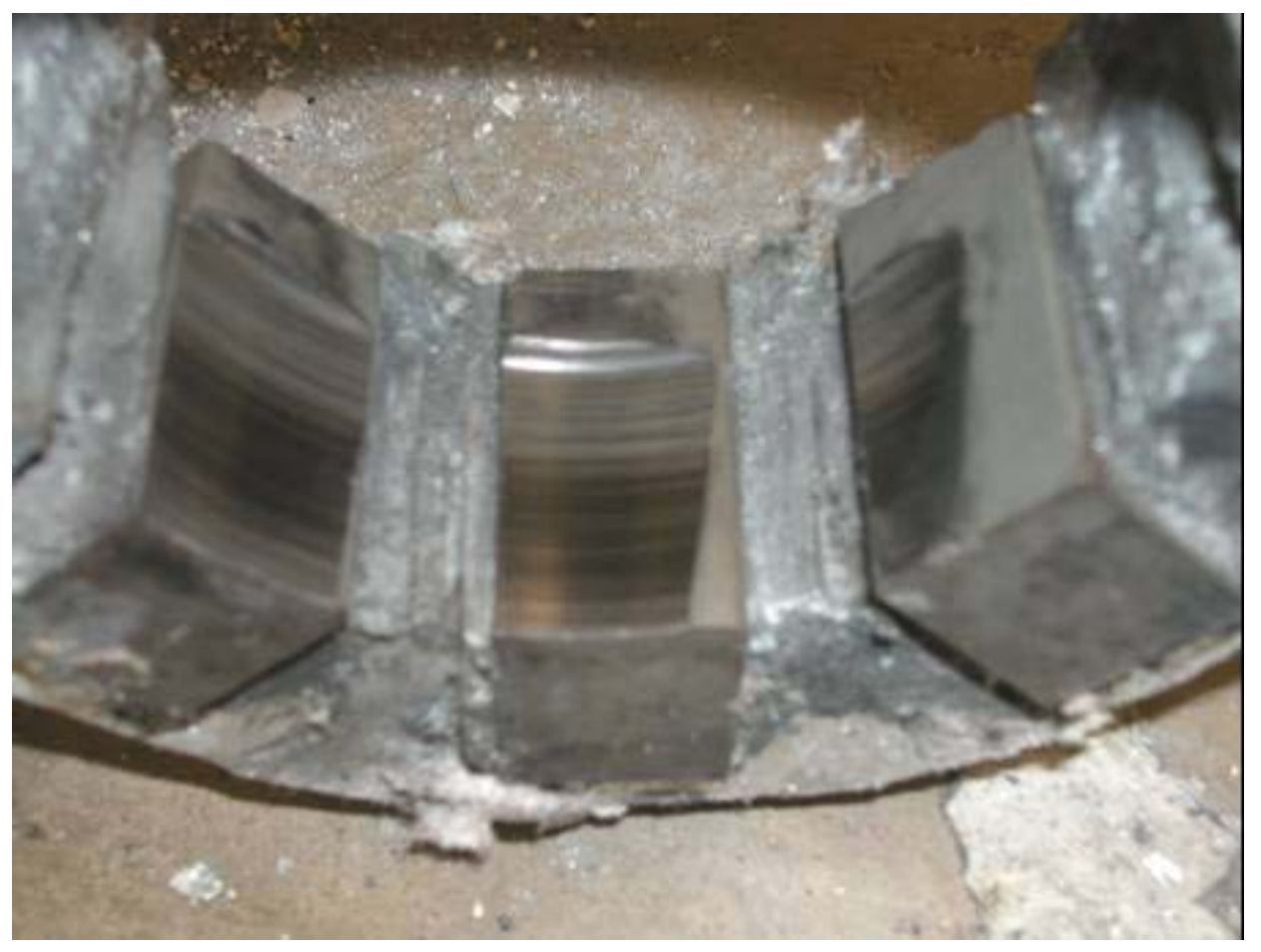

Figure 39 Wearing on Ceramic Insert after Cycle 5 (3 hrs at 50\% Production Line Tension)

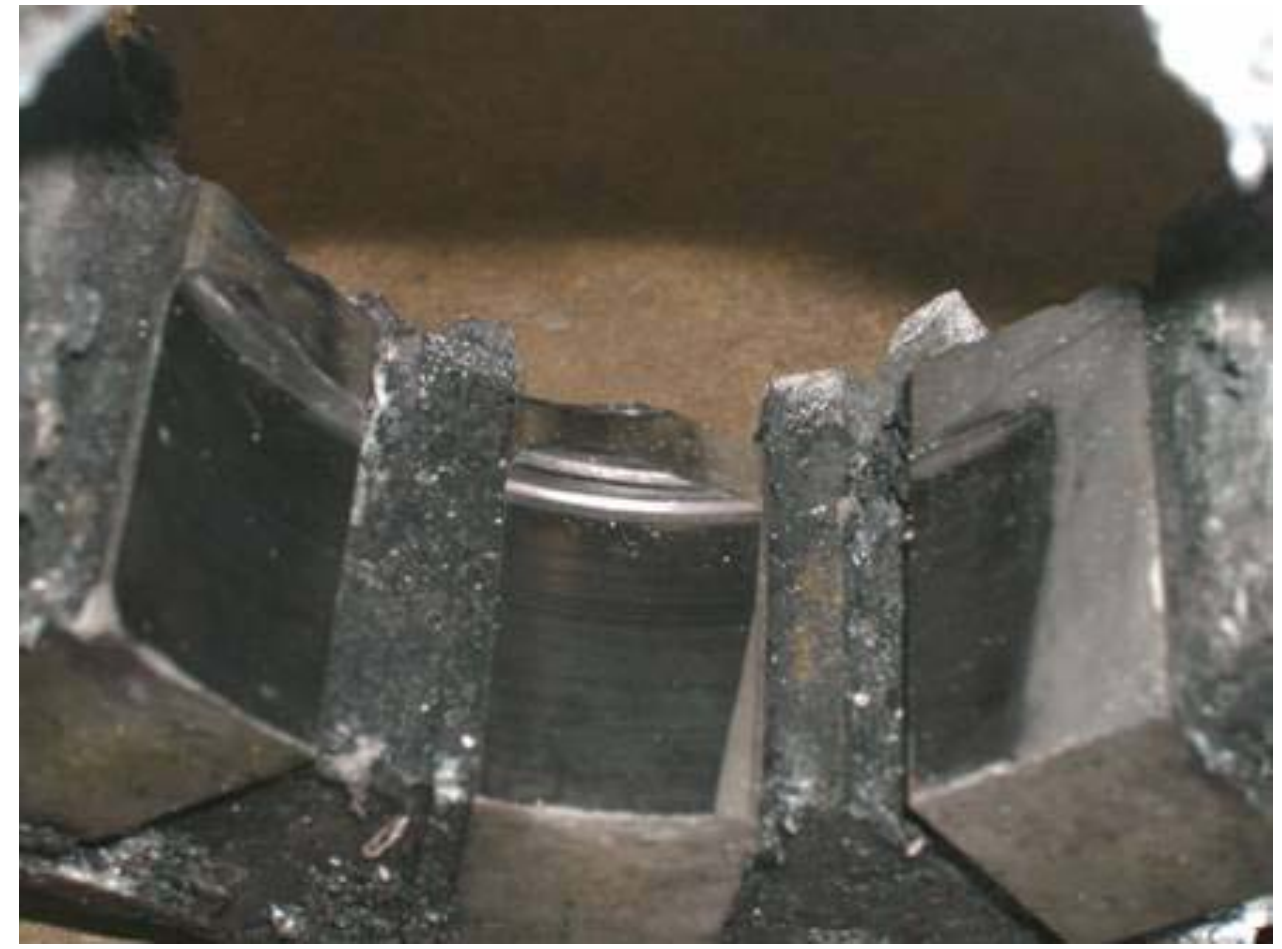

Figure 40 Wearing on Ceramic Insert after Cycle 6 (11 hrs at 50\% Production Line Tension) 
The on site microstructure picture was taken on the bearing sleeve after cycle 2 . This revealed the formation of cracks on the wearing sleeve surface. These cracks caused easy wearing of the tungsten carbide laser clad coating from the matrix and hence high wearing rate when scaled and compared to Test 1 at $32 \%$ production load tension.

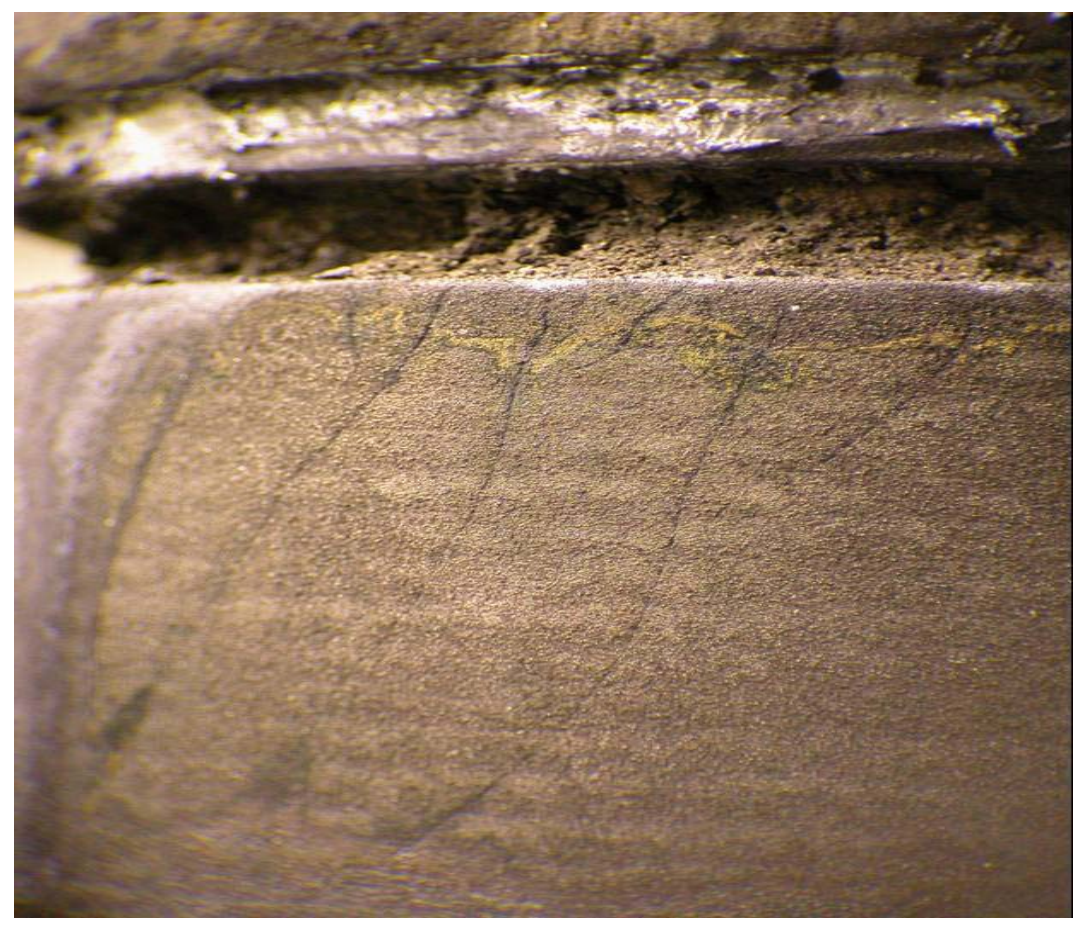

\section{Figure 41 Cracks on the Wearing Sleeve Surface after Test Cycle 2}

On-site hardness measurement was made on the wearing sleeve surface after each cycle. The typical hardness of tungsten carbide laser clad coating layer is $1400 \mathrm{HV}$. Hardness of the surface layer dropped to about $650 \mathrm{HV}-850 \mathrm{HV}$. The drop in hardness values can be attributed to the wearing and depletion of the tungsten carbide particles from the matrix. Further research is currently carried out by another graduate student to correlate the change in hardness to change in surface conditions of the material. Figure 42 shows the hardness variation of the bearing sleeve after each test cycle. 


\subsubsection{Correlation of Hardness with Stiffness of the Material Surface}

Proposed Plan for Finding the Change of Elastic Modulus using UCI Method

The hardness testing instrument (Krautkramer MIC 10 DL) works on the principle of ultrasonic contact impedance (UCI) which assumes that, the hardness value not only depends upon the area of indentation but also the stiffness of the material. The hardness value is calculated based on the frequency shift. A UCI probe typically consists of a Vickers diamond attached to the end of a metal rod. This rod is excited into longitudinal oscillation of about $70 \mathrm{kHz}$ by piezoelectric transducers. The frequency shift is proportional to the size of the indentation produced by the Vickers diamond, and materials Young's modulus.

$$
\begin{aligned}
& \Delta \mathrm{f} \propto \mathrm{E}^{*} \sqrt{\mathrm{A}} \\
& \text { where, } \\
& \Delta \mathrm{f}=\text { Frequency shift of the probe } \\
& \mathrm{E}=\text { Elastic modulus of the material } \\
& \mathrm{A}=\text { Area of indentation }
\end{aligned}
$$

After each test cycle the frequency shift can be measured. After the test is finished, the sleeve is cut and a series of loading-unloading microindentation tests were performed on the cut specimen. Load versus depth curve was plotted and the elastic modulus is measured [12]. Thus the change in elastic modulus can be determined. 


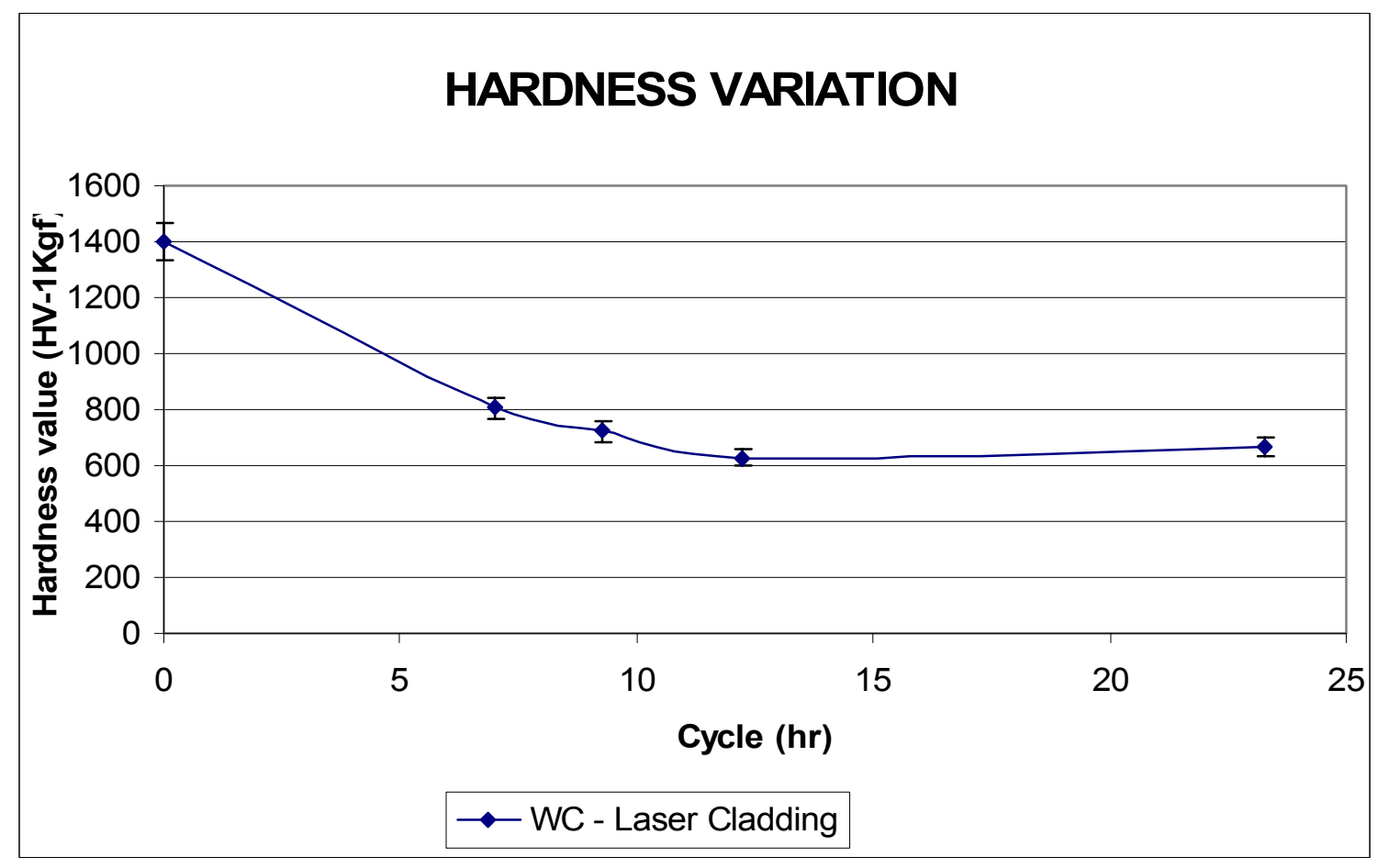

Figure 42 Hardness Variation on the Wearing Sleeve Surface

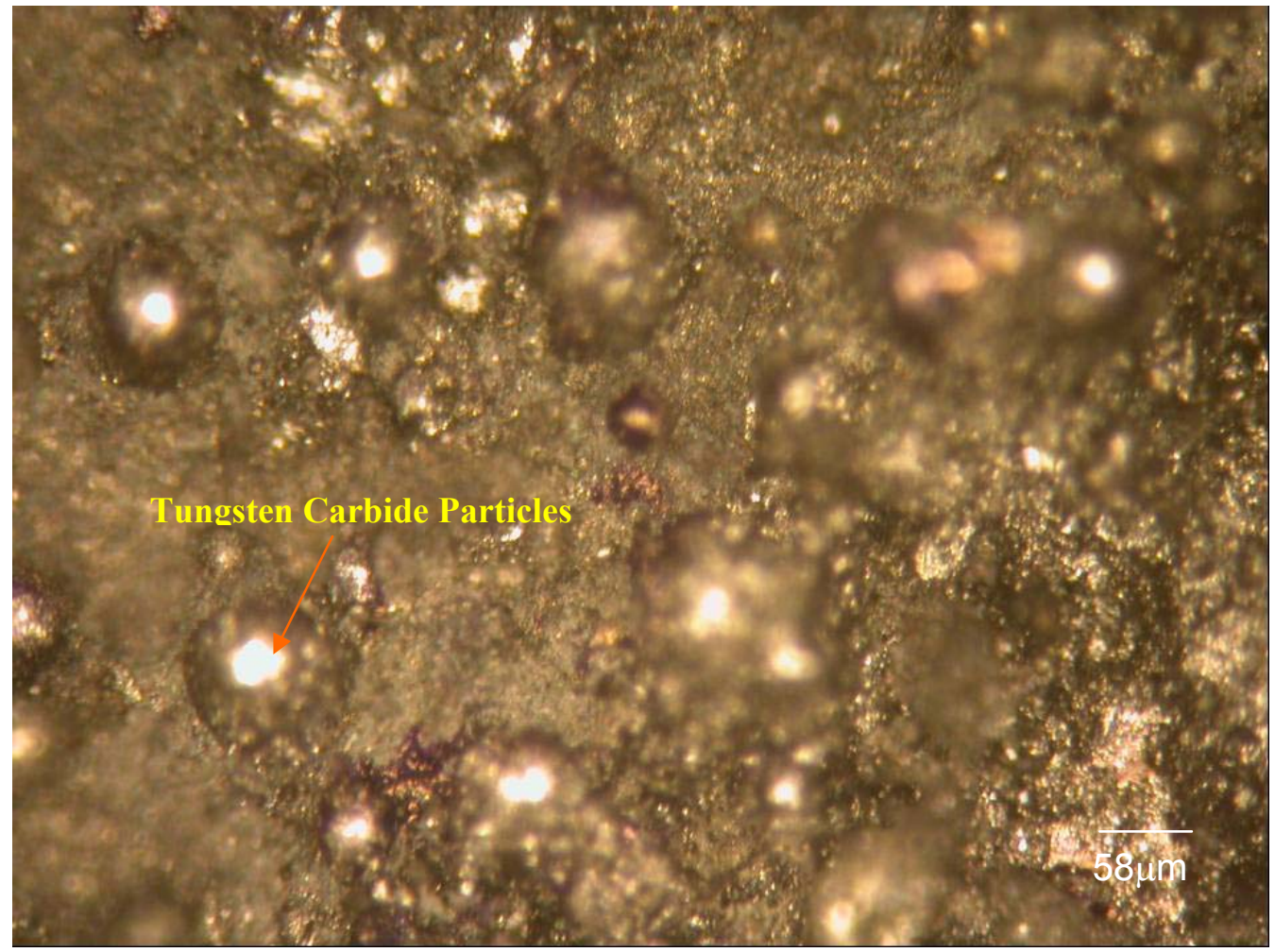

Figure 43 Microstructure of the Wearing Sleeve Surface after Test Cycle 3 (804 HV) 


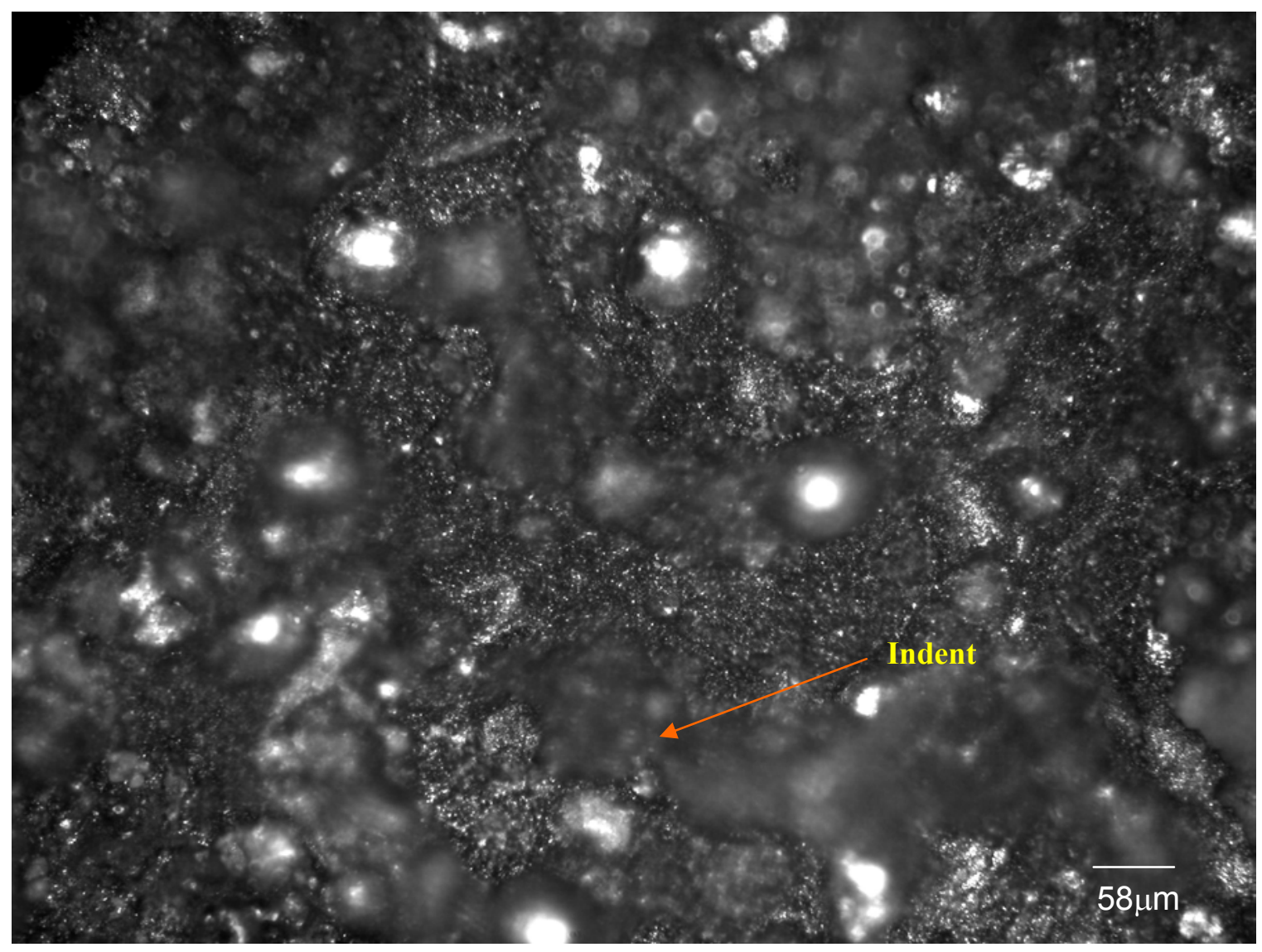

Figure 44 Microstructure of the Wearing Sleeve Surface after Test Cycle 4 (624 HV)

Hardness was measured on the wearing and non wearing region of the bearing sleeve surface. Area of indention was much smaller for non-wearing as compared to wearing region. Typical hardness of the wearing region ranges from $600 \mathrm{HV}-850 \mathrm{HV}$ as shown in Figures 43 and 44 and non-wearing region ranges from $1050 \mathrm{HV}-1250 \mathrm{HV}$ as shown in Figure 45. The drop in hardness values may be correlated to the depletion of the tungsten carbide particles from the matrix. 


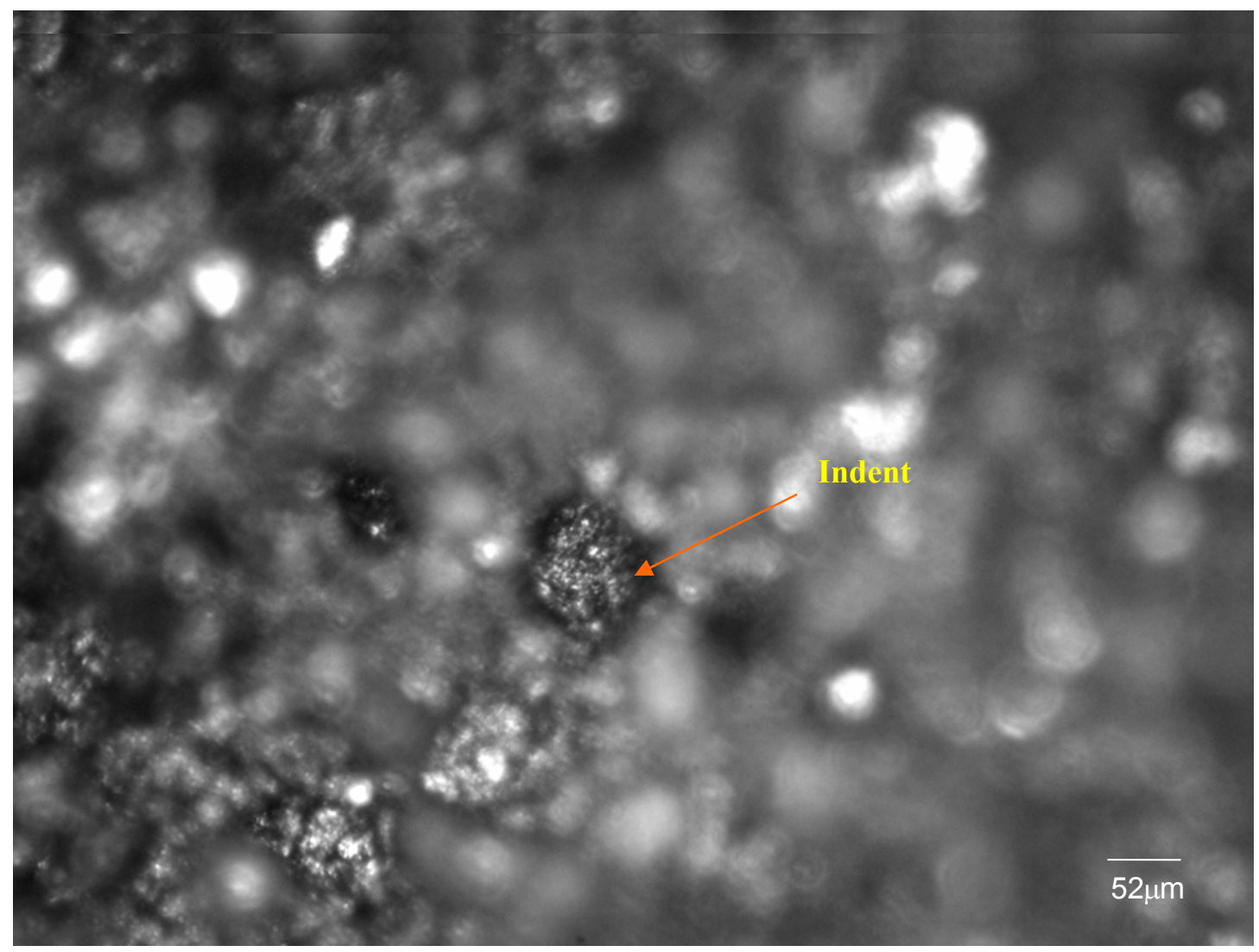

\section{Figure 45 Microstructure of the Non Wearing Sleeve Surface after Test Cycle 4 (1250 HV)}

After the non-wearing surface of the sleeve was polished to remove any zinc layer formed on the surface, the density of tungsten carbide particles increased on the surface. This showed the presence of a layer (might be oxides formed on the sleeve surface) formed on the sleeve surface during the test. Figures 46 and 47 show that the density of the tungsten carbide particles increased after slightly polishing the surface. 


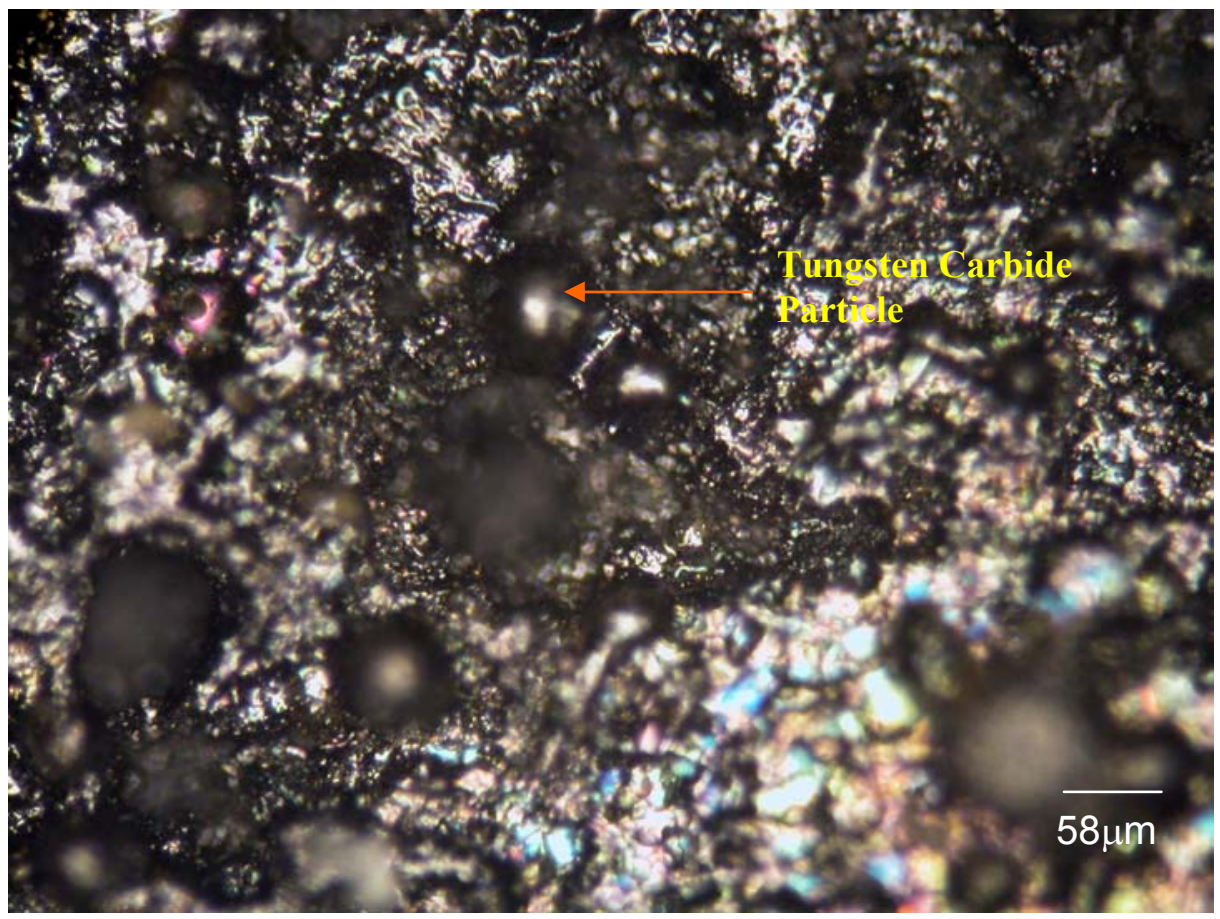

Figure 46 Microstructure of the Non Wearing Sleeve Surface before Polishing

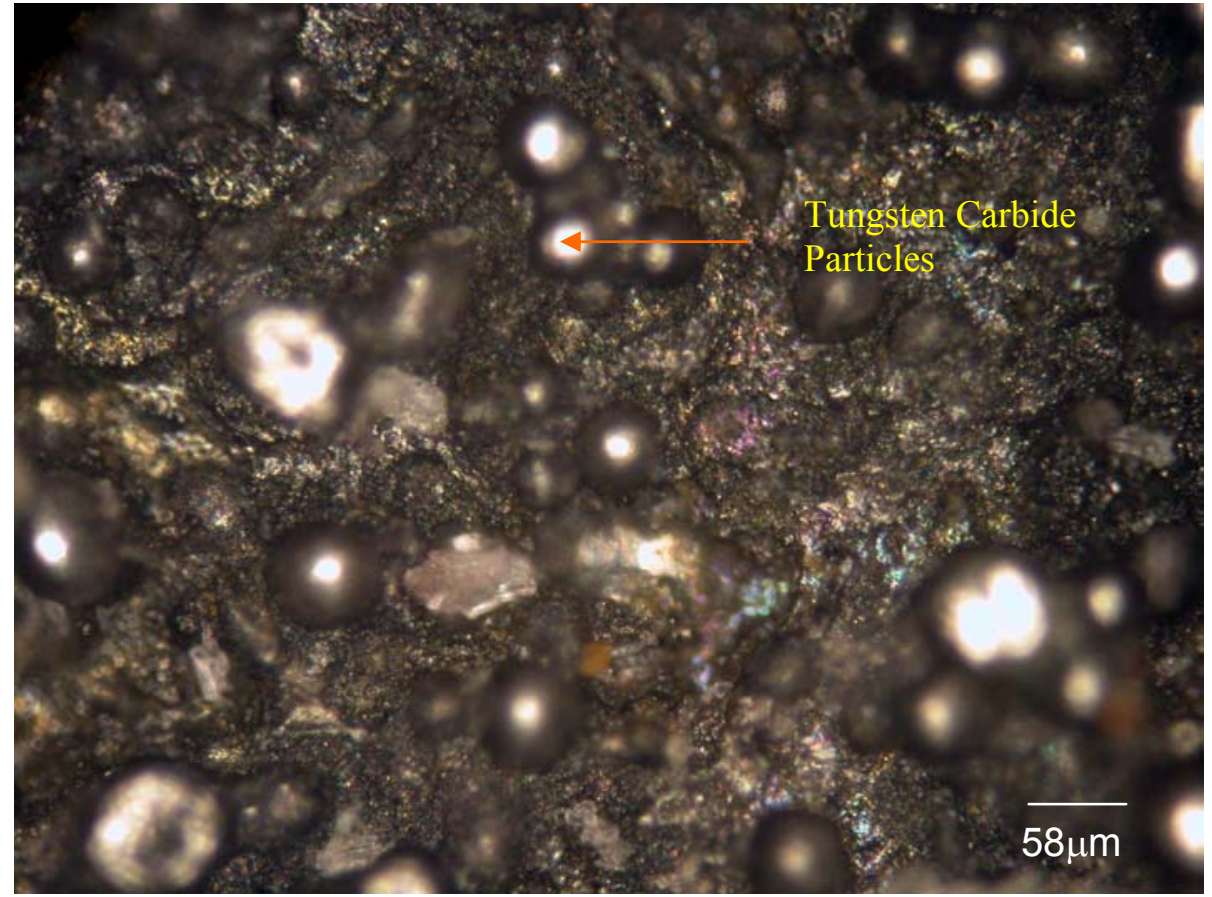

Figure 47 Microstructure of the Non Wearing Sleeve Surface after Polishing 
SEM analysis of the wearing and non-wearing surface of the sleeve showed corrosion attack on both the surface. Loss of material on the wearing surface of the sleeve was possibly due to corrosion assisted abrasive wear. Figure 48 shows the corrosion attack on the wearing sleeve surface. Figure 49 shows the corrosion cracks on the non wearing surface.

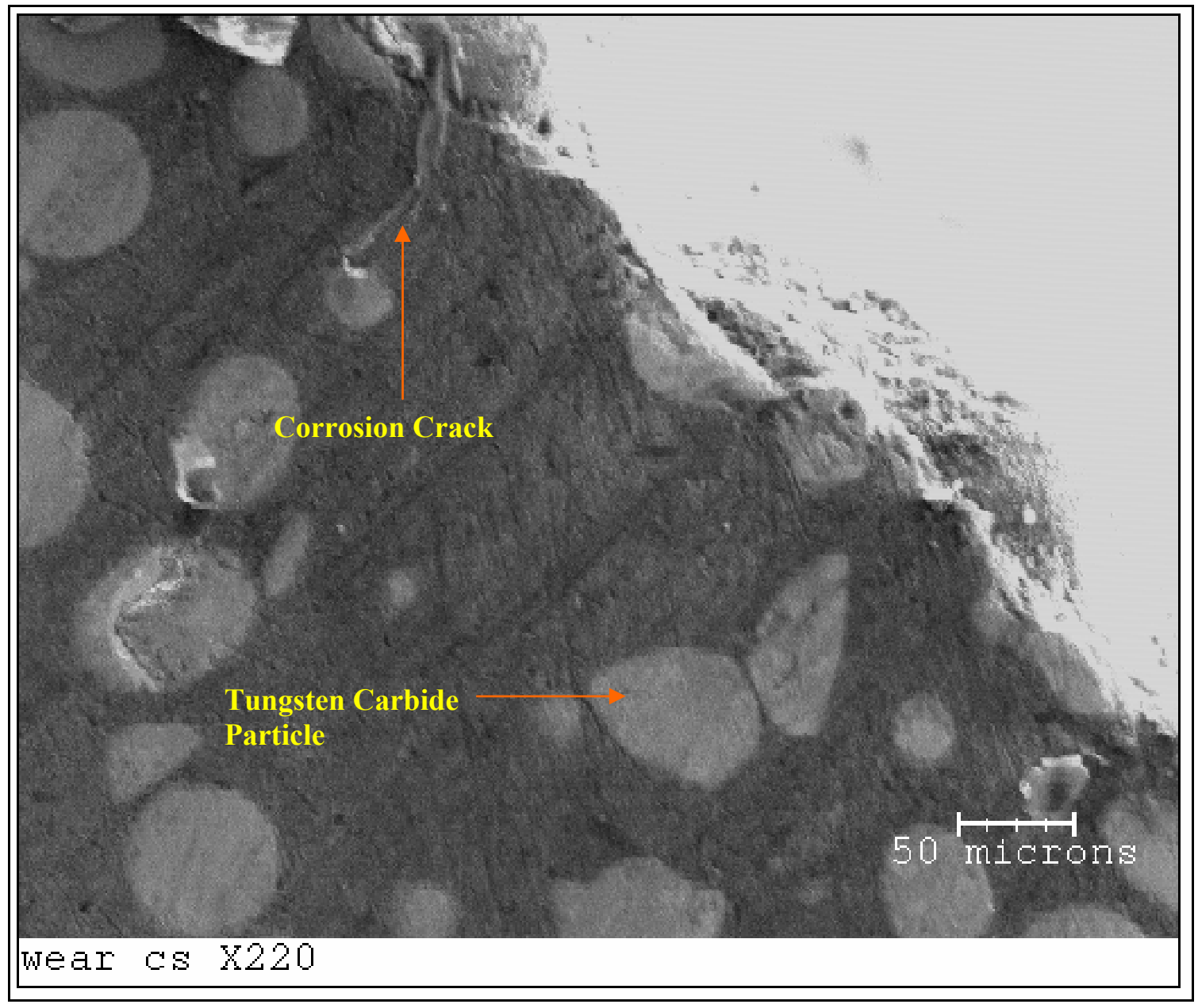

Figure 48 Microstructure of the Wearing Sleeve Surface with Corrosion Attack 


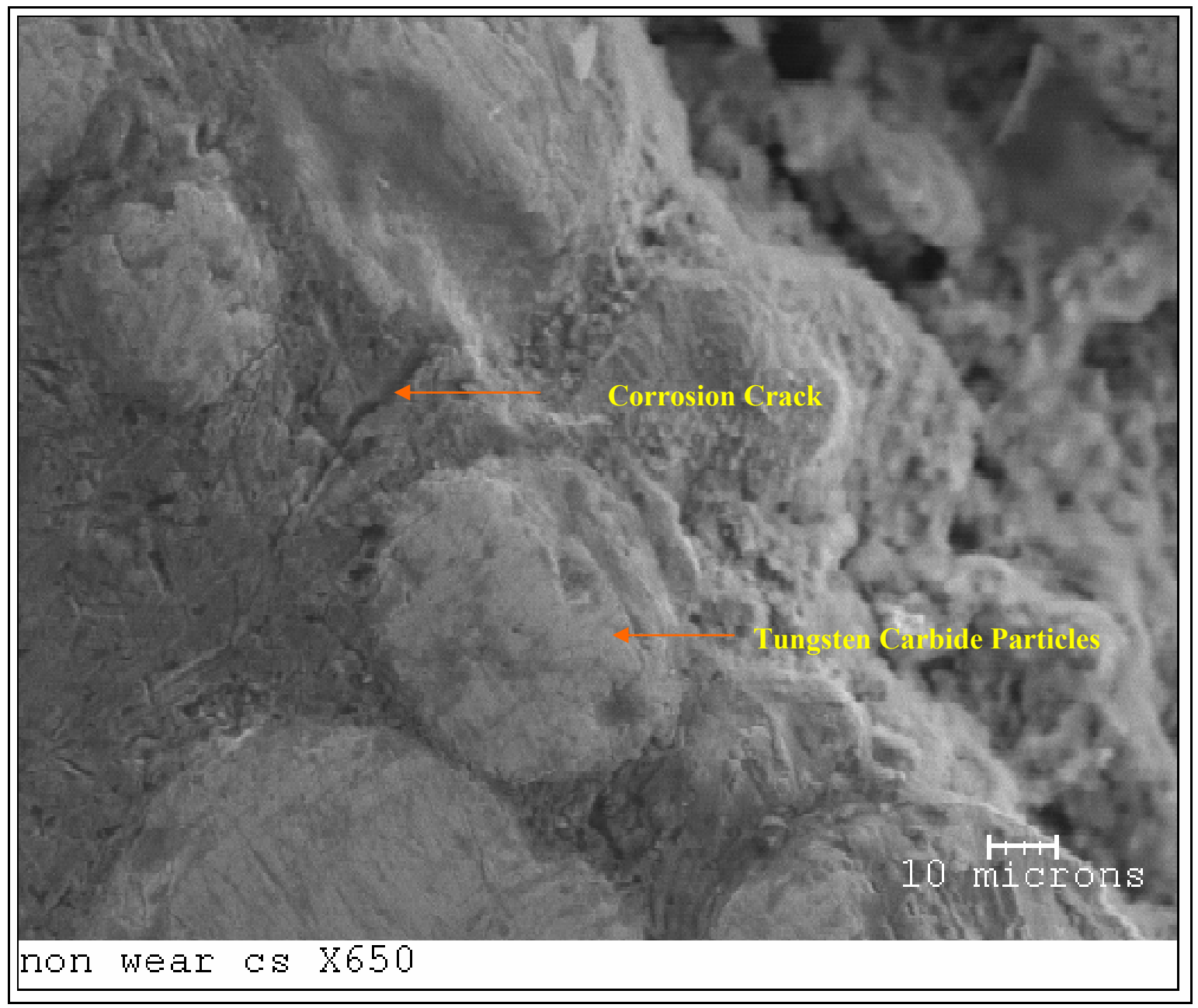

Figure 49 Microstructure of the Non Wearing Sleeve Surface with Corrosion Attack 


\subsection{Test 3 Stellite 6 against Tribaloy T-400}

\begin{tabular}{|l|l|}
\hline BEARING WEARING TEST & Stellite 6 against Tribaloy T 400 \\
\hline DROSS BUILD-UP TEST & $316 \mathrm{LS}$ with WC- S/C \& low carbon steel \\
\hline BEARING LOAD & $4801 \mathrm{~b}(32 \%$ Production Line Tension) \\
\hline BEARING PRESSURE & $82 \mathrm{psi}(32 \%$ Production Bearing Pressure $)$ \\
\hline LINE SPEED & $108 \mathrm{rpm}(\mathrm{Same}$ as Production Line Speed \\
\hline BATH TEMPERATURE & $110 \mathrm{ft} / \mathrm{min})$ \\
\hline & $850-870 \mathrm{~F}$ \\
\hline ROLL PRESSURE & $13 \mathrm{psi}(\mathrm{Same}$ as Production Roll Pressure $)$ \\
\hline
\end{tabular}

Table 16 Test Conditions (Test \#3)

Wearing test was conducted on Stellite 6 bearing sleeve against Tribaloy T-400 half moon bushing. Dross build-up test was also conducted and preliminary test results were obtained. The test conditions are shown in Table 16. Bearing sleeve surface suffered minor wear with few grooves formed on the surface. Wearing rate of the bearing sleeve was linear as compared to the previous wearing tests. Bushing surface looked smooth with only a few shallow grooves. There was almost no wear on the bushing surface. Table 17 shows the wearing result of Stellite 6 bearing sleeve against Tribaloy T-400 bushing. A graph was plotted between bearing sleeve wearing and cycle time as shown in Figure 50. 


\begin{tabular}{|c|c|c|c|c|c|c|c|}
\hline Cycles & Cycle Time & $\begin{array}{l}\text { Time } \\
\text { (hr) }\end{array}$ & $\begin{array}{l}\text { Initial } \\
\mathrm{Di}(\mathrm{mm})\end{array}$ & $\begin{array}{l}\text { Final Df } \\
(\mathrm{mm})\end{array}$ & $\begin{array}{l}\text { Wearing Df-Di } \\
(\mathrm{mm})\end{array}$ & $\begin{array}{l}\text { Wearing Df-D0 } \\
(\mathrm{mm})\end{array}$ & ${ }^{*} A^{*}$ \\
\hline & 0 & 0 & 98.417 & 98.417 & 0 & 0 & \\
\hline 1 & $6 \mathrm{hr} 45 \mathrm{~min}$ & 6.75 & 98.417 & 98.390 & 0.027 & 0.027 & $50 \%$ \\
\hline 2 & $6 \mathrm{hr} 30 \mathrm{~min}$ & 13.25 & 98.390 & 98.304 & 0.086 & 0.113 & $50 \%$ \\
\hline 3 & $7 \mathrm{hrs}$ & 20.25 & 98.304 & 98.249 & 0.055 & 0.141 & $50 \%$ \\
\hline 4 & 15hrs $45 \mathrm{~min}$ & 36 & 98.249 & 98.047 & 0.202 & 0.257 & $50 \%$ \\
\hline
\end{tabular}

Table 17 Wearing Result of Stellite 6 against Tribaloy T-400

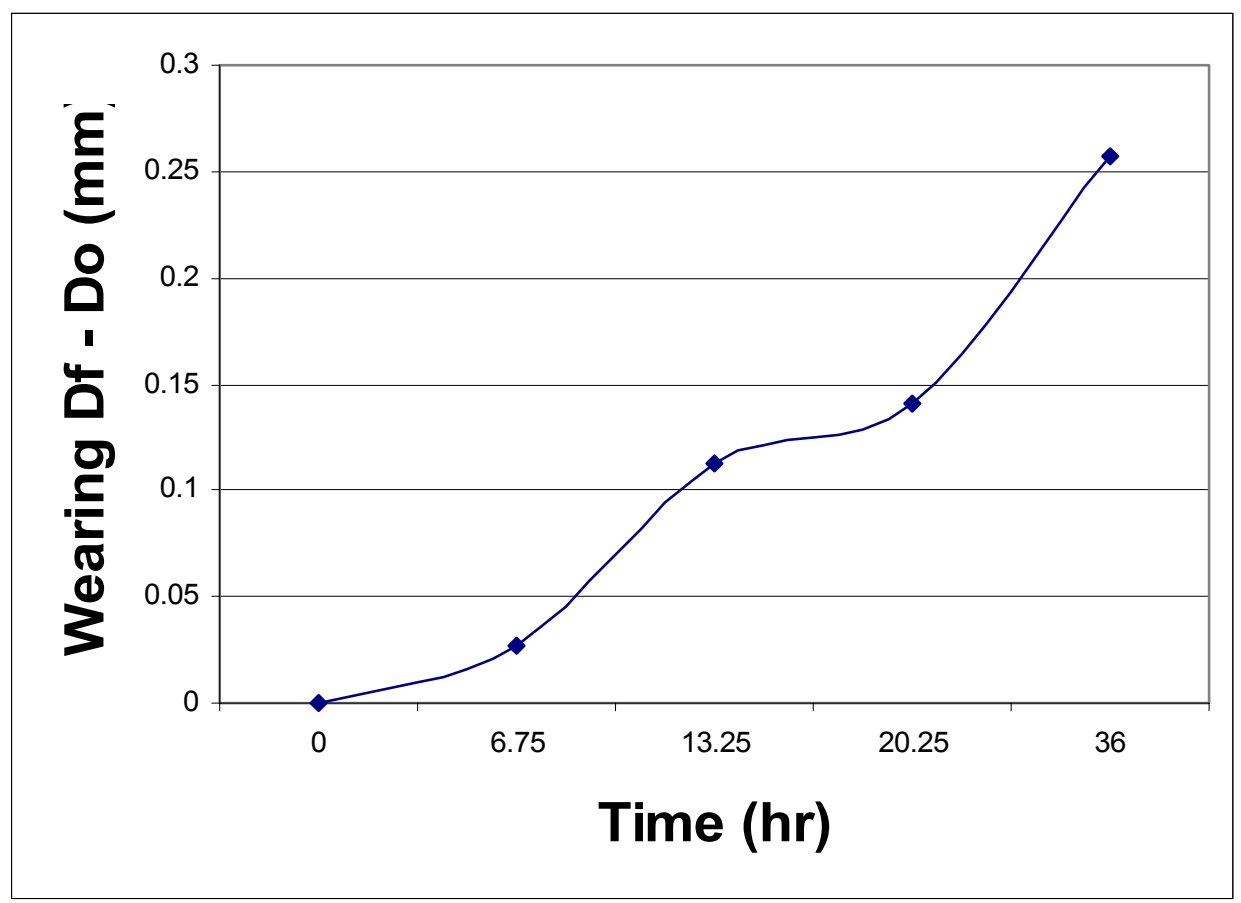

Figure 50 Wearing Result of Stellite 6 against Tribaloy T-400 
After each test cycle selected area of the bearing sleeve was cleaned using hydrochloric acid. Hardness measurement was done on the bearing surface and a graph was plotted between hardness variation and test cycle as shown in Figure 51. Microstructure picture of the test surface was taken after each test cycle.

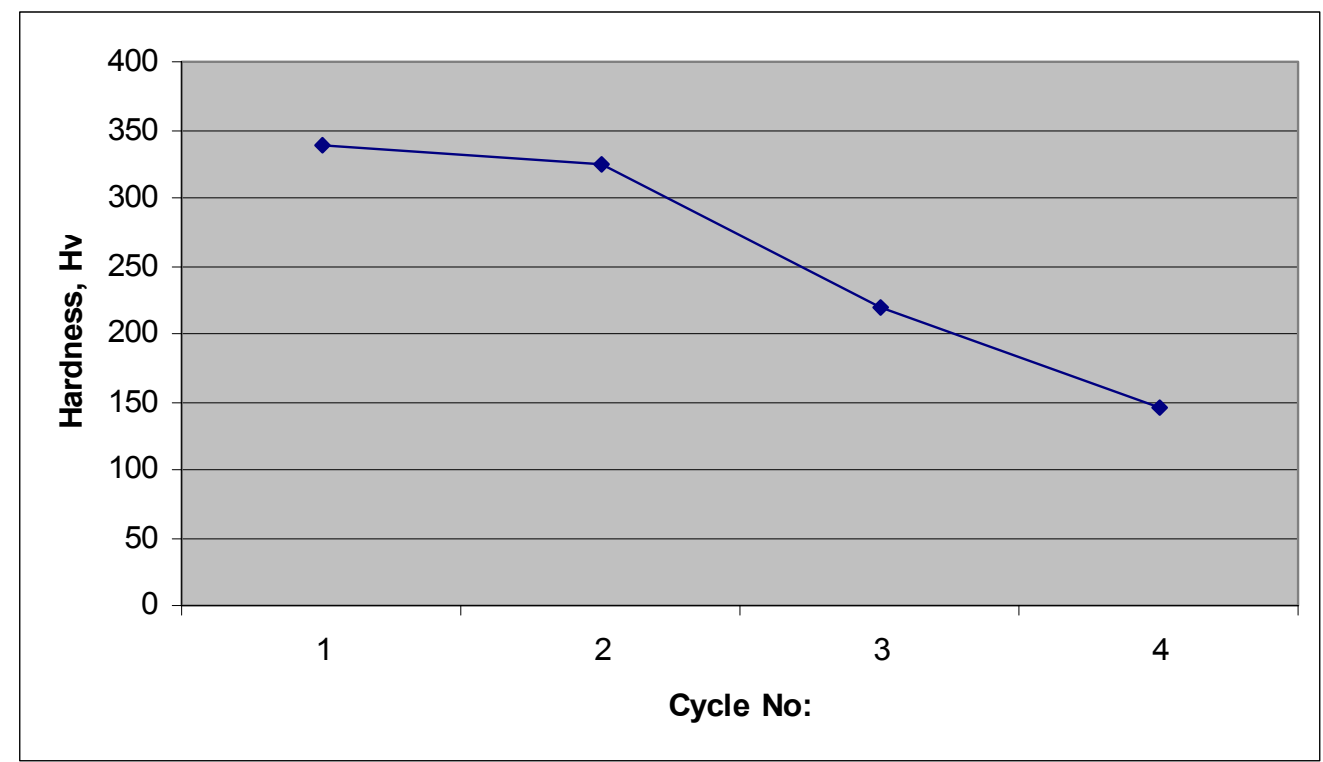

Figure 51 Hardness Variation of Stellite 6 Bearing Sleeve

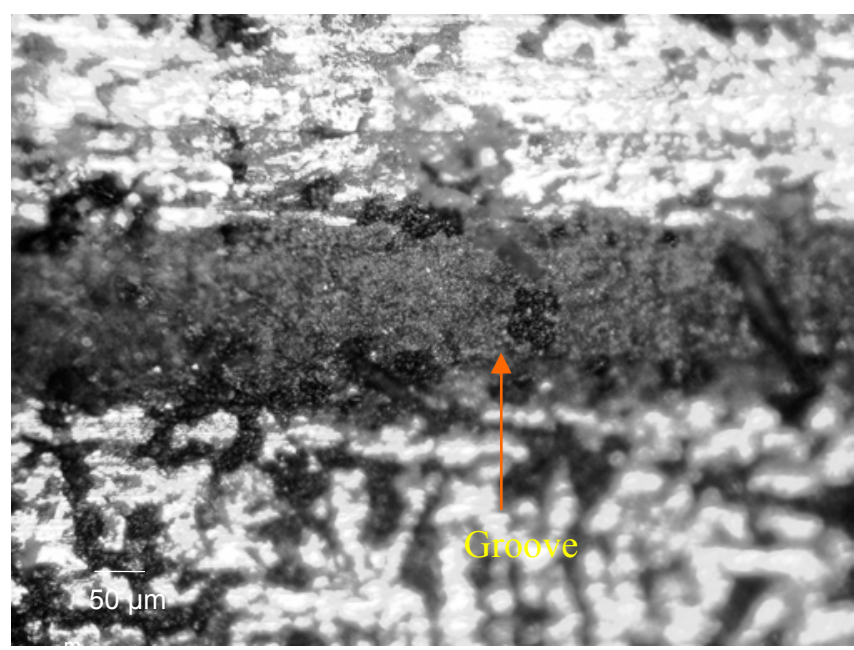

(a)

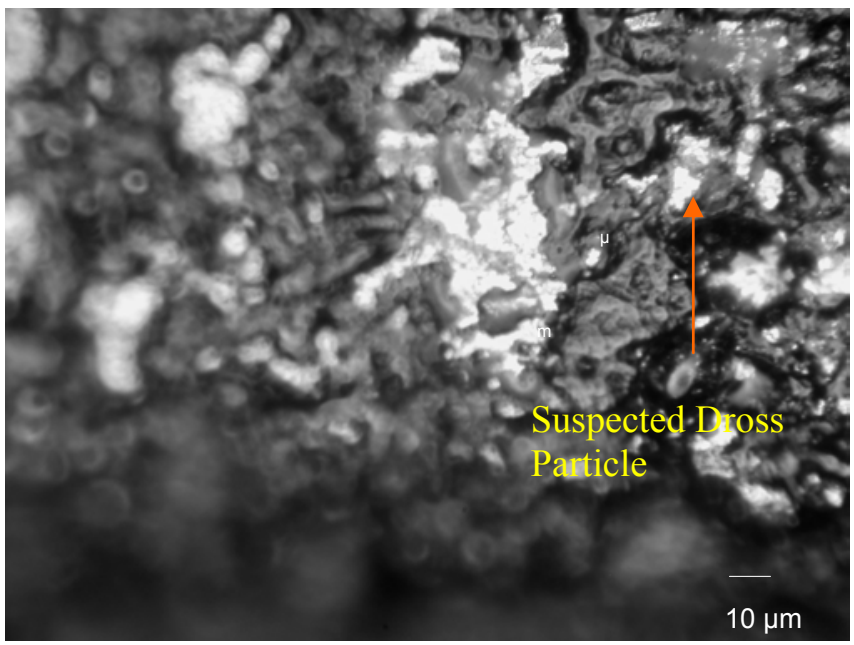

(b)

Figure 52 (a) Microstructure Picture of Grooves on Bearing Surface (b) Particles inside the Groove after Cycle 1 (6 hrs \& 45 min) 


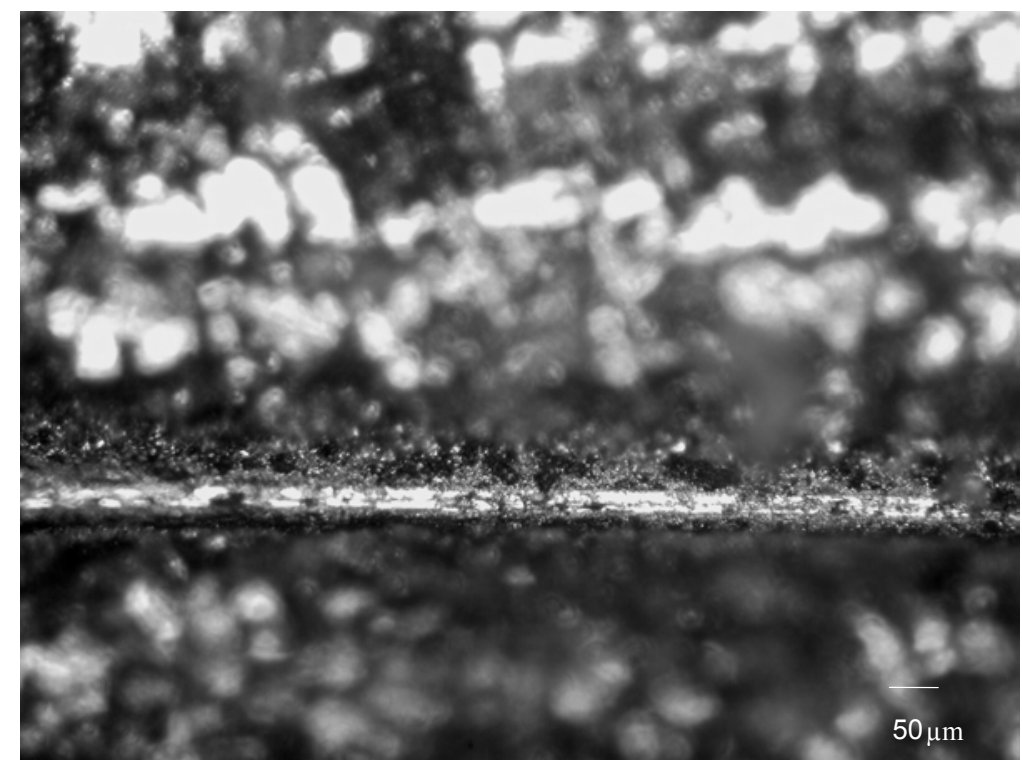

Figure 53 Microstructure Picture of Narrow Grooves on Bearing Surface after Test Cycle 2 (13 hrs \& 15 min)

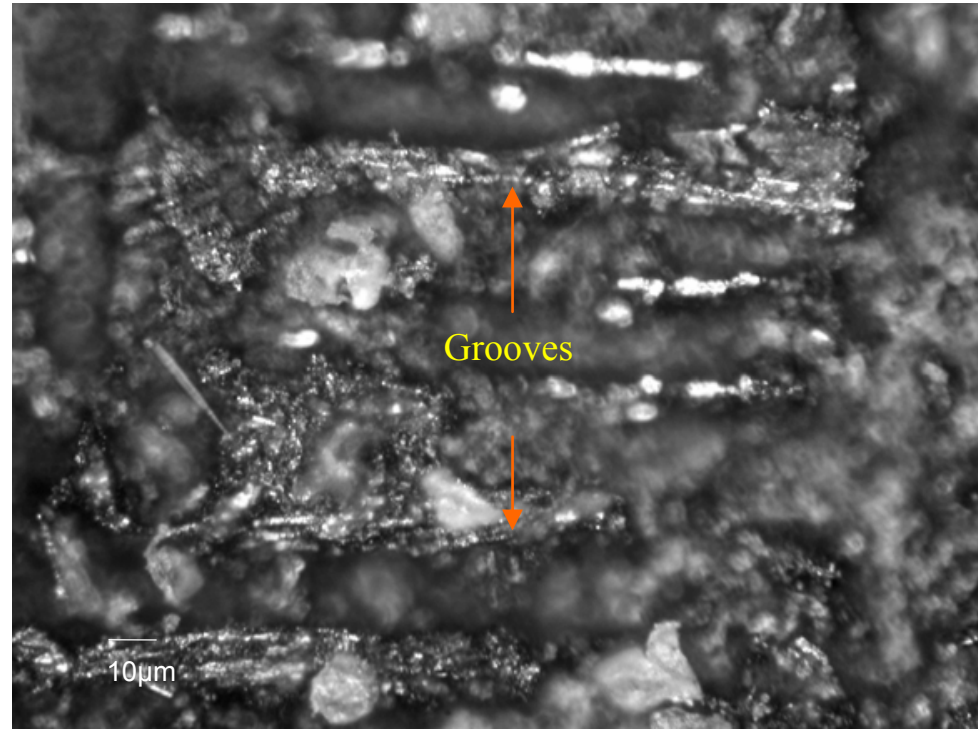

(a)

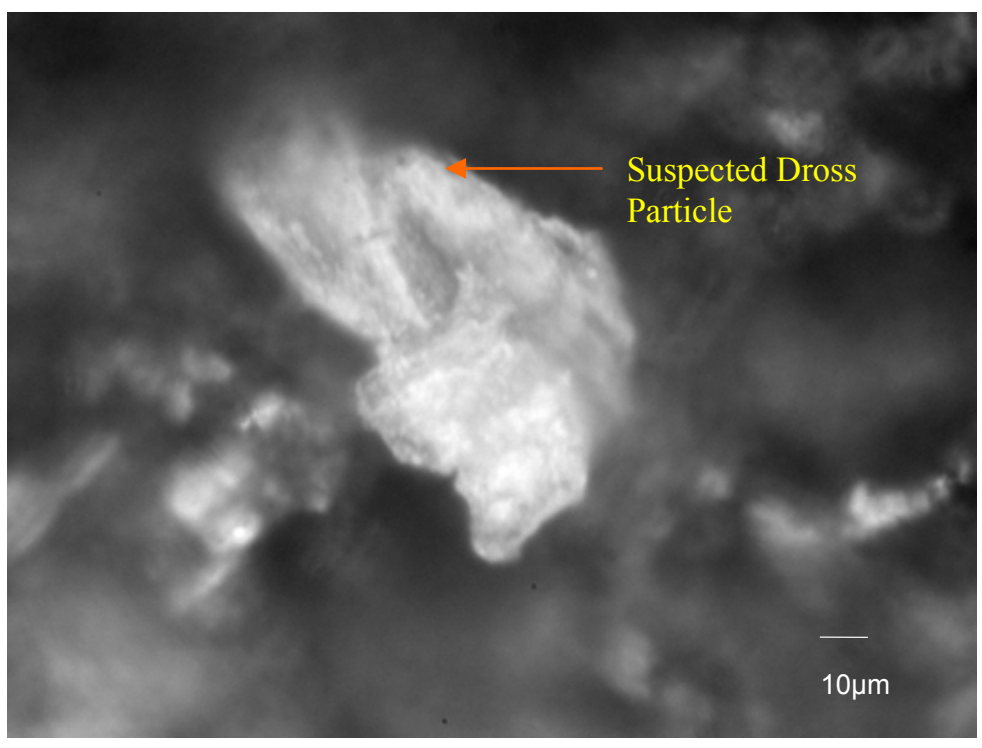

(b)

Figure 54 (a) Microstructure Picture of Grooves on Bearing Surface (b) Particles Inside the Groove after cycle 4 (36 hrs) 
On site microstructure picture was taken on the bearing sleeve surface after each test cycle. Grooves were formed on the bearing surface and possible intermetallic particles were seen sticking inside the grooves as shown in Figures 52-54.

The reaction of molten metal with Stellite 6 is evident by the presence of intermetallic compounds ( $\delta \mathrm{Co})$ on top of an aluminium- rich layer (CoAl) as shown in Figure 55. The intermetallic particles may detach and reattach to the contact surface after reacting with molten zinc. The CoAl compounds, with a micro hardness of $1064 \mathrm{HV}$ are harder than the Stellite 6 bearing sleeve. As a result, deep grooves on the Stellite 6 are possibly due to the plowing of CoAl compound on the contact surface during sliding.

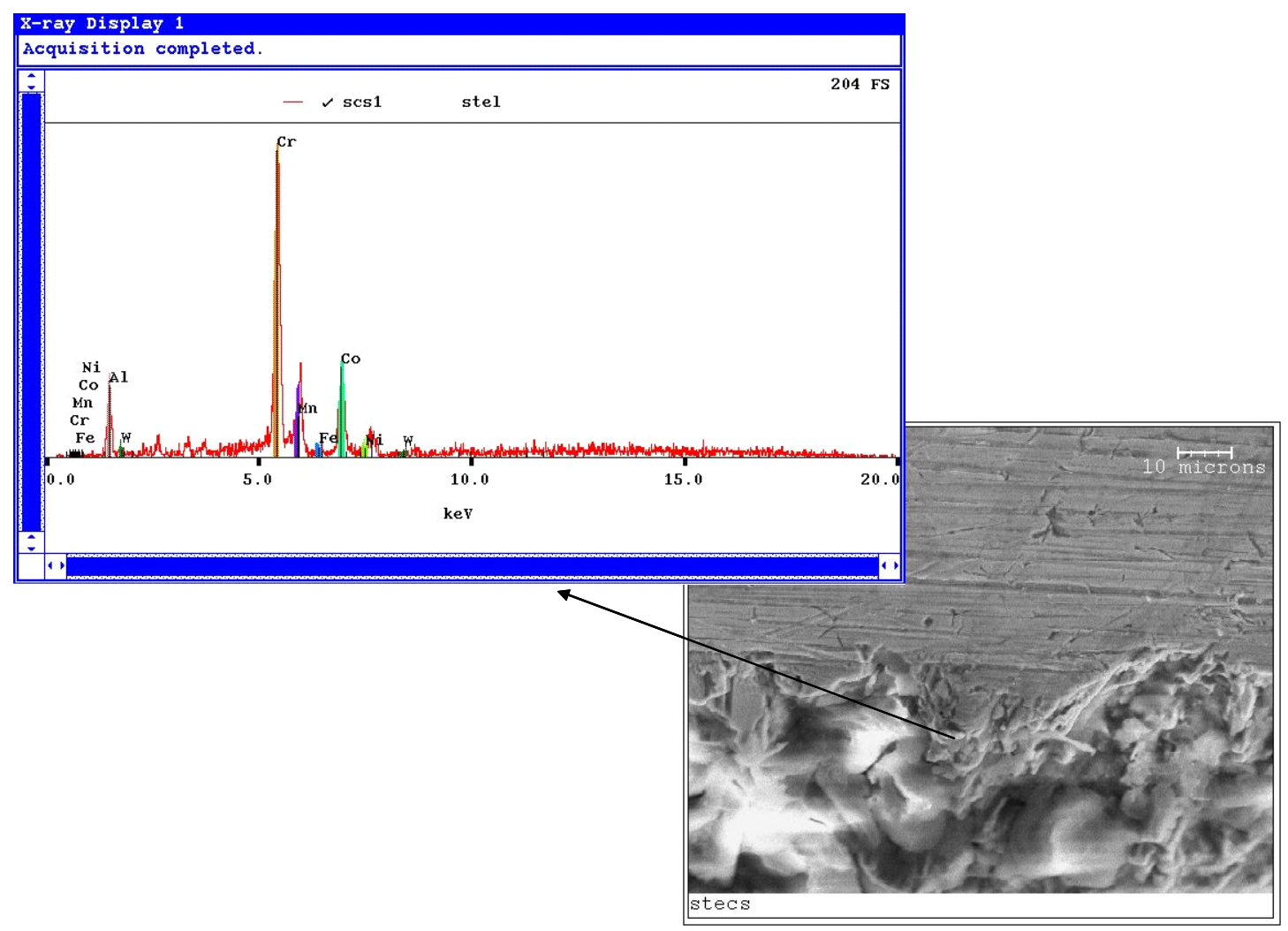

Figure 55 Cross Sectional View Showing Diffusion of Co from Matrix (Thickness of Diffusion Layer) 


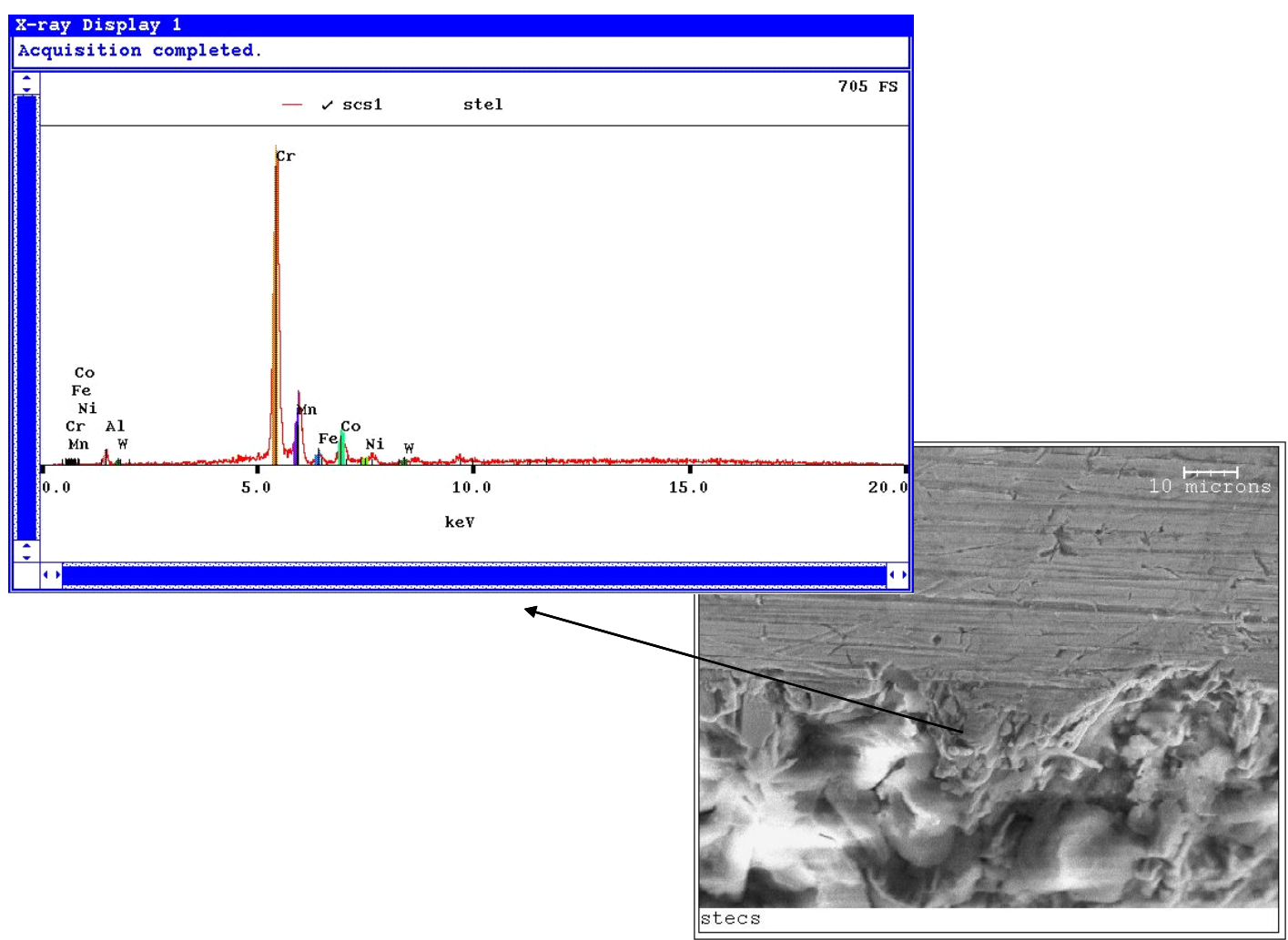

Figure 56 Cross Sectional View Showing Diffusion of Co from Matrix (Thickness of Diffusion Layer)

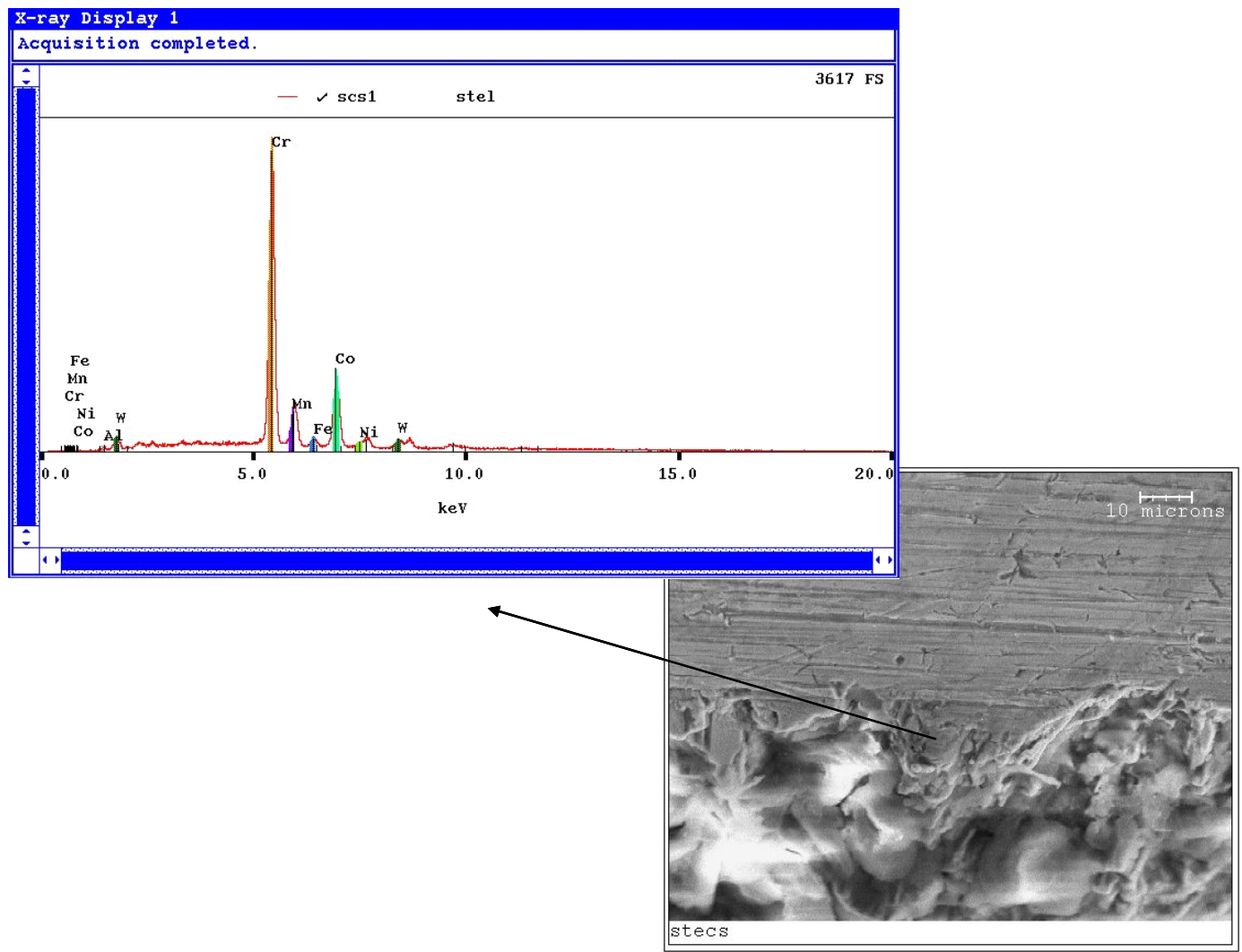

Figure 57 Cross Sectional View Showing Diffusion of Co from Matrix (Thickness of Diffusion Layer) 


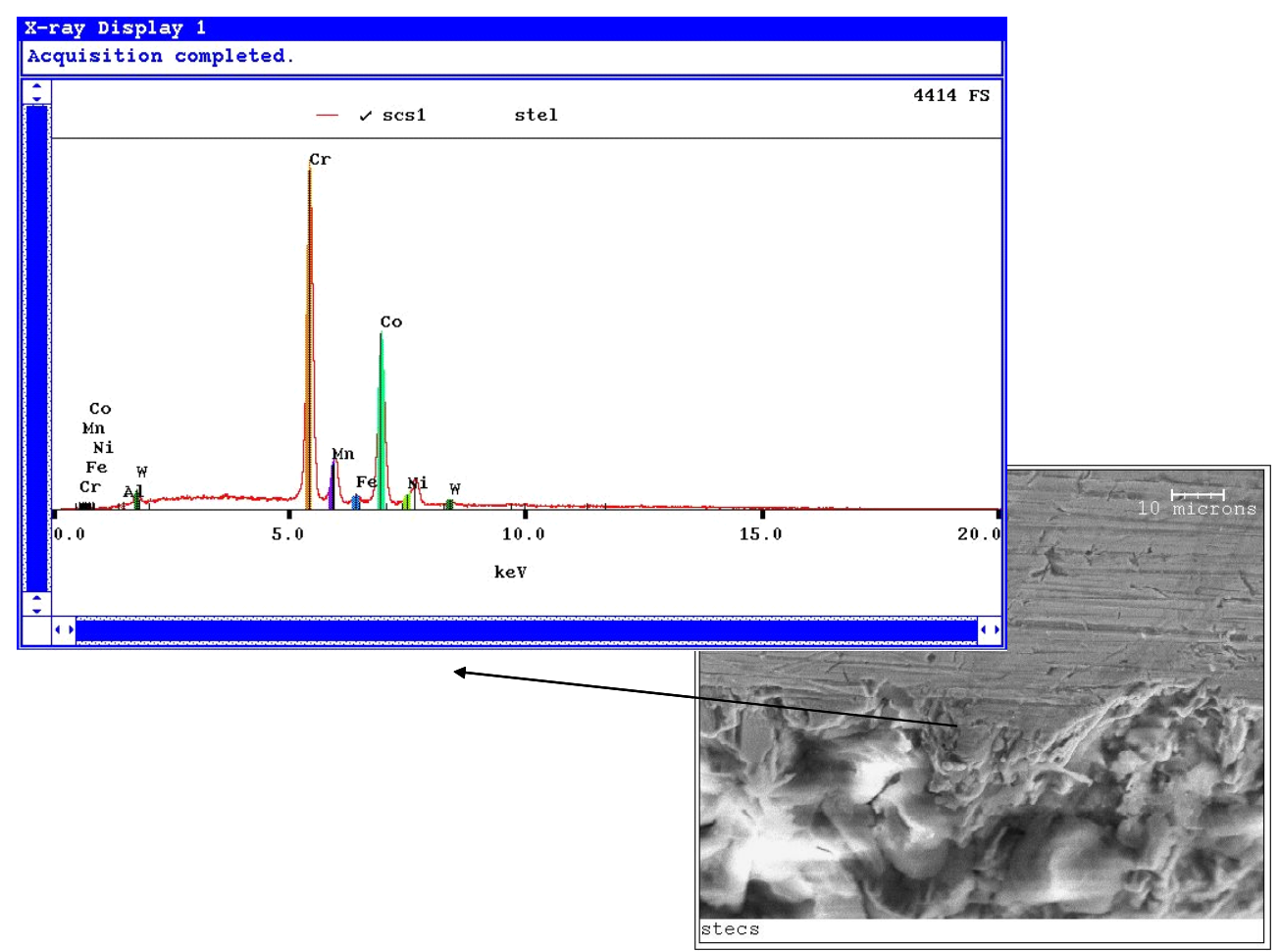

Figure 58 Cross Sectional View Showing Diffusion of Co from Matrix (Thickness of Diffusion Layer)

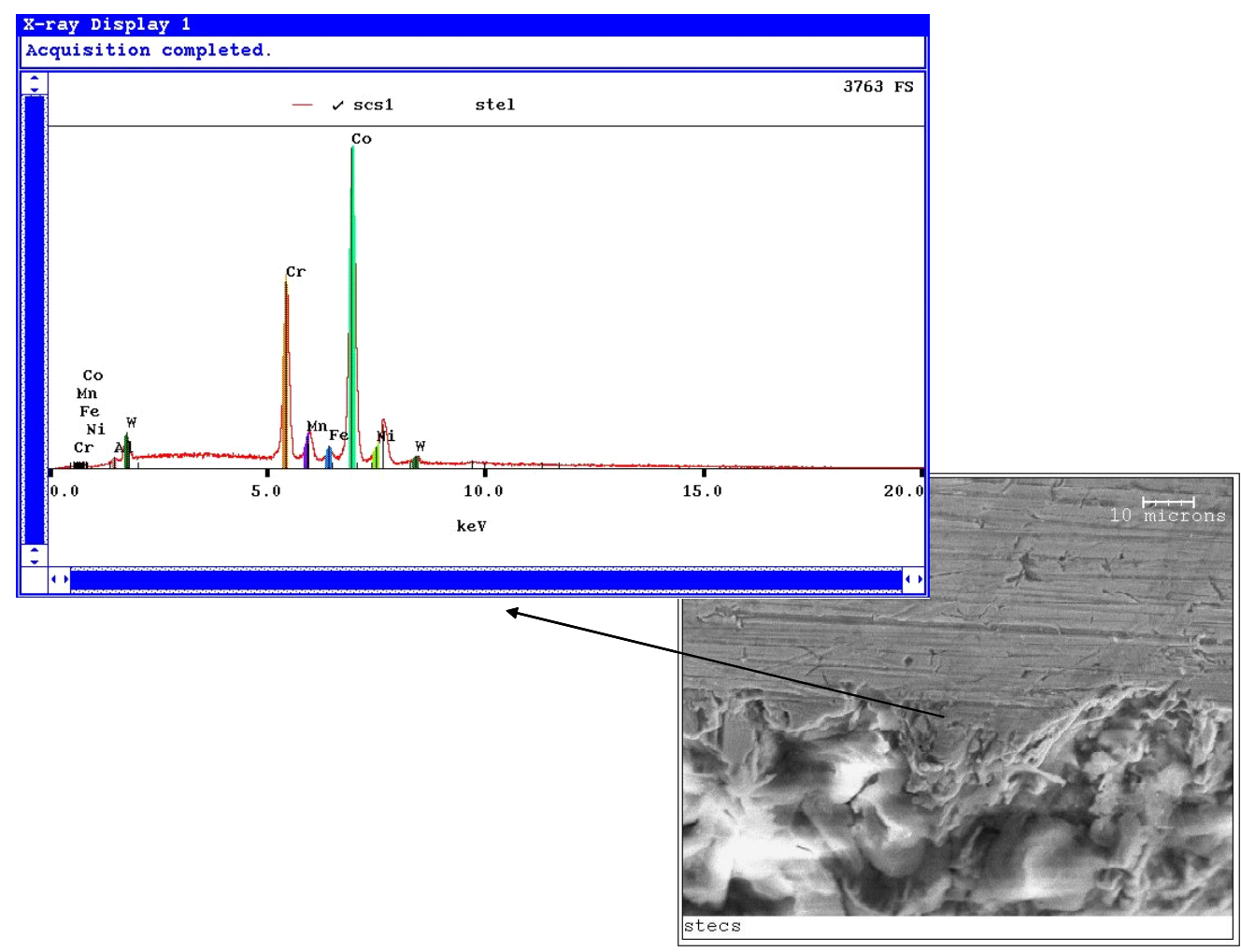

Figure 59 Cross Sectional View Showing Diffusion of Co from Matrix (Typical Stellite 6 Composition) 
Small specimens were cut from the bearing sleeve surface and prepared for the microstructure analysis. Analysis showed that the eutectoid chromium carbide is not affected by corrosion and showed the diffusion of Co from the matrix into the bath[14]. The spectrum analysis was done starting from the edge of wear surface cross section until the actual Stellite 6 composition was reached as shown in Figures 56 to 59 . The analysis was repeated on different locations of the wearing cross section. Thickness of the Co depletion diffusion zone was not uniform and typical thickness ranged from $5 \mu \mathrm{m}$ to $20 \mu \mathrm{m}$. The formation of the diffusion zone could be a possible reason for the drop in hardness value of the material, as it no longer posses Stellite 6 properties.

\subsection{Dross Build-Up Test}

Dross build-up test was conducted. The tungsten carbide spray coated sleeve simulates the roll surface and low carbon sleeve simulates steel sheet in galvanizing lines. Preliminary study was done on the dross formation in the roll groove. SEM analysis showed the existence of intermetallics between iron-chromium (Tetragonal Sigma Phase) [15] formed inside the groove of test roll sleeve as shown in Figures 60 and 61. 


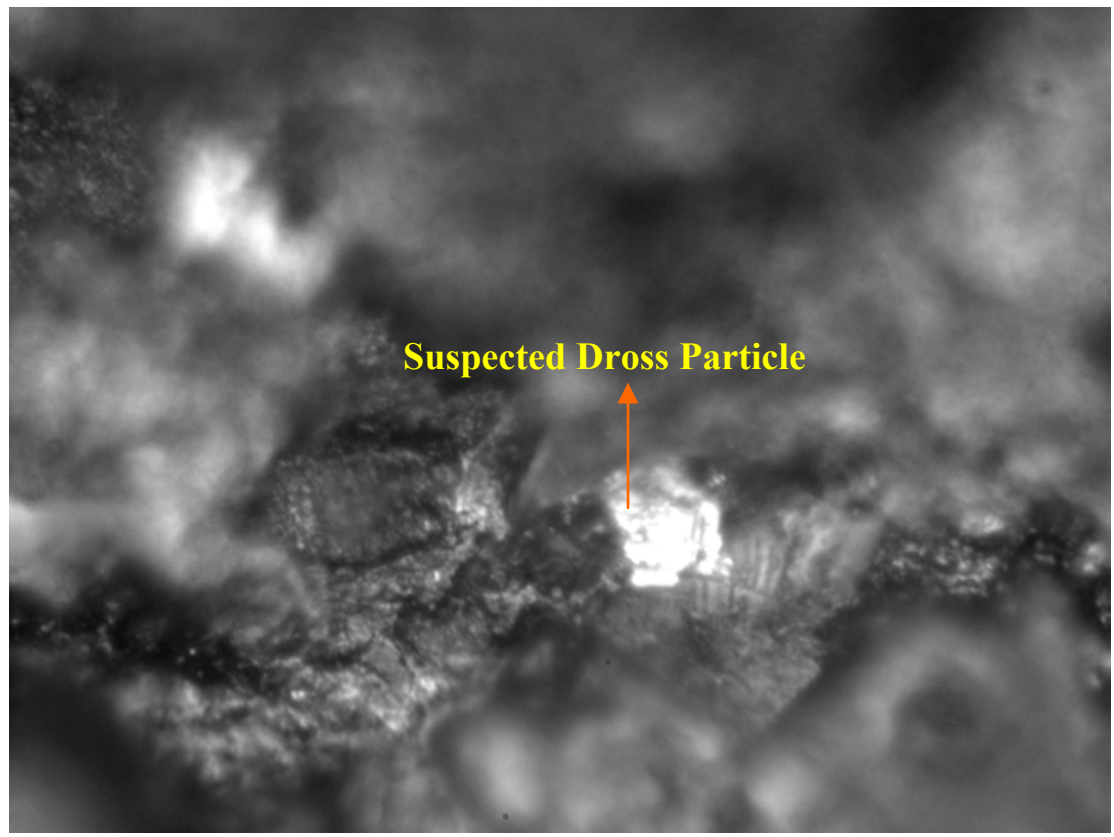

Figure 60 Suspected Dross Particle inside the Groove of Test Roll after Cycle 4 (36 hrs)

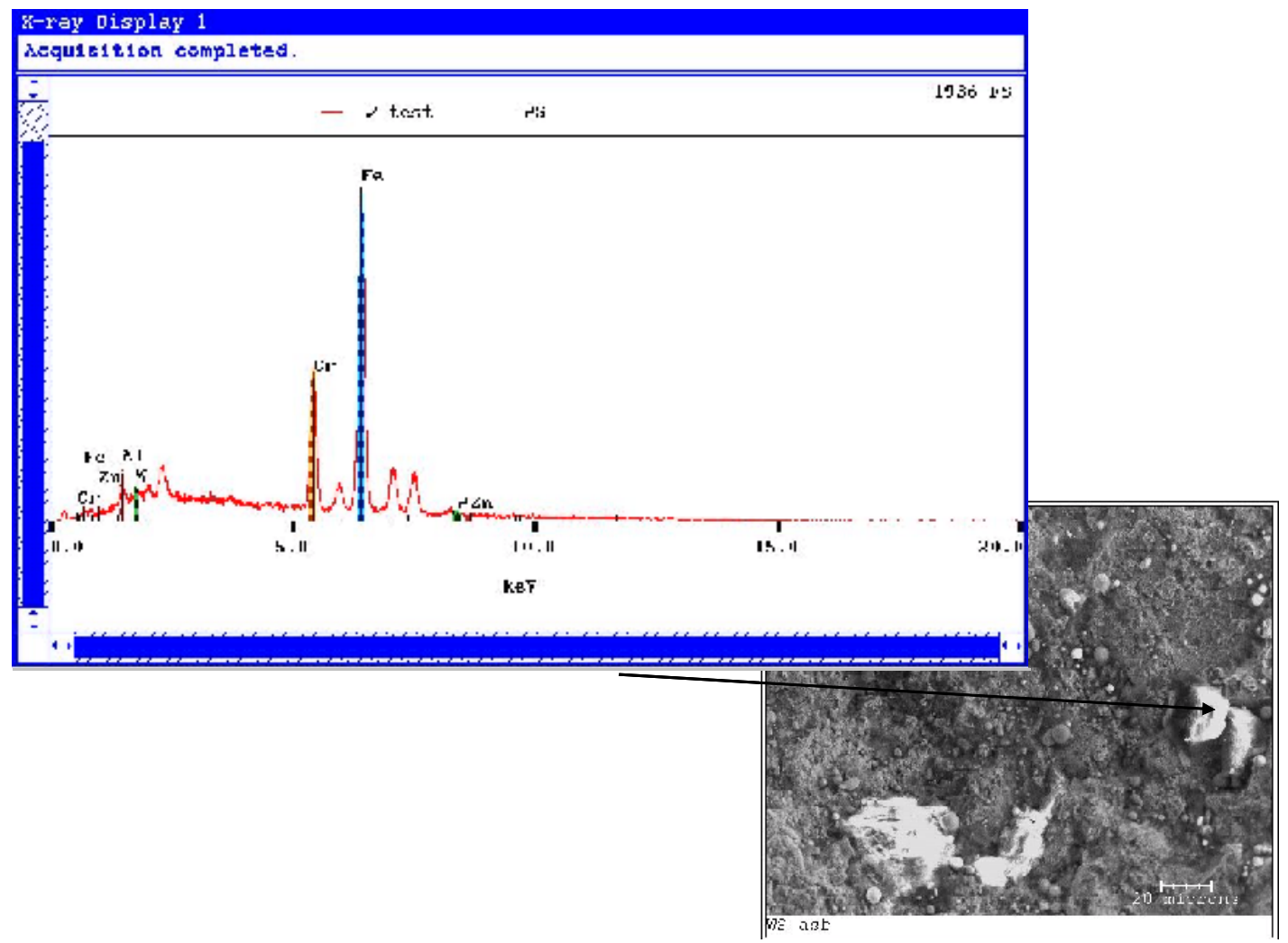

Figure 61 Existence of Intermetallic formed between $\mathrm{Fe}-\mathrm{Cr}$ inside Test Roll Groove 


\section{SUMMARY AND CONCLUSIONS}

This research was aimed to conduct bearing wear and dross build-up tests for different sleeve and roller materials. A lab scale test configuration was designed and fabricated to study wearing and dross build-up of pot hardware material. A high precision diametric unit was designed to measure the bearing sleeve diameter with resolution of $1 \mu \mathrm{m}$.

Wearing test was conducted on $316 \mathrm{~L}$ with $\mathrm{WC}$ laser cladding cermets coating against SiAlON ceramics and Co based alloy (Stellite 6 against Tribaloy T-400). Matrix of the coating reacted with molten zinc bath. The reaction of the matrix material with molten zinc reduced the bonding strength between the binder material and WC particle, thereby making the bearing sleeve readily vulnerable to wear damage. The wearing of bearing sleeve was mainly due to abrasive wear and the SiAlON ceramics experienced abrasive wear with grooves formed on the wear surface. The wearing rate of the journal bearing was found to be $7.2 \mu \mathrm{m} / \mathrm{hr}$, at $50 \%$ production line tension.

Stellite 6 bearing sleeve reacted with the molten zinc bath. A hard CoAl intermetallic was formed on the wearing surface at test conditions. The hard intermetallic compound plough the softer bearing sleeve and causes grooves on the bearing surface during sliding. The wearing of the bearing sleeve was mainly due to abrasive wear and adhesive wear. Cross-sectional view of wearing surface using SEM showed the formation of a Co depletion zone. The thickness of the depletion zone varied from $5 \mu \mathrm{m}$ to $20 \mu \mathrm{m}$. The wearing rate of Stellite 6 journal bearing was found to be $7.3 \mu \mathrm{m} / \mathrm{hr}$, at $50 \%$ production line tension. 


\section{RECOMMENDATIONS}

- Conduct wearing and dross build-up test on different test alloys at different testing conditions in order to performance of the test alloys at different working environment.

- Perform SEM analysis and phase identification of the intermetallics.

- Examine the mechanism dictating the formation of dross particles on the sleeve and roll surface.

- Measure the wearing rate of the ceramic inserts and Tribaloy T-400 bushing.

- Conduct more detailed study on change in hardness of the sleeve and correlate to the change in surface stiffness of the test alloy. 


\section{REFERENCES}

1. Praxair S.T Technology Inc. Patent \# 6,037,287

2. Nai-Yong Tang, "Dross Management in Continuous Galvanizing”, Cominco Ltd.

3. "The Role of Aluminum in Continuous Hot Dip Galvanizing”, GalvInfoNote.

4. Harold H. Fukubayashi, "Failures in Thermal Spray Coating and Their Prevention", 2003 Galvanizer's Association, Annual Meeting, Oct 19-22, Mexico.

5. Mark Hall, "Reduced Downtime and Improved Strip Stability with Ceramic Bearings", Vesuvius McDanel, 2000 Galvanizer's Annual Meeting, Toronto.

6. Edward J.Dean, Jr and Michael S. Brennan, "Reduced Downtime and Improved Strip

Quality through the Use of ACD Wearguard Bearings \& Praxair Laser Weld Overlaid End Caps/Sleeves”, 2002 Galvanizers Association, Annual Meeting, Dearborn, MI.

7. K.Zhang, N.Y.Tang,and F .E. Goodwin, "Effect of Bearing Design on the Wear of a Journal Bearing Sliding in Molten Zinc", $44^{\text {th }}$ MWSP Conference Proceedings, Vol. XL, 2002.

8. K.Zhang, and L. Battiston, , "Friction \& Wear Characterization of Some Cobalt and Iron based Superalloys in Zinc Alloy Bath”. Elsevier Science, December 2001.

9. K.Zhang, N.Y.Tang, and A.B.File, "A Particle Approach to Enhance Wear Resistance of Bearing in Molten Zinc", Galvatec 2002.

10. K.Zhang and N.Y.Tang, "Reaction of Various Materials with a Galvanizing Bath”,2003 Galvanizer's Association, Annual Meeting, October 19 - 22 .

11. K.Zhang, L. Battiston, and F .E. Goodwin, "Friction \& Wear Characteristic of Materials In Molten Zinc”, Galvatec 2001, pp 247 -254. 
12. W.C.Oliver and G.M. Pharr, "An Improved Technique for Determining Hardness and Elastic Modulus using Load and Displacement Sensing Indentation Experiments", Volume 7, No. 6, June 1992, Materials Research Society.

13. Eric.P.Lowen, Hannah Yount, "HT - 9 Corrosion Growths in Flowing Pb-Bi at 550

and 650 C", American Nuclear Society Winter Meeting, 2002.

14. Xingbo Liu, Shalini Rangarajan, Ever Barbero and Mathew Yao, "Corrosion of Stellite 6 in Industrial Hot - Dipping Baths".

15. www.npl.co.uk/npl/cmmt/mtdata.html

16. www.galvinfo.com

17. Boresi, A.P and Schmidt, R.J, “Advanced Mechanics of Materials”, 2002. 